C2020, Elsevier. Licensed under the Creative Commons Attribution-NonCommercialNoDerivatives 4.0 International http://creativecommons.org/about/downloads

(c) $\$=$ 


\title{
Additive Manufacturing Technologies for Drug Delivery Applications
}

\author{
Abdullah Mohammed ${ }^{1}$, Amr Elshaer ${ }^{2}$, Pooya Sareh ${ }^{1}$, Mahmoud Elsayed ${ }^{3}$, Hany Hassanin ${ }^{1, *}$ \\ ${ }^{1}$ School of Engineering, University of Liverpool, Liverpool, L69 7ZX, UK \\ ${ }^{2}$ Drug Discovery, Delivery and Patient Care (DDDPC), School of Life Sciences, Pharmacy \\ and Chemistry, Kingston University London, Kingston Upon Thames, Surrey, KT1 2EE, UK \\ ${ }^{3}$ Department of Industrial Engineering, Arab Academy for Science Technology and \\ Maritime, Alexandria, Egypt.
}

[*] Corresponding author: Dr Hany Hassanin, Email:h.hassanin@ liverpool.ac.uk

\begin{abstract}
Patient to patient variability is one of the issues when administering medications to individuals with different health conditions, pharmacokinetic, age, fitness, gender, and race. This requires introducing smart and personalised drug delivery systems with controlled release profile manufactured using novel approaches. Additive manufacturing (AM) provides opportunities such as full customisation, design freedom, and on-site manufacturing, and materials recycling. As a result, the academic and industrial demand for additive manufacturing for drug delivery has been continuously increasing and showing impressive results for a wide range of products. This paper provides an extensive overview of AM technologies and their applications for drug delivery. The review discusses AM technologies including their working principles, processed materials, as well as current progress in drug delivery to produce personalized dosages for every patient with controlled release profile. AM potentials, industrial scale, and challenges are investigated with regards to practice and industrial applications. The paper covers novel possibilities of AM technologies and their pharmaceuticals applications, which indicate a promising healthcare future.
\end{abstract}

Keywords: additive manufacturing; drug delivery; personalised mediations; polypill 


\section{Contents}

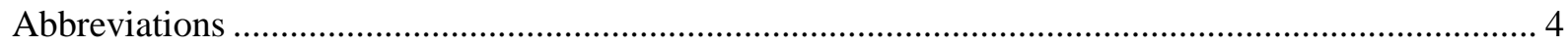

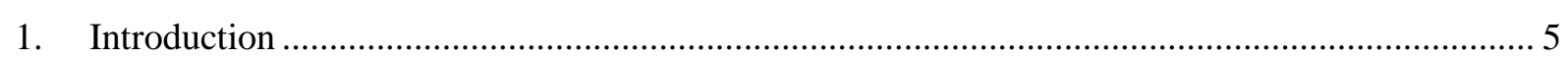

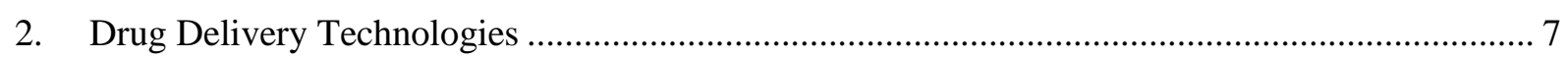

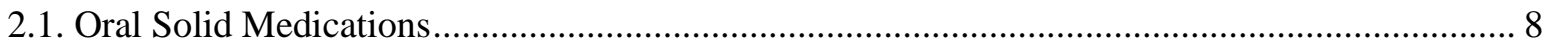

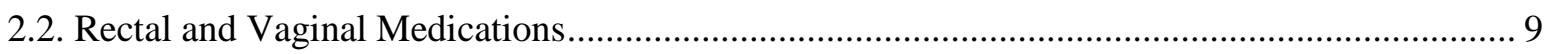

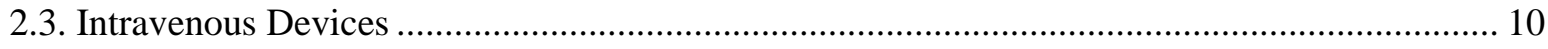

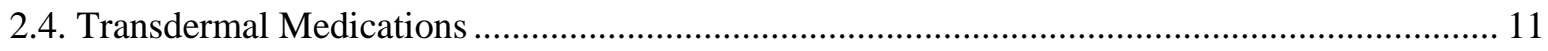

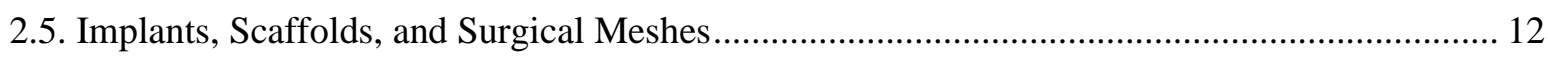

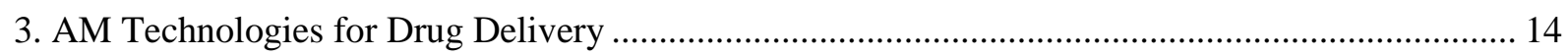

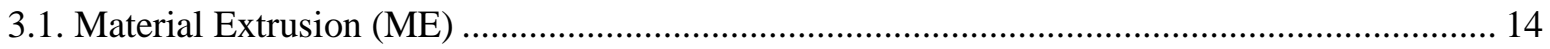

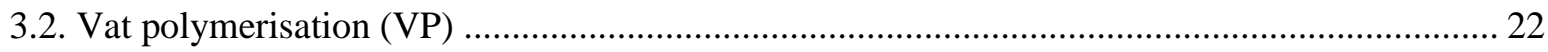

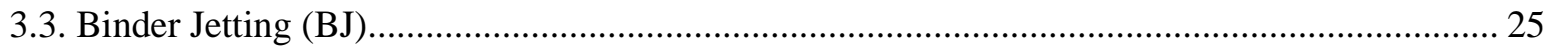

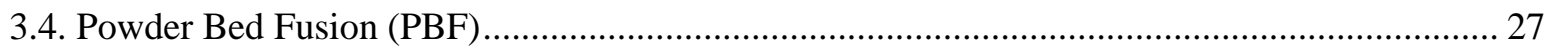

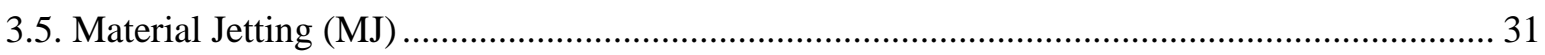

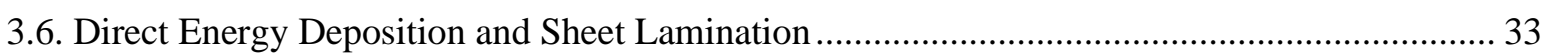

4. Industrial Scale, Current Progress, and Challenges......................................................................... 34

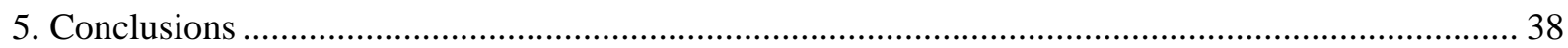

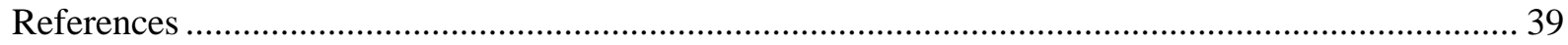




\section{Abbreviations}

3D: 3-Dimensional; 5-ASA: 5-Aminosalicylic Acid; AM: additive manufacturing; BF: Powder Bed Fusion; BJ: Binder Jetting; BMP-2: Bone Morphogenic Protein-2; CAD: Computer Aided Design; CIJ: Continuous Inkjet; CLIP: Continuous Liquid Interface Production; CU2O: Copper Dioxide; DED: Eirect energy Deposition; DLP: digital Light Processing; DMLS: Direct Metal Laser Sintering; DMOG: Dimethyloxallyl Glycine Dod: Drop on Demand; DPPO: Diphenyl(2,4,6-trimethylbenzoyl) Phosphine Oxide; EBM: Electron Beam Melting; EVA: Ethylene Vinyl Acetate; FDM: Fused-Deposition-Modelling; FPLA: Flex Ecopla ${ }^{\mathrm{TM}}$; Gbr: Guided Bone Regeneration; HCL: Hydrochloride; HPC: Hydroxypropyl Cellulose; HPMC: Hydroxypropyl Methylcellulose E100; HPMCAS: Hydroxypropylmethylcellulose Acetate Succinate; IRGACURE 184: 1Hydroxycyclohexyl Phenyl Ketone; MBG-CH3: Methylic Mbg; ME: Material Extrusion; MICROCLI: Micro-Continuous Liquid Interface Production System; MJ: Material Jetting; MMC: Microcrystalline Cellulose; MN: Microneedles; MOO3: Molybdenum Trioxide; MPDC: Methacrylated Poly (1, 12 Dodecamethylene Citrate); MPEXSL: Mask Projected Excimer Laser Stereolithography; NAP: Naproxen; OGP: Osteogenic Growth Peptide; PBF: Powder Bed Fusion; PCL: Polycaprolactone; PDLA: Poly D-Lactic Acid; PE: Pneumatic Extrusion; PEUS: Poly (Ester Urea) S; PHBHHX: Poly (3Hydroxybutyrate-Co-3-Hydroxyhexanoate); PLGA: Poly (Lactic-Co-Glycolic Acid); PU: Polyurethane; PVA: Polyvinylalcohol; PVP K30: Polyvinylpyrrolidone K30; RHBMP-2: Recombinant Bone Morphogenetic Protein-2; SE: Syringe Extrusion; SHS: Selective Heat Sintering; SLM: Selective Laser Melting; SR: Sustained Release; SR-MBG : Strontium-Containing Mesoporous Bioactive Glass; TCP : Tricalcium Phosphate; TIO2: Titanium Dioxide; VP: Vat Polymerisation; B-TCP: Beta-Tricalcium Phosphate; 2PP: 2-Photon Polymerisation; 3DM: 3D-Materials; 4-ASA: 4Aminosalicylic Acid; 5-FU: Fluorouracil; ABS: Acrylonitrile Butadiene Styrene; APAP: Acetaminophen; ASTM: American Society For Testing AND Materials; CAM: Computer-Aided Manufacturing; CASIO3: Calcium Silicate; CT: Computed Tomography Scan; DOM: Domperidone; EAC: Ethyl Acrylate Copolymer; EEA: Ethylene-Ethyl Acrylate; FDA: Food And Drug Administration; FDC: Fixed Dose Combination; FDCT: Fixed Dose Combination Therapy; GE: General Electric; GSK: Glaxosmithkline; HA: Hydroxyapatite; HDPE: High-Density Polyethylene; HIPS: High Impact Polystyrene; HME: Hot Melt Extrusion; HMSCS: Human Mesenchymal Stem Cells; IJP: Inkjet Or Binder Jet Printing; INH: Isoniazid; ISO: International Organization For Standardization; IUS: Intrauterine Systems; LC: Laser cladding; LDW: laser deposition welding; LENS: laser energy net shaping; LOM: laminated object manufacturing; LVFX: levofloxacin; MA: methacrylic acid; MBG: mesoporous bioactive glass; MBG-COOH: carboxylic MBG; MCC: microcrystalline cellulose; MJF: multi jet fusion; MJP: multi-jet printing; MPDC: methacrylated poly-diol citrate; P25: anatase; PAA: poly (acrylic acid); PC: poly carbonate; PDLLA: poly D,L-lactic acid; PE: polyethylene; PEC: chitosan-pectin; PEG: polyethylene glycol; PEGDA: poly (ethylene glycol) diacrylate; PET: polyethylene terephthalate; PG: propylene glycol; PGC: polyethylene glycol copolymer; PH: potential OF hydrogen; PJP: poly-jet printing; PLA: polylactic acid; PLLA: poly (L-lactic acid); PMMA: polymethyl methacrylate; PMPC: poly(2methacryloyloxyethyl phosphorylcholine); PP: polypropylene; PPF: poly (propylene fumarate); PS: polystyrene; PTMC: poly(trimethylene carbonate); PVP: polyvinylpyrrolidone; RFP: rifampicin; SEM: scanning electron microscope; SFP: solid foil polymerization; SHM: selective heating melting; SL: sheet lamination; SLA: stereolithographic apparatus; SLS: selective laser sintering; TCP: TRI calcium phosphate; TOB: tobramycin; TPU: thermoplastic polyurethane; UAM: ultrasonic additive manufacturing; ULTEM: polyetherimide; UV: ultraviolet; VA: vinyl acetate; VNC: vancomycin; WAAM: wire AND arc additive manufacturing 


\section{Introduction}

The rise of Industry 4.0, also known as digital technology, makes factories smarter, and helps manufacturers to enhance quality, productivity, and profitability. Additive manufacturing (AM), an important pillar of digital technology, is a manufacturing tool that has been progressing over the last three decades. The technology was first invented by Charles Hull in 1986 using UV sensitive polymers and ultraviolet (UV) light to create 3D objects (Prasad and Smyth, 2016). The technology was later known as Stereolithography Apparatus (SLA). Since then, scientists and engineers have developed various novel AM techniques. Currently, there are many commercially available AM equipment and many more innovative concepts are still under investigation. The increasing demand for $\mathrm{AM}$ is set to continuously generate more investments and introduce many thousands of new jobs. A report by the World Economic Forum in Davos demonstrated that most of today's children would have jobs related to industry 4.0 (Schwab, 2017). The technology has shown a great promise as a tool in both industry and research to fit with various industrial demands.

Benefits of AM can be summarized as follows:

1- Shortened lead-time;

2- Mass customization with no additional processing;

3- Improved supply chain competence;

4- Printing assemblies and systems;

5- Manufacturing functional parts with complex geometries;

6- Lightweight manufacturing of cellular structures;

7- Materials recycling and sustainable manufacturing;

8- Scalable workflow;

9- On-demand manufacturing of parts;

10- Quality improvement of services.

In AM, different materials such as polymers (Klippstein et al., 2018b), metals (Qiu et al., 2015), and ceramics (Essa et al., 2017) can be built layer-by-layer to achieve the required geometry according to a digital design, which is different from conventional manufacturing or forming techniques where the required geometry is achieved by subtracting or forming. AM technologies have been used in many sectors, such as biomedical (Hassanin et al., 2018), energy (Sabouri et al., 2017), aerospace (Galatas et al., 2018; Klippstein et al., 2018a), and defence (Li et al., 2016). This can be attributed to capabilities of AM technologies to create complex designs rapidly with high degrees of precision and accuracy, in addition to their ability to recycle materials. These benefits and advantages have attracted the attention of many researchers and industrial organisations to enable AM for broader adoption and investigate their capabilities and limitations. This can be clearly seen in the increased number of published papers and patents on using AM/3D printing technology over the last ten years (Figure 1a). The number of published papers increased from below 500/year in 2008 to over 6000/year in 2018. In addition, the numbers of patents filed have raised from just above 2000/year in 2008 to over 7000/year in 2018.

Drug delivery represents a group of technologies used to safely introduce a pharmaceutical material into the body for a specific therapeutic effect (Tiwari et al., 2012). Recently, the technology has significantly progressed in all of its aspects ranging from oral tablets to drug eluted implants. The concept of pharmaceutical delivery is based on the incorporation of a drug, the release of its active materials, and the subsequent passage of such materials to the site of action. Patient-to-patient variability is considered as a challenge when administer patients with 
a drug delivery solution. Pharmaceutical manufacturing techniques such as capsule filling and tabletting have been advanced, particularly with respect to controlling drug-releasing profile using approaches such as nano-particles, functionalized liposomes, and biomimetic particles. However, the associated research and scaling-up costs are barriers to advance drug delivery systems using these approaches. In the past decade, advanced drug delivery have been introduced because of the advancement of several manufacturing technologies and hence many research activities have been carried out in this area. Figure $1 \mathrm{~b}$ shows statistical data of published papers and patents on drug delivery using AM technologies from 2008-2018. As shown, initially, the papers number grows then picked up significantly after 2012. The published paper number has been increased from 120/year in 2008 to more than 3000/year. On the other hand, there was a prompt rise in 2018 reaching to approximately 1725 patents in that year. This paper reviews the use of AM technology and its capabilities for different drug delivery approaches including oral solid medications, transdermal patches, vaginal and rectal drug delivery, and drug-loaded implants and scaffolds. The general processing concept, potentials, and challenges of each AM tools are discussed in details. In addition, the research, industrial progress, and outlook are also summarised.
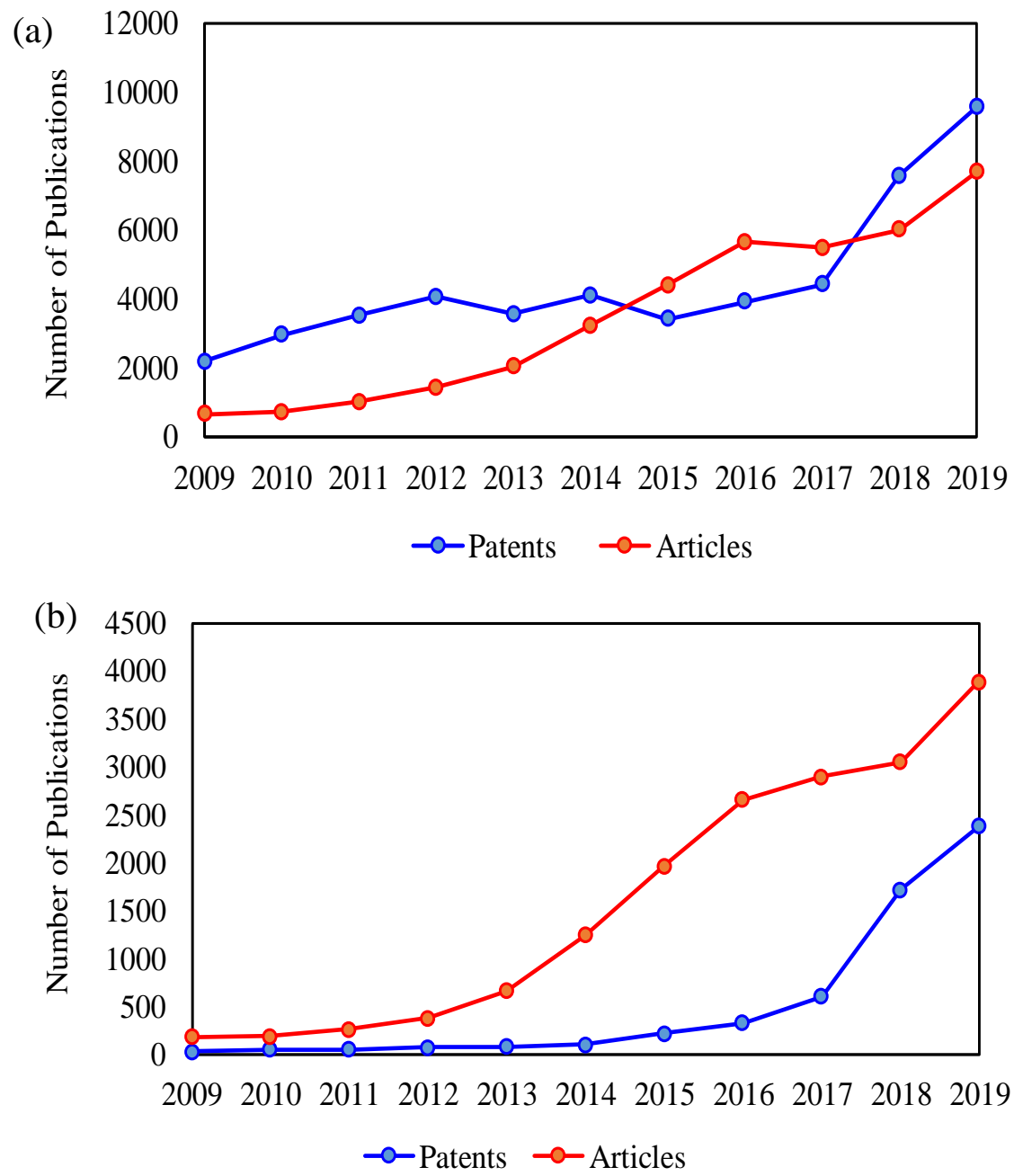

Figure 1: (a) number of published papers and filed patents on 3D printing over the last 10 years, (b) Number of papers published on drug delivery using 3D printing. 


\section{Drug Delivery Technologies}

A medication can be introduced into a patient body using several techniques to achieve a systemic biological effect and treat certain diseases. These techniques are generally classified by the body location at which the pharmaceutical materials are targeted. The choice of a drug delivery method depends on factors including disease, the desired effect, the performance of the drug effective materials, and in some cases patients' preferences. Additive manufacturing has revolutionised the drug delivery industry towards personalisation medication. Additively manufactured drug delivery workflow is shown in Figure 2. A typical AM drug delivery system starts with a laboratory examination, which may include computed tomography scanning (CT) or magnetic resonance imaging (MRI).This offers useful data regarding the patient condition and the design requirements aiming to achieve patient centred dosage form and a programed release profile. This is followed by preparation of treatment plan, which may include the desired administered drugs and their desired release profile. AM technology has the capability not only to provide personalised medication but also capable to deliver programmable drug release. Next, a digital model is created using computer aided design (CAD). Finally, drug loaded delivery system is produced using additive manufacturing to be administered into routes such as oral solid medications, intravenous devices, rectal and vaginal delivery, transdermal patches, intravenous devices, biomedical implants, and scaffolds drug delivery.
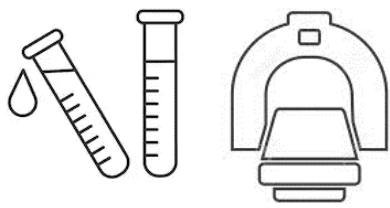

1-Laboratory examination

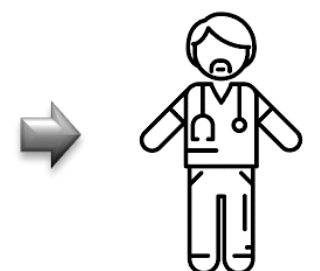

2-Treatment plan

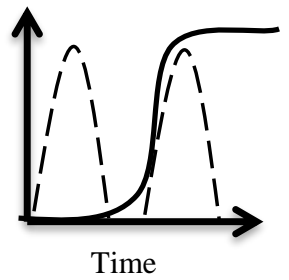

3- Programmable release profiles

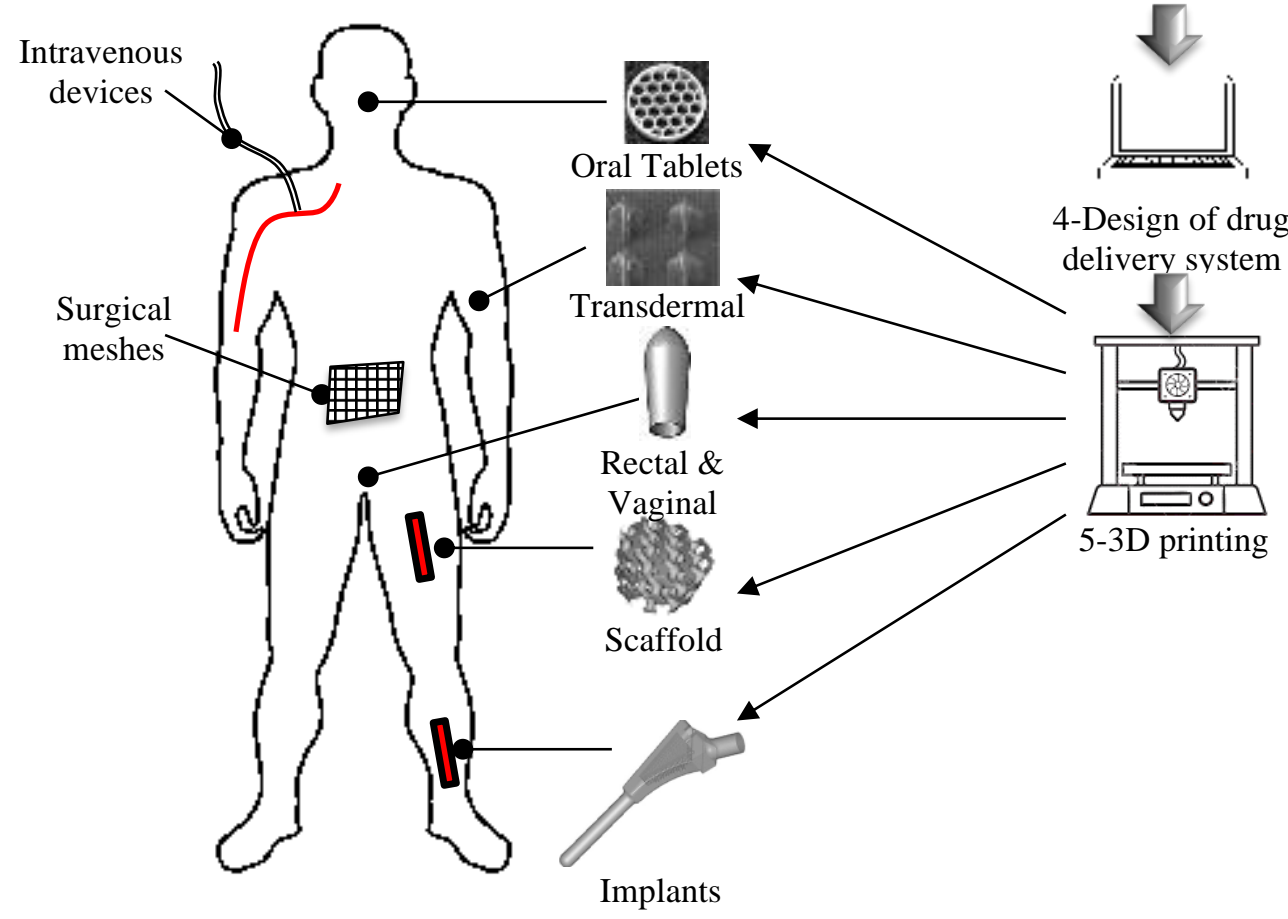

Figure 2: Additively manufactured drug delivery systems workflow and their available body routes. 


\subsection{Oral Solid Medications}

Oral solid medication can be considered is the oldest and the most well-known drug administering technique. It is cheap, easy to use, non-invasive and has high absorption properties. Different forms of this technique are available such tablets, pills, capsules, troches, lozenges, films and pellets (Al-Hashimi et al., 2018; Hassanin et al., 2017; Prausnitz and Langer, 2008). However, there are limitations of oral solid medications such as the variability of release profile, medication concentration, and the decomposition of some drug formulation due to their sensitivity to low $\mathrm{pH}$ values existing in human digestive system before reaching the body part of interest. Typically, oral solid medications are manufactured using powder processing routes. This includes powder preparation, blending, milling, granulation, compression, and hot-melt extrusion. Despite these techniques have been around for more than 50 years, powder processing is still the preferred manufacturing technology for innovations in oral drug delivery. This is because they are reliable processes, and are less prone to typical malfunctioning issues. However, the current conventional manufacturing technologies faces several challenges of issues such as patient variability and hence cannot fulfils the demand of personalised medication. In addition, a study found that was less than $50 \%$ of patients with chronic diseases achieve drugs goals and majority of the patients do not adhere to their medication. This is related to health complications, high morbidity and early mortality rates besides the high healthcare costs (2003). Polytherapy and dosing regimen are amongst the factors that worsen patients' compliance. Pill burden is associated with suboptimal clinical outcomes and pharmaceutical companies have tried to overcome this issue by introducing fixeddose combination therapy (FDCT) where two medications are combined in one tablet. Glucovance ${ }^{\circledR}$, Avandamet ${ }^{\circledR}$, and Metaglip ${ }^{\mathrm{TM}}$ are FDCTs that were approved between 20002002. Some improvement of FDCT is well reported in the literature (Blonde et al., 2003). Nevertheless, FDCT does not offer dose flexibility, which could vary from patient to patient. Moreover, FDCT combines anti-diabetic drugs only. For example, diabetes mellitus which is one of the most widespread conditions is usually associated with cardiovascular and kidney diseases as they share a similar pathophysiological pattern. In a study by Alonso-Moran, around $90 \%$ of diabetes patients were multi-morbid and had heart failure, hypertension, kidney problems, ischaemic heart disease, atrial fibrillation, mental problems, digestive, bone or joint diseases (Alonso-Morán et al., 2015). Multi-morbid Diabetes patients are usually on polytherapy that in turn worsens their adherence to medication and causes deterioration in their health condition. A single and personalised tablet that combines all medications for patients with chronic diseases will significantly improve their compliance and adherence to treatment. AM technology allows administered oral medication to be personalised in different structure, shapes, release profile, and included with multiple drugs that are challenging to achieve using traditional techniques, see Figure 3. 


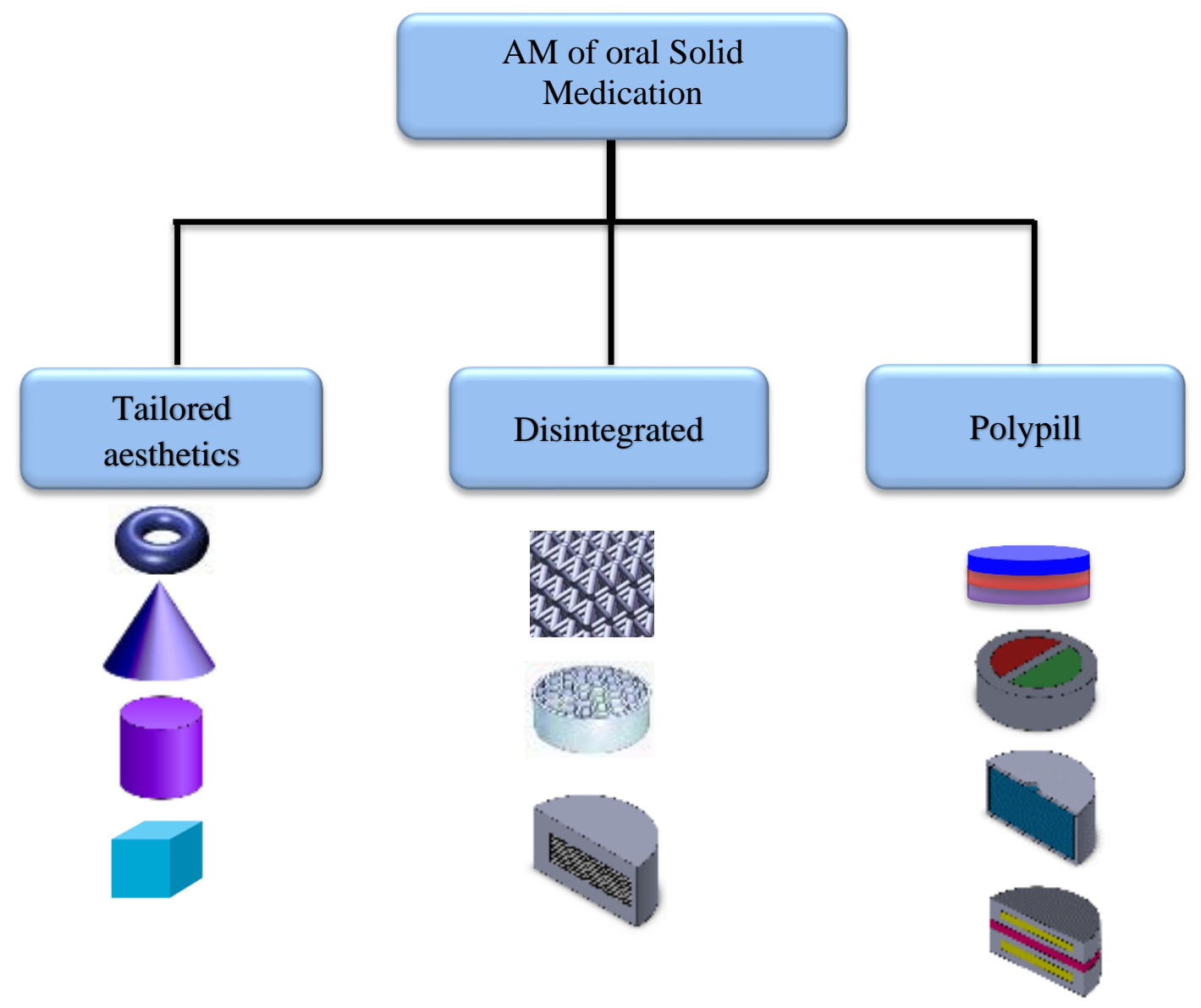

Figure 3: Additive manufacturing of oral dosage medication (Goyanes et al., 2015b; Goyanes et al., 2015c; Khaled et al., 2014; Khaled et al., 2015b; Okwuosa et al., 2017; Rowe et al., 2000; Sun and Soh, 2015; Yu et al., 2009a)

\subsection{Rectal and Vaginal Medications}

Rectal drug medication administer drugs to rectum. The medication is absorbed through the rectum's vessels that deliver it to the body's circulatory system. Rectal medications have been utilised for hundreds of years especially for elderly people and children (Hua, 2019). However, some cultures and countries neglect or avoid the use of this technique due to cultural barriers and privacy concerns. Despite the route restrictions, rectal administration is a recommended technique for unconscious, reluctant, vomiting and difficult to swallow patients. Several forms of rectal drug delivery are available such as rectal capsules, suppositories, ointments, creams, and gels. The technique has many benefits over oral drug delivery such as bypassing the enzymatic activities in the gastro intestinal tract; hence, a safer approach for sensitive drugs, partially bypassing the first pass metabolism, high performance for localized treatments for some conditions. Challenges that prevent the wide use of this mythology are the high interindividual variability and low/variable absorption efficiency of the rectum. Efforts must be carried out to tackle these difficulties by developing personalised dosage form with controlled drug release, and muco-adhesive dosage forms. Like rectum, women vagina has been also utilised as a location of drug delivery since ancient times. Many forms and shapes of vaginal medications are available such as pessaries, tablets, solutions, gels, suppositories, and vaginal rings which are in use to treat a number of conditions such as osteoporosis, contraception hormone replacement therapy, infertility, infections, and other related conditions (Jain, 2008; 
Jain, 2014). This is because of the several benefits such as low enzymatic activity, high vascularization, and avoidance of metabolism. Other benefits include easy access, the prolonged retention of medication, and the excessive permeation of the place (Hussain and Ahsan, 2005). Several researches introduced vaginal and rectal devices with various shapes and eluting medications, see Figure 4.

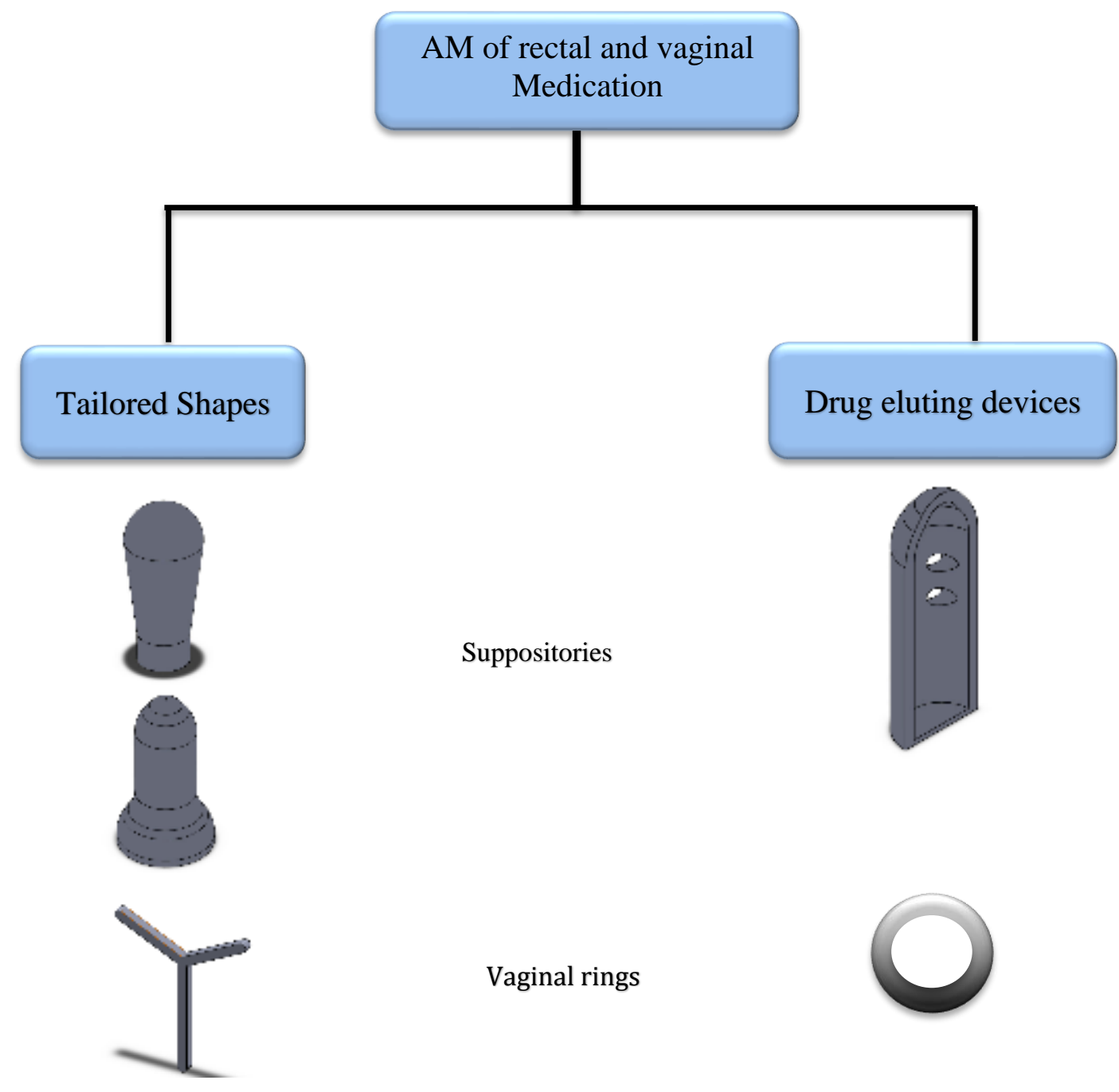

Figure 4: Additive manufacturing of oral dosage medication (Fu et al., 2018; Krezić et al., 2020; Smith et al., 2013; Tagami et al., 2019)

\subsection{Intravenous Devices}

Intravenous devices are used in drug delivery by an intravenous injection or infusion into a body vein using a tube or a needle. They are typically used in situations at which there is an essential need to control medications into the body or when patient must have the medication quickly into the bloodstream such as in emergency or when oral medications would be break down during metabolism (Peterfreund and Philip, 2013). There are different types of intravenous devices and the most common one is the standard intravenous device, which is used in short-term situations such pain relief, antibiotic, and nausea medications. With standard intravenous, a needle is typically inserted into a vein in the wrist or the back of the hand. Next, a catheter is pushed over the needle then the needle is removed, while the catheter stays in the vein. Push intravenous devices are another type which employed by an intravenous infusion or injection directly into a body vein using a push of a syringe. On the other hand, catheter is a 
long tube that deliver medication from a vein near the elbow, chest or neck to a vein near the heart (Hallaj-Nezhadi et al., 2010). Additive manufactured intravenous devices was focused on the development of customised catheters to for local drug delivery, see Figure 5.

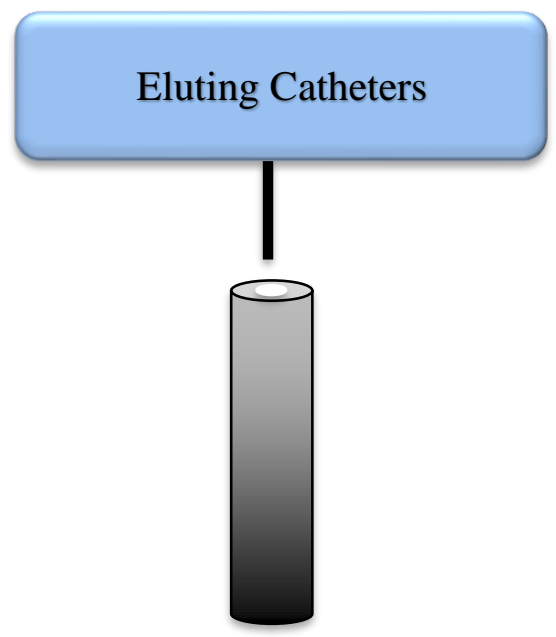

Figure 5: Additive manufacturing of eluting catheters.

\subsection{Transdermal Medications}

Transdermal patches are a type of drug delivery systems that are used to introduce medications through the skin for curative purposes and to replace other drug delivery systems. For many centuries, people have used different materials to treat various skin diseases. Nowadays, a wide range of topical products has been introduced to achieve therapeutic effects. The first transdermal medication was approved by the FDA for more than 40 years. An example of commercially transdermal drug delivery is the nicotine patch which was made available in the late eighties (Jain, 2008; Jain, 2014). Typically, transdermal drug delivery consists of direct skin formulations such as gels and creams, drug carriers, penetration enhancers, and patches. Transdermal medications methods have demonstrated several advantages; they are easy to use, cheap, non-invasive, self-administered, and have prolonged release profiles. In addition, the use of such systems enables the drug to avoid liver metabolism associated with oral drug delivery. Compared to injections, transdermal medication is not painful and does not transmit diseases associated with needle re-use. However, the density and the impermeability of stratum corneum , the outer layer of the skin, makes it difficult for medications to penetrate across the skin at desired rates. As such, the development of advanced transdermal drug delivery with improved characteristics has become the subject of intensive research and the potential of advanced technologies is broadly considered (Prausnitz and Langer, 2008). Microneedles patches are the most common applications of transdermal medications. They have microscopic needles used to deliver medications through skin. The size of microneedles can in range of 150-1500 $\mu \mathrm{m}$ long, 50-250 $\mu \mathrm{m}$ wide, and have 1-25 $\mu \mathrm{m}$ tip dimension. Therefore, micro fabrication techniques such as soft lithography have been used to fabricate microneedles with high reloustion (Iliescu et al., 2017), though it was typically used to replicate polymers and ceramics micro parts(Hassanin and Jiang, 2009b; Hassanin and Jiang, 2011; Hassanin and Jiang, 2013a; Zhu et al., 2010). However, soft lithography requires many fabrications steps and special equipment to fabricate fine micro parts (Hassanin and Jiang, 2009a, 2010a, b, 2013b). Drug coated and uncoated eluting microneedle patches were developed using AM, which provides many advantages over micro fabrication techniques, see Figure 6. 


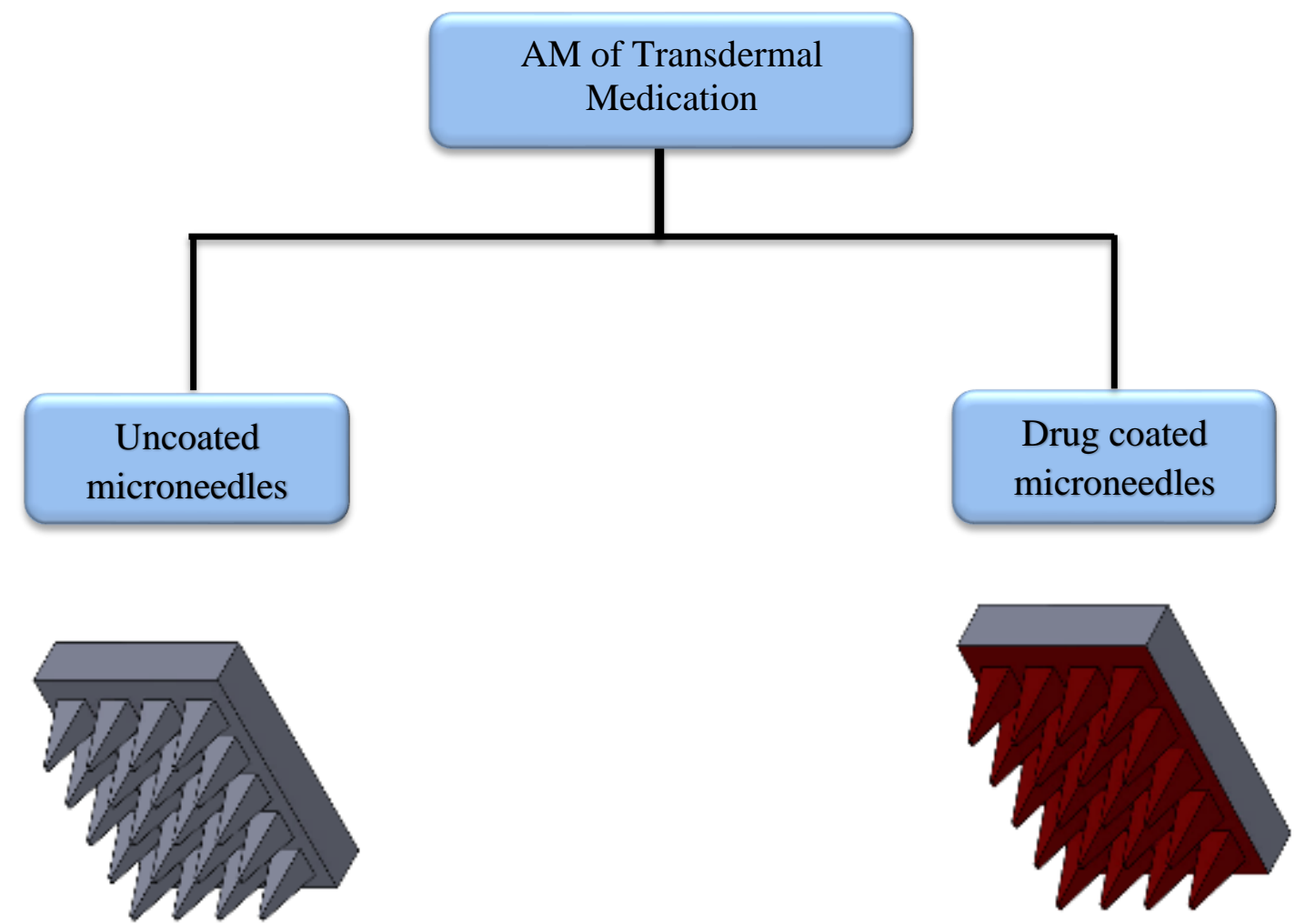

Figure 6: Additive manufacturing of transdermal medication (Caudill et al., 2018; Uddin et al., 2020)

\subsection{Implants, Scaffolds, and Surgical Meshes}

Biomedical implants are devices placed inside the body to achieve a variety of functions or to replace a missing body tissue. Recently, there has been a growing merging between biomedical implants and drug delivery. Novel implants have succeeded to improve patients' quality of life, therapeutic effectiveness, and improved patient safety. Many researchers have developed novel implants with site-selective and controlled drug release profiles. High-performance implants with the controlled release of medications are of interest in different applications. Typically, implantable drug release methods can be classified into physical \& chemical systems. The physical release system is based on the absorption of the medication through a specific polymeric matrix or coating. Stents, for example, are fitted with drug-loaded coatings that serve as a medication delivery system. The thickness of the coating material allow a varied control over the medication release profile. Furthermore, the drug in these devices can be included within or surrounded by the coating material, which allows further control over drug release. On the other hand, chemical-based delivery systems work by techniques such as degradation, swallowing the drug carrier or by splitting of chemically bound drugs. The swelling properties of chemically drug-loaded systems such as hydrogels are controlled with the change in surroundings temperature, $\mathrm{pH}$, or the electrical field. Materials used in biomedical implants include biocompatible polymers, ceramics, and metals. Technologies used to manufacture these materials are well-established. However, novel implantable drug delivery systems is moving towards the personalisation and customisation, which are difficult to achieve using conventional manufacturing. Biomedical scaffolds are used as a template to guide cell attachment, differentiation, proliferation tissue growth, and to support new viable body tissues for a medical purpose. Scaffolds requirements include high biocompatibility, adequate porosity that mimics the natural body tissue and allows the transportation of body fluid, sufficient 
mechanical characteristics, and controlled biodegradability. Scaffolds are also used as a mean of drug delivery devices (Elsayed et al., 2019; Hassanin et al., 2017). During the last few years, scaffolds loaded with drugs were used to stimulate the recovery of bone conditions and prevent infections. Scaffolds with loaded drugs are capable of delivering high drug concentrations to the target location. Traditional techniques of the fabrication of scaffold implants include compression, solvent casting, hot melt extrusion, and injection moulding. In this context, several researchers have reported that the manufacturing technique of scaffold drug delivery would significantly affect the amount and the quality of the porous structure, degradation rate, and subsequently its drug release profile.

On the other hand, surgical meshes have been used since 1891 to support body organs during surgeries. They are woven sheets made from biological or biocompatible inorganic materials. They are two types of meshes, temporary and permanent. Temporary meshes decompose over the time, whereas permanent ones remain in the body. Hernia and pelvic repair surgeries are the most common practices to use surgical meshes. Surgical meshes must allow the repair of fascial defect and tissue growth, have high strength, and maintain minimum adhesions to body tissues. Polypropylene (PP) is the most common polymer material used for the manufacturing of permanent surgical meshes. However, there are evidences of developing infection, chronic pain, and hernia recurrences. Therefore, efforts have been invested in developing novel meshes to improve these issues (Baylón et al., 2017). Drug coated and eluting implants, meshes, and scaffolds were introduced using AM to add functionality to the device such as healing, preventing an infection, or to reduce pain, see Figure 7.

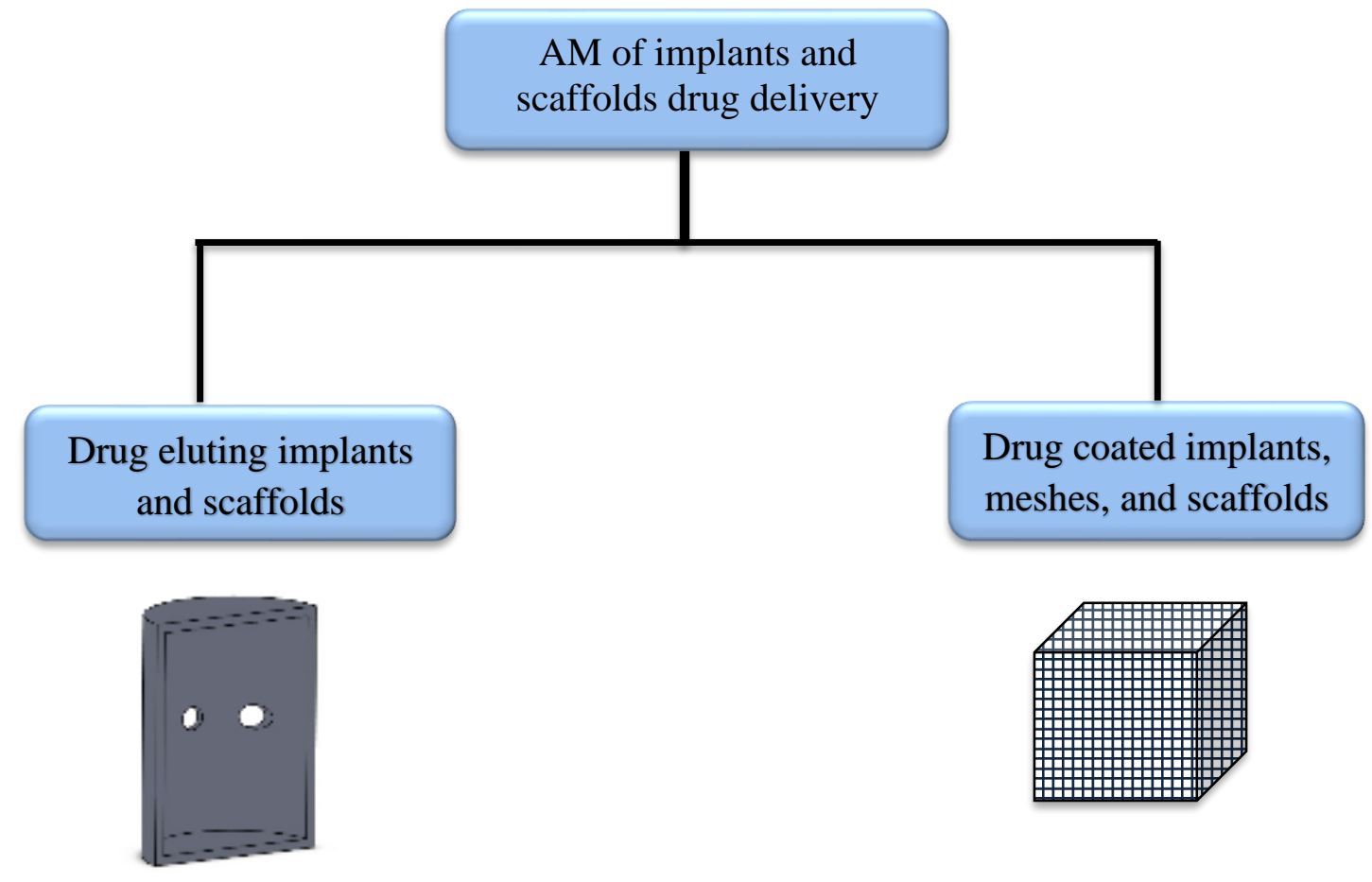

Figure 7: Additive manufacturing of implants, meshes and scaffolds drug delivery (Cox et al., 2016; Hassanin et al., 2018; Mohanty et al., 2015) 


\section{AM Technologies for Drug Delivery}

There are wide ranges of AM techniques that are currently available in the market. A standardised classification of these technologies is introduced by the American society of testing and the international organization for standardization (ISO/ASTM). This standard is the AM ISO/ASTM 52900:2015, which categorises the well-established AM techniques into seven main groups; Material Extrusion, Powder bed fusion, Vat Photo Polymerisation, Direct Energy Deposition, Binder Jetting, Material Jetting, and Sheet lamination (Table 1). The next section discusses the concept of each group and its application in drug delivery.

Table 1: The standardised AM technologies

\begin{tabular}{|c|c|c|c|c|}
\hline AM Group & Techniques & $\begin{array}{l}\text { Processed } \\
\text { Materials }\end{array}$ & \begin{tabular}{|c|} 
Feed Stock \\
Physical \\
Form \\
\end{tabular} & $\begin{array}{c}\text { Consolidation } \\
\text { tool }\end{array}$ \\
\hline $\begin{array}{l}\text { Material } \\
\text { Extrusion } \\
\text { (ME) }\end{array}$ & $\begin{array}{c}\text { Fused Deposition Modelling } \\
\text { (FDM), Pneumatic Extrusion (PE), } \\
\text { Syringe Extrusion (SE) }\end{array}$ & \begin{tabular}{|l|} 
Polymers, \\
Metals, \\
Ceramics, \\
Composites \\
\end{tabular} & Filaments & $\begin{array}{l}\text { Thermal and } \\
\text { cross-linking }\end{array}$ \\
\hline $\begin{array}{l}\text { Vat Photo- } \\
\text { polymerization } \\
\text { (VP) }\end{array}$ & $\begin{array}{c}\text { Stereolithography (SLA), } \\
\text { Continuous Liquid Interface } \\
\text { Production (CLIP), Digital Light } \\
\text { Processing (DLP) }\end{array}$ & $\begin{array}{l}\text { Polymer, } \\
\text { Ceramics }\end{array}$ & Liquids & UV Light \\
\hline $\begin{array}{l}\text { Binder Jetting } \\
\text { (BJ) }\end{array}$ & Ink-Jet 3D printing & $\begin{array}{l}\text { Polymers, } \\
\text { Metals, } \\
\text { Ceramics }\end{array}$ & Particles & $\begin{array}{l}\text { Binder/ Photo- } \\
\text { polymerization }\end{array}$ \\
\hline $\begin{array}{l}\text { Powder Bed } \\
\text { Fusion (PBF) }\end{array}$ & $\begin{array}{c}\text { Selected Laser Melting /Sintering } \\
\text { (SLS/SLM), Selective Heating } \\
\text { Melting (SHM), Electron Beam } \\
\text { Melting (EBM) }\end{array}$ & $\begin{array}{l}\text { Polymers, } \\
\text { Metals, } \\
\text { Composites }\end{array}$ & Particles & $\begin{array}{c}\text { Laser, Electron } \\
\text { Beam }\end{array}$ \\
\hline $\begin{array}{l}\text { Material } \\
\text { Jetting (MJ) }\end{array}$ & $\begin{array}{l}\text { Continuous or Drop on Demand } \\
\text { (DOD) Poly-Jet, Multi-Jet }\end{array}$ & $\begin{array}{l}\text { Polymers, } \\
\text { Metals, } \\
\text { Composites }\end{array}$ & Liquids & UV Light \\
\hline $\begin{array}{l}\text { Direct Energy } \\
\text { Deposition } \\
\text { (DED) }\end{array}$ & $\begin{array}{c}\text { Laser Energy Net Shaping (LENS), } \\
\text { Laser Deposition Welding (LDW), } \\
\text { Laser Cladding (LC) }\end{array}$ & $\begin{array}{c}\text { Metals, } \\
\text { Composites }\end{array}$ & $\begin{array}{l}\text { Wire, } \\
\text { Particles }\end{array}$ & Laser \\
\hline $\begin{array}{l}\text { Sheet } \\
\text { Lamination } \\
\text { (SL) }\end{array}$ & $\begin{array}{l}\text { Laminated Object Manufacturing } \\
\text { (LOM), Ultrasonic Additive } \\
\text { Manufacturing (UAM), Solid Foil } \\
\text { Polymerization (SFP) }\end{array}$ & $\begin{array}{c}\text { Metals, } \\
\text { Composites }\end{array}$ & Sheets & $\begin{array}{l}\text { Cutting and } \\
\text { Gluing }\end{array}$ \\
\hline
\end{tabular}

\subsection{Material Extrusion (ME)}

Material extrusion is characterised by fairly low cost and high speed (Ngo et al., 2018). In ME, the material is heated until softened and extruded under pressure through a narrow nozzle following the path of the part digital model. The extruded thermoplastic or paste material is then dropped on top of the building platform and solidify upon cooling. Fused deposition modelling (FDM) is a popular technique of ME where the printed materials must be thermoplastic to allow the extrusion and the adhesion with previous layers. The technique is shown schematically in Figure 8a. Examples of thermoplastic used in FDM include thermoplastic polyurethane (TPU), polylactic acid (PLA), and acrylonitrile butadiene styrene (ABS). Metal/thermoplastic and ceramic/thermoplastic composites materials were also utilised 
by FDM to print out composite parts with added functionality. Gels and pasts can be also extruded with the aid of pressure as in pneumatic or syringe extrusion (PE/SE) techniques. The $\mathrm{PE} / \mathrm{SE}$ process starts with filling the syringe with a printing material; then the material is extruded through the nozzle, see Figure $8 \mathrm{~b}$. The advantages of using pneumatic or syringe extrusion (PE/SE) over FDM is that they can be utilised to print several materials at low temperatures without the need to melt them (Lim et al., 2018). Bioprinters based on PE/SE systems are capable of printing biomedical objects with high precision using small nozzles diameter (Huang, 2018).
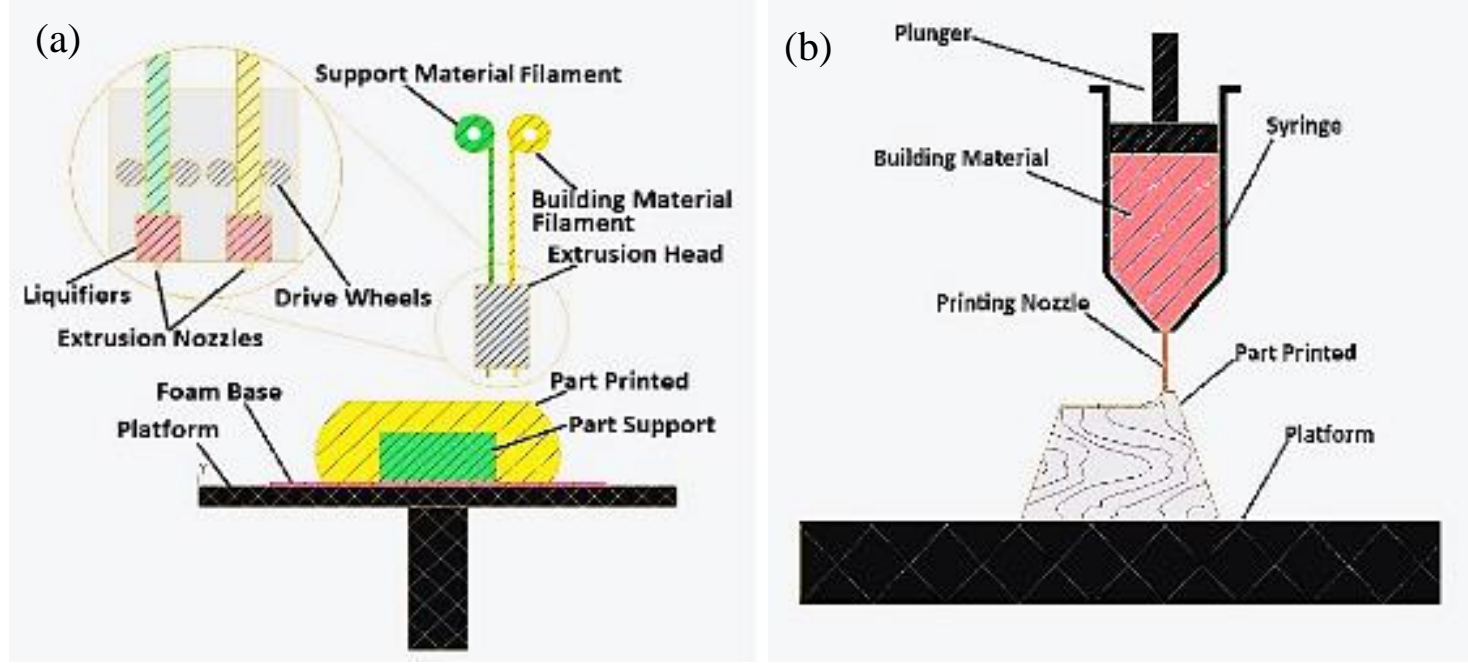

Figure 8: Schematic diagrams of (a) fused deposition modelling; (b) pneumatic or syringe extrusion $(\mathrm{PE} / \mathrm{SE})$.

Material extrusion is the most AM technology adopted for many drug delivery routes (oral, rectal, vagina, transdermal, scaffolds, and implants). Both FDM and PE have been implemented to manufacture oral solid tablets because of their ability to deal with a wide range of biocompatible materials. Many researchers have extensively investigated the use FDM's ability to produce several forms of oral drug products, including tablets, capsules, and beads. A summary of the literature use of FDM in oral drug delivery is summarised in Table 2. As can be seen from this table, the vast majority of the literature has been focused on development of FDM printed tablets with controlled drug profile. Releasing medication in a timely manner is essential for optimal drug effect in the human body. Different types of controlled drug release are necessary to be implemented according to patient condition. For example, constant drug release is an important type as it has a narrow concentration range in which the medicine can work efficiently in the body. Below the required concentration, the drug will not be effective while above it unfavourable side effects may occur. 3D printed tablets and caplets have been fabricated with different infill density, drug-loading contents, and complex structure aiming to achieve immediate or extended release profile. Materials used as the matrix include PVA, Irgacure, PLA, HPC, and HPMC. On the other hand, a wide range of drugs has been experimented such as Curcumin, Paracetamol, Caffeine, Orange G, Fluorescein, Acetaminophen, and Prednisolone. Figure 9 shows porous paracetamol and caffeine printed tablets and their drug release profile (Goyanes et al., 2014). The results show that all printed samples released the entire loaded drug in less than 480 minutes. It was also found that the drug release is rapid when the tablets include a higher drug loading content. 


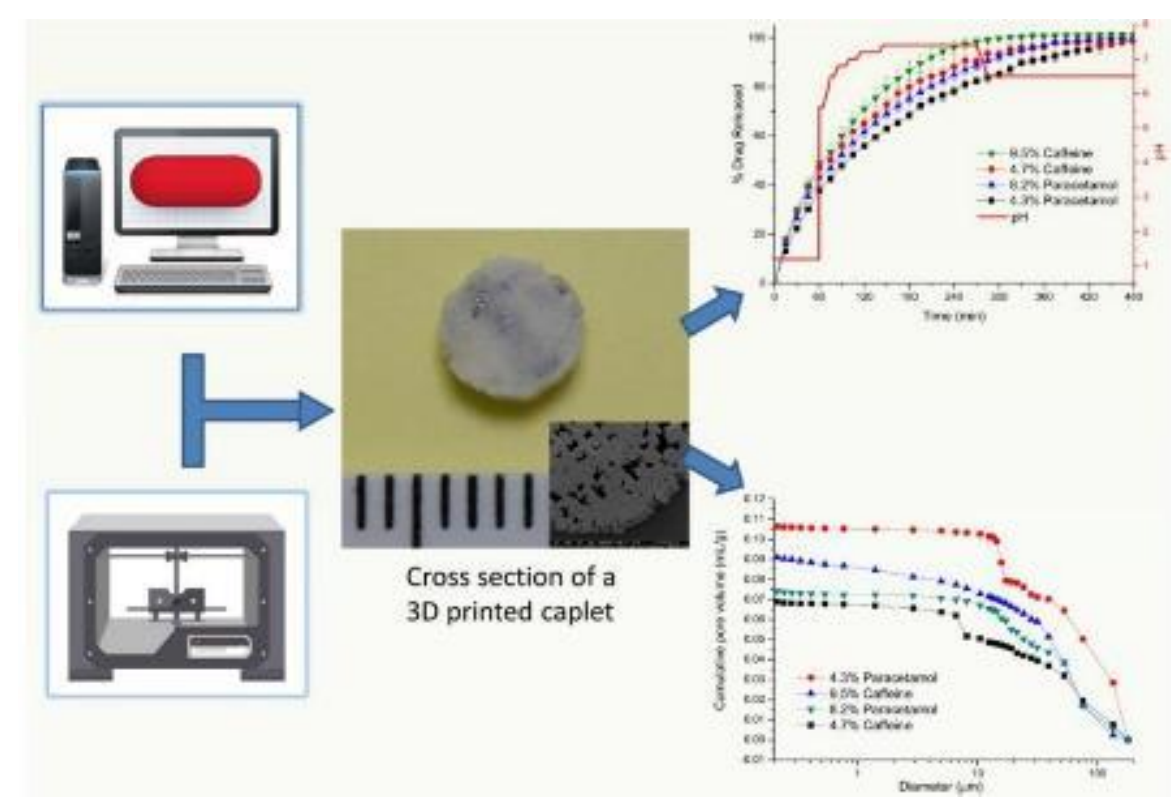

Figure 9: FDM printing of porous paracetamol- and caffeine-based tablets and their and drug release profiles (Goyanes et al., 2014).

Aiming to reduce the administered medication to patients, FDM was implemented to develop sustained release intragastric floating and poly pills drugs. (Chai et al., 2017) used FDM to prepare Domperidone based tablets to be used as a floating intragastric system for a sustained release aiming to enhance its oral bioavailability and simplifying the schedule of the given prescription. Hot-melt extrusion technique was used to load Domperidone into hydroxypropyl cellulose (HPC) filaments. Results showed that the tablets exhibited a sustained, controlled release and were able to stay floating for more than 10 hours in vitro. It also retained inside rabbits stomach for more than $8 \mathrm{hrs,} \mathrm{see} \mathrm{Figure} \mathrm{10.} \mathrm{On} \mathrm{the} \mathrm{other} \mathrm{hand,} \mathrm{(Okwuosa} \mathrm{et} \mathrm{al.,} \mathrm{2017)}$ developed poly pill medication with shell-core structure using dual FDM 3D printer. The results showed the potential of using FDM to introduce multiple drugs in the same tablets with different release profile. Poly-pills or poly-therapy have been widely explored with pneumatic extrusion technique (PE) (Khaled et al., 2014; Khaled et al., 2015a, b). One of the studies introduced by Khalid et al. explored the use of PE to develop a polypill five different drugs and with two independently release rate and concentration. The developed tablet showed that complex drugs could potentially enhance patients' compliance with medications. 

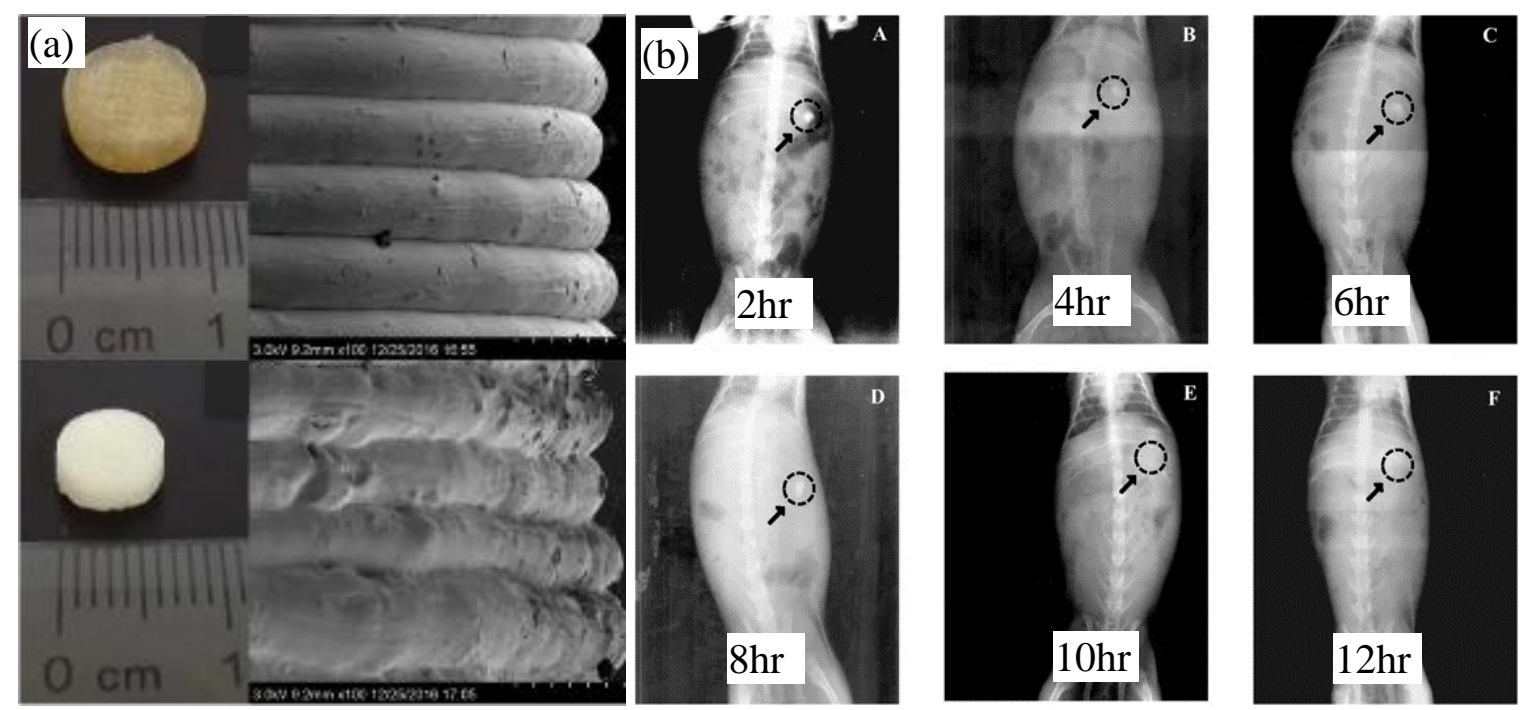

Figure 10: (a) Images of 3D printed tablets (b) X-rays showing the positions of the 3D printed medication in the gastrointestinal tract of rabbits at several time intervals, (Chai et al., 2017).

Table 2: Material extrusion technology for oral drug delivery applications.

\begin{tabular}{|c|c|c|c|c|c|}
\hline $\begin{array}{l}\text { AM } \\
\text { Tech }\end{array}$ & Purpose of Use & Materials & Drug & Drug Loading & References \\
\hline \multirow[t]{3}{*}{ FDM } & $\begin{array}{l}\text { Personalised dosage } \\
\text { Tablets with controlled } \\
\text { release }\end{array}$ & $\begin{array}{ll}\text { - } & \text { PVA } \\
\text { - } & \text { Polyanhydride } \\
\text { - } & \text { PLA } \\
\text { - } & \text { HPGC } \\
\text { - } & \text { Eudragit L100 } \\
\text { - } & \text { HPMC } \\
\text { - } & \text { PVP } \\
\text { - } & \text { Talc } \\
\text { - } & \text { Eudragit EPO } \\
\text { - } & \text { MMC } \\
\text { - } & \text { TCP } \\
\text { - } & \text { Methacrylic acid } \\
\text { - } & \text { PCL } \\
\text { - } & \text { PVA } \\
\end{array}$ & $\begin{array}{ll}\text { - } & \text { Curcumin } \\
\text { - } & \text { Paracetamol } \\
\text { - } & \text { Caffeine } \\
\text { - } & \text { Orange G } \\
\text { - } & \text { Acetaorescein } \\
\text { - } & \text { Prednisolone } \\
\text { - } & \text { 5-ASA } \\
\text { - } & \text { 4-ASA } \\
\text { - } & \text { Dipyridamole } \\
\text { - } & \text { Theophylline } \\
\text { - } & \text { 5-ASA captopril } \\
\text { - } & \text { Theophylline } \\
\text { - } & \text { Prednisolone }\end{array}$ & $\begin{array}{l}\text { Soaking, } \\
\text { mixing/milling }\end{array}$ & 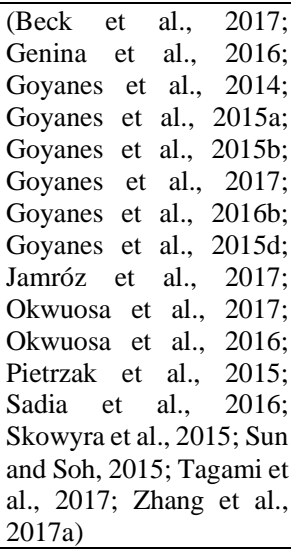 \\
\hline & $\begin{array}{l}\text { Intragastric floating } \\
\text { tablet with extended \& } \\
\text { sustained release }\end{array}$ & $\begin{array}{l}\text { - HPC } \\
\text { - Eudragit L100 } \\
\text { - HPMC }\end{array}$ & - $\mathrm{DOM}$ & Mixing & (Chai et al., 2017) \\
\hline & $\begin{array}{l}\text { Multiple-drug based } \\
\text { tablets with controlled } \\
\text { release }\end{array}$ & - PVA & $\begin{array}{ll}\text { - } & \text { Paracetamol } \\
\text { - } & \text { Caffeine }\end{array}$ & Mixing & (Li et al., 2017) \\
\hline PE & $\begin{array}{l}\text { Multiple-drug based } \\
\text { tablets with controlled } \\
\text { release }\end{array}$ & $\begin{array}{l}\text { - PEG } 6000 \\
\text { - D-mannitol } \\
\text { - Cellulose acetate } \\
\text { - PVP K30 } \\
\text { - Sodium starch } \\
\quad \text { glycolate } \\
\text { - HPMC } 2208 \\
\text { - MCC } \\
\text { - HPMC } 2910 \\
\text { - } \text { PAA }\end{array}$ & $\begin{array}{ll}\text { - } & \text { Captopril } \\
\text { - } & \text { Nifedipine } \\
\text { - } & \text { Glipizide } \\
\text { - } & \text { Captopril } \\
\text { - } & \text { Nifedipine } \\
\text { - } & \text { Glipizide } \\
\text { - } & \text { Aspirin } \\
\text { - } & \text { Hydrochlorothiazi } \\
& \text { de } \\
\text { - } & \text { Pravastatin } \\
\text { - } & \text { Atenolol } \\
\text { - } & \text { Ramipril } \\
\text { - } & \text { Guaifenesin } \\
\end{array}$ & Mixing paste & $\begin{array}{l}\text { (Khaled et al., 2014; } \\
\text { Khaled et al., 2015a, b) }\end{array}$ \\
\hline
\end{tabular}


Conventional rectal, vaginal drug delivery, transdermal patches and dressing do not consider specific patients' needs, health conditions, and anatomy, which restrict patient adherence to medication as well as the medication effectiveness due to the biological and physical differences between patients. Recent progress in AM helped to introduce solutions to the inherited issues of rectal and vaginal drug administration. Proof of concept studies of using ME technologies were carried for rectal and vaginal medications. Examples of vaginal and rectal drug delivery systems include rectal and vaginal suppositories, uterine systems, vaginal rings, and vaginal applicators, see Table 3. (Krezić et al., 2020) developed personalised rectal and vaginal suppositories using FDM technology to prepare PLA moulds and Witepsol H 15 as suppositories formulation. Several studies have shown that the suppositories shape significantly affects the preferences and adherence to medicine for patients. Rocket-shaped, torpedo-shaped, and bullet-shaped suppositories were developed using FDM (Krezić et al., 2020).

On the other hand, personalised and fixable shaped wound dressing and topical patches drugloaded systems were demonstrated by FDM, altered in size and geometry to patients (Goyanes et al., 2016a; Muwaffak et al., 2017). (Luzuriaga et al., 2018) used the FDM to fabricate high resolution microneedles, though the resolution of the printed parts were far from the microneedle geometrical requirements. The authors used an etching post processing to etch the printed parts down to the required shape.

A Furthermore, (Welsh et al., 2019) investigated the use of PE to manufacture dapivirine loaded vaginal rings. The developed rings were compared to those produced using injection moulding. Different infill density of the rings were achieved using PE. The results showed that the developed rings outperformed the IM rings and it showed a great potential to control release profile of the loaded medication in a much better way, Figure 11. 
(a)
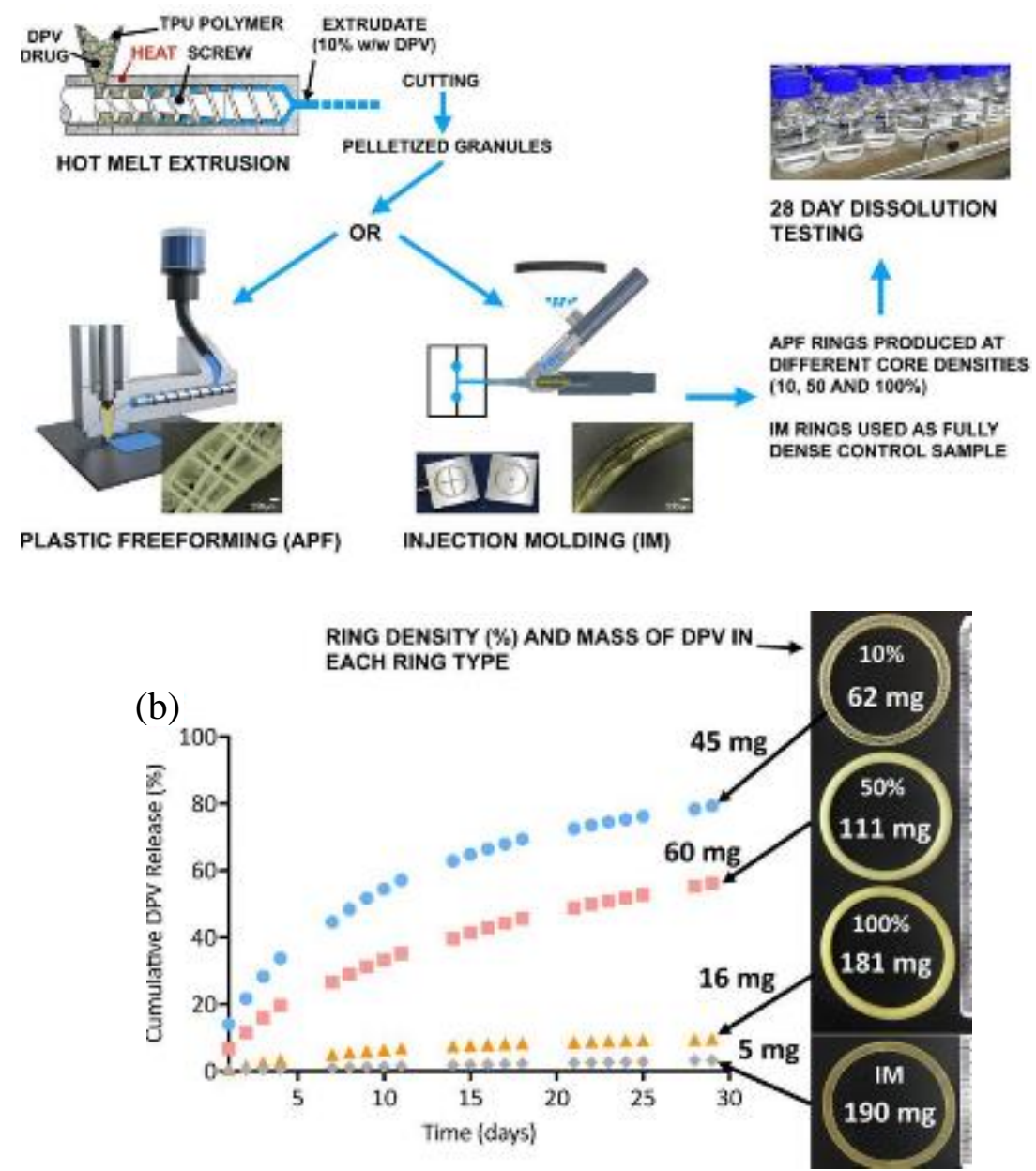

Figure 11: (a) Manufacturing process of PE vaginal ring; (b) drug release profile when compared to IM rings (Welsh et al., 2019).

Table 3: ME technology for Rectal, vaginal and transdermal patches drug delivery systems.

\begin{tabular}{|c|c|c|c|c|c|}
\hline $\begin{array}{l}\text { AM } \\
\text { Tech }\end{array}$ & Purpose of Use & Materials & Drug & Drug Loading & References \\
\hline \multirow{7}{*}{ FDM } & $\begin{array}{l}\text { Rectal and vaginal } \\
\text { suppositories }\end{array}$ & $\begin{array}{l}\text { - PLA for the mould } \\
\text { - Witepsol H } 15\end{array}$ & - None & None & (Krezić et al., 2020) \\
\hline & Suppository shell & - Polyvinylalcohol & - $\quad$ Progesterone & None & (Tagami et al., 2019) \\
\hline & $\begin{array}{l}\text { Vaginal } \\
\text { applicators }\end{array}$ & • ULTEM 908 & $\begin{array}{l}\text { - } \text { Soft tissue- } \\
\text { PMMA }\end{array}$ & None & (Lee et al., 2019) \\
\hline & $\begin{array}{l}\text { Intrauterine } \\
\text { systems }\end{array}$ & $\begin{array}{l}\text { - PCL-PVA } \\
\text { - EVA }\end{array}$ & - Indomethacin & Mixing & $\begin{array}{l}\text { (Genina et al., 2016; Holländer et } \\
\text { al., 2016) }\end{array}$ \\
\hline & $\begin{array}{l}\text { Personalised nose } \\
\text { acne patch }\end{array}$ & $\begin{array}{l}\text { - PCL } \\
\text { - FPLA }\end{array}$ & - Salicylic acid & Mixing & (Goyanes et al., 2016a) \\
\hline & $\begin{array}{l}\text { Drug loaded } \\
\text { wound dressing }\end{array}$ & - $\mathrm{PCL}$ & - Indomethacin & Mixing & (Holländer et al., 2016) \\
\hline & $\begin{array}{l}\text { Microneedle } \\
\text { patches }\end{array}$ & - PLA & - N/A & N/A & (Luzuriaga et al., 2018) \\
\hline PE & Vagina ring & $\begin{array}{l}\text { - Polyurethane } \\
\text { - PLA-PCL }\end{array}$ & $\begin{array}{ll}- & \text { Dapivirine } \\
- & \text { Progesterone }\end{array}$ & Hot mixing & $\begin{array}{l}\text { (Fu et al., 2018; Welsh et al., } \\
\text { 2019) }\end{array}$ \\
\hline
\end{tabular}

Bone is a complex connective tissue made up of cells, fibres and minerals. It is different from other connective tissues with unique features at which the extracellular components are mineralized, giving it significant strength and rigidity, which allows it to play a major role within the body such as supporting the structure of the body and allowing the skeletal movement. Typically, bone fracture and defects are not customised treated. Recently, ME 
technologies such as FDM and PE have facilitated the manufacturing of implants and scaffolds with loaded drugs, see Table 4. On-demand, intraoperative FDM of surgical meshes have to enable patient-specific medicine for localized drug delivery aiming to avoid systemic toxicity and achieve required therapeutic levels (Ballard et al., 2017). PLA filament loaded with gentamicin was used to print the bioactive meshes, see Figure 12. A printed mesh to chemically treat pancreatic cancer were fabricated using PE. PCL (PLGA/PCL) and PLGA were loaded with 5-FU and printed as a patch. The results showed a successful delivery of a high concentration of chemotherapy drug at the site of a tumour. It also showed that the developed 5-FU-PLGA/PCL patches revealed a minimum side effect, prolonged-release period, the attachable flexibility, and a substantial suppressive on the growth of cancer (Yi et al., 2016). In another study, (Long et al., 2019) developed chitosan-pectin wound dressing contains lidocaine loaded hydrogel. Figure 13 shows the PE printed hydrogels with high quality, self-adhesion and dimensional integrity to skin. The 3D printed samples showed high swelling amount and good absorption of water, which revealed a suitable moist wound healing environment. Additionally, polyurethane loaded with levofloxacin for soft tissue reinforcement in vaginal surgery (Domínguez-Robles et al., 2020), polycaprolactone loaded with stem cells for pelvic floor application (Paul et al., 2019), and polypropylene loaded with ciprofloxacin antibiotic were all developed using FDM technology (Qamar et al., 2019).
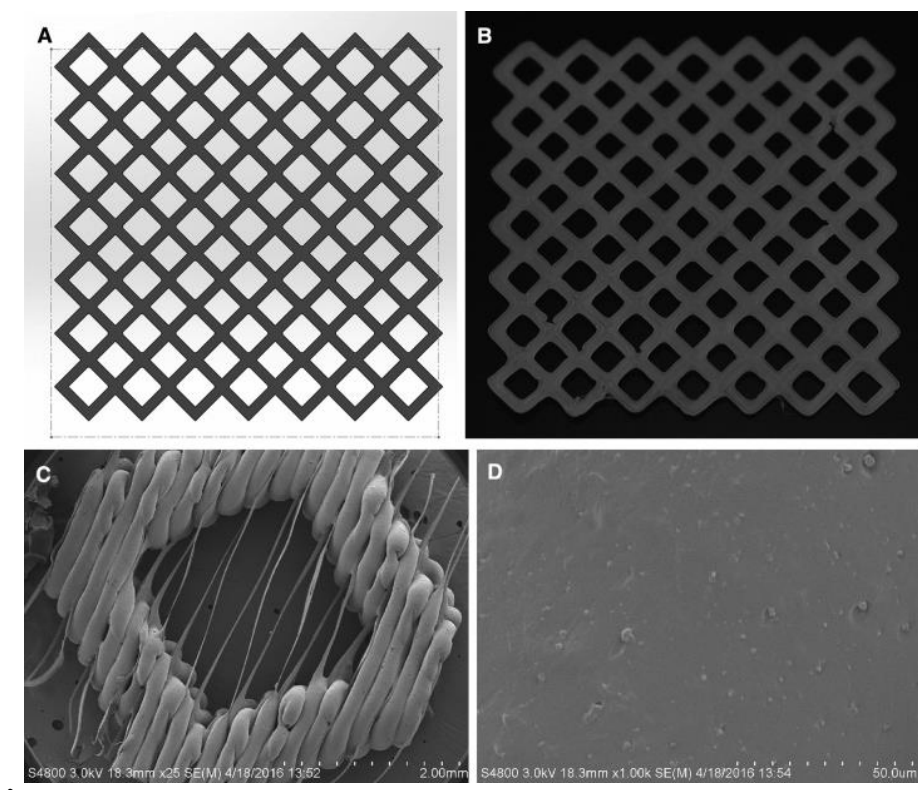

Figure 12: (A) Mesh CAD model. (B) FDM printed mesh. (C) SEM image at $25 \times$ presenting developed mesh fibres. (D) SEM image at 1,000× magnification presenting loaded gentamicin antibiotic (Ballard et al., 2017). 


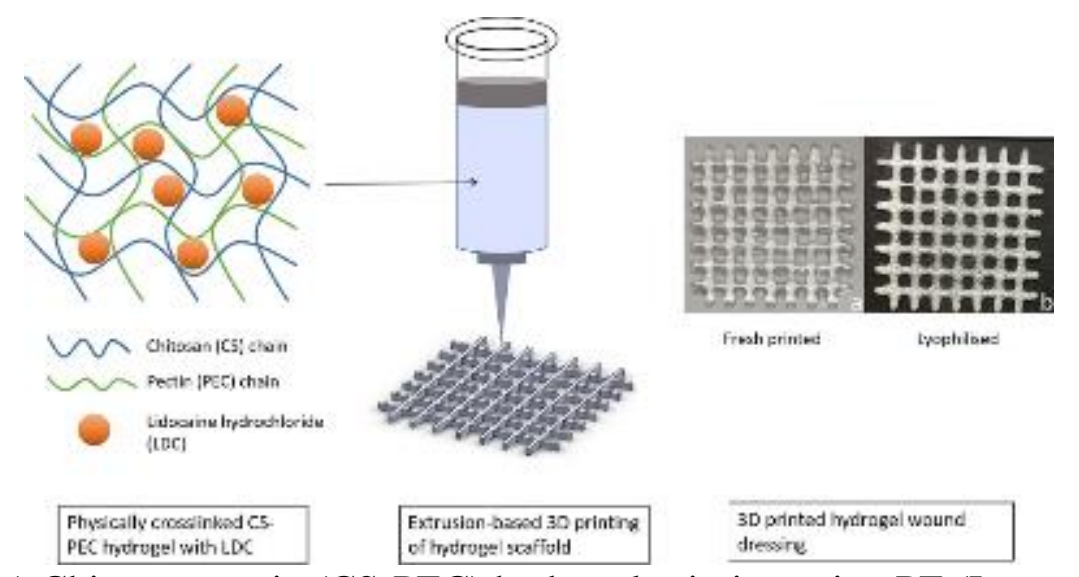

Figure 13: (a) Chitosan-pectin (CS-PEC) hydrogel printing using PE (Long et al., 2019).

Table 4: ME technologies for implants, meshes, and scaffolds drug delivery systems.

\begin{tabular}{|c|c|c|c|c|c|}
\hline $\begin{array}{l}\text { AM } \\
\text { Tech }\end{array}$ & Purpose of Use & Materials & Drug & $\begin{array}{l}\text { Drug } \\
\text { Loading }\end{array}$ & References \\
\hline \multirow{3}{*}{ FDM } & $\begin{array}{l}\text { Drug loaded } \\
\text { implants and surgical } \\
\text { meshes }\end{array}$ & $\begin{array}{l}\text { - } \text { PLA } \\
\text { - Metolose }{ }^{\circledR} \text { 60SH } \\
\text { - } \text { HA } \\
\text { - PCL } \\
\text { - PLGA }\end{array}$ & $\begin{array}{ll} & \text { Nitrofurantoin } \\
\text { - } & \text { Inositol } \\
\text { - } & \text { Niclosamide } \\
\text { - } & \text { Vancomycin } \\
\text { - } & \text { Fluorouracidime } \\
\end{array}$ & Mixing & $\begin{array}{l}\text { (Ballard et al., 2017; Boetker et al., } \\
\text { 2016; Chou et al., 2017; Misra et al., } \\
\text { 2017; Sandler et al., 2014; Water et al., } \\
\text { 2015; Yi et al., 2016) }\end{array}$ \\
\hline & $\begin{array}{lr}\text { Drug } & \text { loaded } \\
\text { scaffolds } & \text { for } \\
\text { enhanced } & \text { tissue } \\
\text { regeneration } & \end{array}$ & $\begin{array}{ll} & \text { Propargyl } \\
- & \text { L-phenylalanine } \\
- & \text { PEU } \\
\text { - } & \text { PU } \\
\text { HA }\end{array}$ & $\begin{array}{ll}- & \text { N3-OGP } \\
- & \text { N3-BMP-2 } \\
- & \text { TGF } \beta 3\end{array}$ & Mixing & (Hung et al., 2016; Lim et al., 2017) \\
\hline & $\begin{array}{lr}\text { Drug } & \text { loaded } \\
\text { Scaffolds } & \text { for } \\
\text { enhanced } & \text { tissue } \\
\text { regeneration } & \end{array}$ & $\begin{array}{ll} & \text { CPC } \\
\text { - } & \text { PCL } \\
\text { - } & \text { PLGA } \\
\text { - } & \text { PHBHHx } \\
\text { - } & \text { MBG } \\
& \\
\text { - } & \end{array}$ & $\begin{array}{ll}- & \text { VEGF-laden } \\
- & \text { Tobramycin } \\
- & \text { Strontium } \\
\text { - } & \text { INH } \\
- & \text { RFP } \\
\text { - } & \text { DMOG } \\
- & \beta-\mathrm{TCP} \\
\end{array}$ & Mixing & $\begin{array}{l}\text { (Ahlfeld et al., 2017; Li et al., 2015; } \\
\text { Min et al., 2015; Shim et al., 2015; } \\
\text { Zhang et al., 2014; Zhang et al., 2017b) }\end{array}$ \\
\hline PE & $\begin{array}{lr}\text { Drug } & \text { loaded } \\
\text { Scaffolds } & \text { for } \\
\text { enhanced } & \text { tissue } \\
\text { regeneration } & \end{array}$ & $\begin{array}{ll}\text { - } & \text { CPC } \\
\text { - } & \text { PCL } \\
\text { - } & \text { PLGA } \\
\text { - } & \text { PHBHHx } \\
\text { - } & \text { MBG }\end{array}$ & $\begin{array}{ll} & \text { VEGF-laden } \\
- & \text { Tobramycin } \\
- & \text { Strontium } \\
- & \text { INH } \\
- & \text { RFP } \\
\text { - } & \text { DMOG } \\
\beta-T C P\end{array}$ & Mixing & $\begin{array}{l}\text { (Ahlfeld et al., 2017; Li et al., 2015; } \\
\text { Min et al., 2015; Shim et al., 2015; } \\
\text { Zhang et al., 2014; Zhang et al., 2017b) }\end{array}$ \\
\hline
\end{tabular}

(Weisman et al., 2019) developed a personalized drug delivery in interventional radiology by enabling FDM to produce drug-loaded catheters. Bioactive-laden bioabsorbable catheters were loaded with chemotherapeutics and antibiotics by mixing and extruding PLA coated pellets. The chemotherapeutics and antibiotics were found dispersed into the PLA matrix. The results showed that the developed catheter had sustained drug release profile up to the 5 days and the antibiotics loaded catheters inhibited the bacterial infection as required, see Figure 14. Similar study was conducted by (Mathew et al., 2019) to use FDM technology to produce thermoplastic polyurethane loaded with tetracycline hydrochloride catheter with various drug contents. The results showed that tetracycline hydrochloride was dispersed within the polyurethane. In addition, the developed catheters showed a strong inhibitory influence on the bacterial growth for up to 10 days and a bacterial adherence reduction of up to $99.97 \%$. 


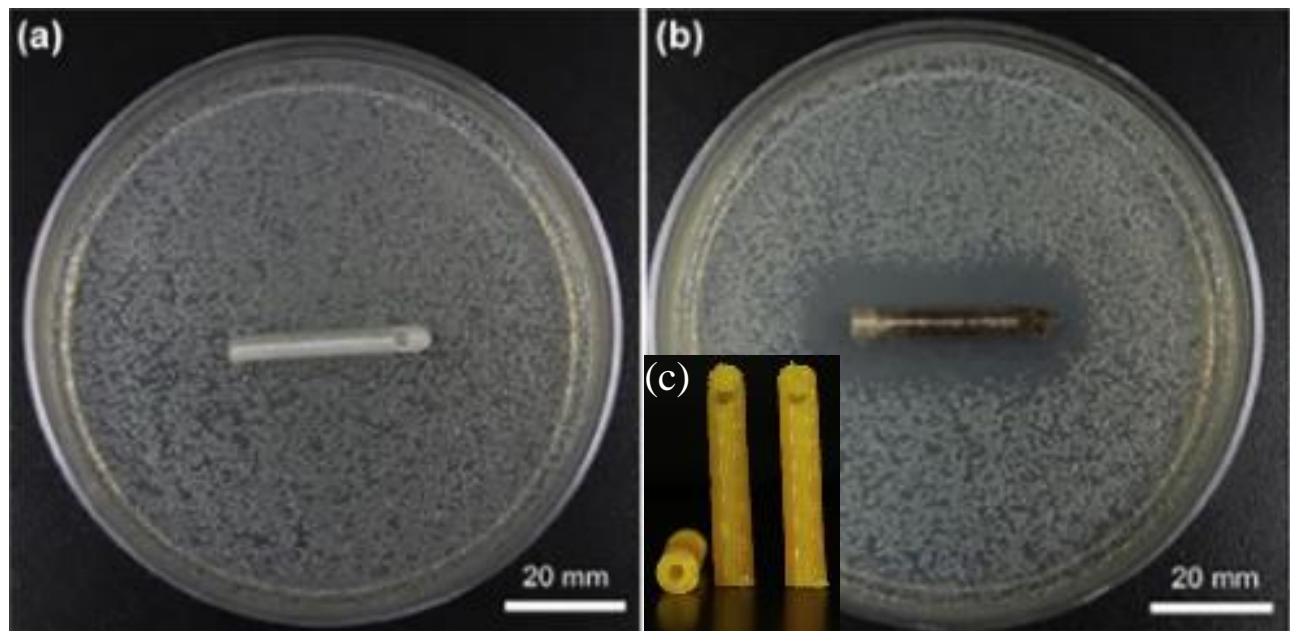

Figure 14: (A) Antimicrobial effect of catheters (a) PLA, (b) PLA+ $1 \mathrm{wt} \%$ gentamicin, (c) 3D printed drug loaded catheters (Weisman et al., 2019).

Table 5: ME technologies for intravenous devices.

\begin{tabular}{|c|c|c|c|c|c|}
\hline $\begin{array}{l}\text { AM } \\
\text { Tech }\end{array}$ & Purpose of Use & Materials & Drug & $\begin{array}{l}\text { Drug } \\
\text { Loading }\end{array}$ & References \\
\hline FDM & $\begin{array}{l}\text { drug-loaded } \\
\text { catheters for local } \\
\text { drug delivery }\end{array}$ & $\begin{array}{ll}- & \text { PLA } \\
- & \text { TPU }\end{array}$ & $\begin{array}{l}\text { - } \quad \text { Gentamicin } \\
\text { - Tetracycline hydrochloride }\end{array}$ & Mixing & $\begin{array}{l}\text { (Mathew et al., 2019; Weisman et } \\
\text { al., 2019) }\end{array}$ \\
\hline
\end{tabular}

\subsection{Vat polymerisation (VP)}

Vat polymerisation (VP) is one of the oldest AM approaches. This technique uses UV light to chemically initiate the crosslinking of a selective layer of photosensitive resin and cure it into a solid polymer. Next, another layer of the photosensitive polymer is cured onto the previous layer. Spreading the resin material and curing it using UV layer is repeated until the part is completed, see Figure 15. Afterwards, the cured part inside the resin tank is removed. Postprocessing such as cleaning and heating can be applied to some materials to achieve better structural integrity and desirable mechanical properties. Metal and ceramic particles can be dispersed with the resin to achieve specific properties. The approach is one of the best AM to achieve high resolution, which can go as low as few microns. However, VP is relatively slow, expensive, and limited to photosensitive materials, which restrict its applications. VP techniques include Continuous Liquid Interface Production (CLIP), stereolithography (SLA), 2 photon polymerization, and digital light processing (DLP). 

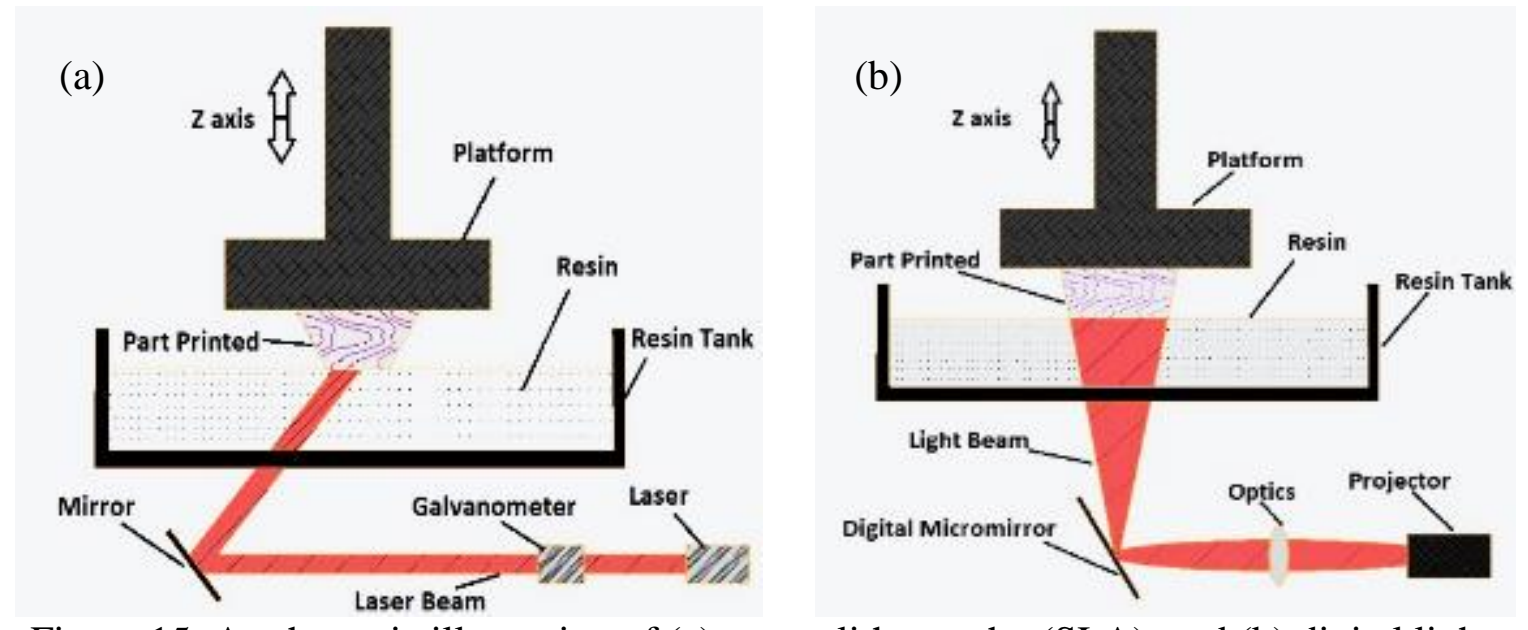

Figure 15: A schematic illustration of (a) stereo-lithography (SLA), and (b) digital light processing (DLP)

VP technology has the ability to produce components with relatively high resolution and better precision than any other AM techniques. This is beneficial not only for fabricating highly complicated geometries necessary for personalised implants and transdermal delivery systems, but also for controlling drug release kinetics for oral tablets. Compared to FDM technology, SLA is a non-thermal process, which allows the printing of tablets incorporating thermosensitive drugs and hence decreases medication degradation. Tablets containing paracetamol and 4-ASA were developed using SLA technique (Wang et al., 2016). In addition, SLA was used to produce suppository moulds to meet the needs of patients' personalized medications (Sun et al., 2016). Transdermal microneedles were fabricated using SLA, CLIP and DLP technologies (Johnson et al., 2016; Kavaldzhiev et al., 2017; Lim et al., 2017; Yeung et al., 2019). In one of the studies, polymeric resin was used to fabricate microneedle arrays for improved transdermal patch containing cisplatin for epidermoid skin cancer treatment. The developed microneedles were built by using SLA followed by a coating process at which cisplatin was deposited on top of the developed microneedles using inkjet printing. Figure 16 shows SEM images of the printed samples with and without coating. The results revealed that the prepared microneedles had excellent piercing capacity with $80 \%$ penetration depth (Uddin et al., 2020). Several studies were carried out and showed that high performance microneedles can be fabricated by using SLA for insulin delivery (Economidou et al., 2019) and microencapsulated cell extrusion (Farias et al., 2018). In addition, SLA technique was used to print hydroxyapatite-coated scaffolds using SLA. The coated samples exhibited osteopromotive properties, see Figure 17. The results showed that bone regeneration was considerably enhanced using the HA-coated scaffolds. Further examinations showed that the scaffold had a rich microscale layer of HA that mimics bone materials and hence helps to improve the healing process (Guillaume et al., 2017). Other drug delivery devices such as rapid reconstitution packages and coated vascular stents were fabricated using SLA and CLIP, respectively (D'hers et al., 2019; van Lith et al., 2016). 


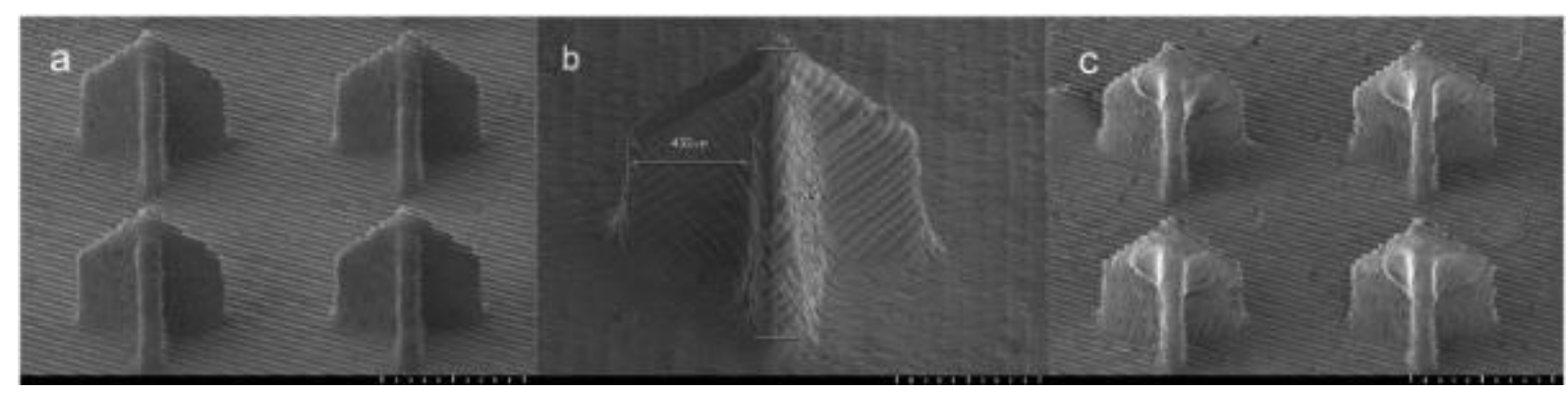

Figure 16: SEM images of the developed microneedles (a) uncoated (b) magnified uncoated (c) coated (Uddin et al., 2020).

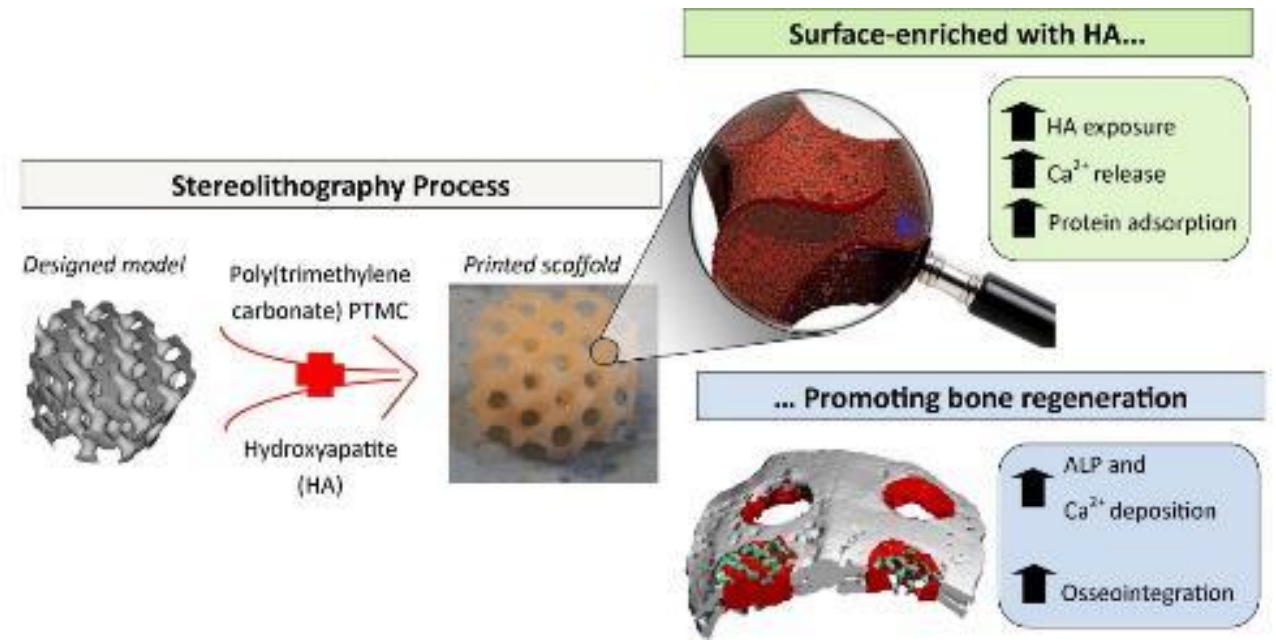

Figure 17: SLA of HA-coated scaffolds (Guillaume et al., 2017).

Table 6: VP for drug delivery systems

\begin{tabular}{|c|c|c|c|c|c|}
\hline $\begin{array}{l}\text { AM } \\
\text { Tech }\end{array}$ & Purpose of Use & Materials & Drug & Drug Loading & References \\
\hline \multicolumn{6}{|c|}{ Oral drug delivery } \\
\hline SLA & $\begin{array}{l}\text { Personalised drug- } \\
\text { loaded tablets }\end{array}$ & $\begin{array}{ll}\text { - } & \text { PEGDA } \\
\text { - } & \text { PEG } \\
\text { - } & \text { DPPO }\end{array}$ & $\begin{array}{ll}\text { - } & \text { 4-ASA } \\
\text { - } & \text { Paracetamol }\end{array}$ & Mixing & $\begin{array}{l}\text { (Martinez et al., 2018; Robles- } \\
\text { Martinez et al., 2019; Wang et } \\
\text { al., 2016) }\end{array}$ \\
\hline \multicolumn{6}{|c|}{ Rectal \& Vaginal Drug Delivery } \\
\hline SLA & $\begin{array}{l}\text { Non-dissolving } \\
\text { suppositories with } \\
\text { controlled drug } \\
\text { release }\end{array}$ & $\begin{array}{ll}\text { - } & \text { Silastic Q7-4720 } \\
\text { - } & \text { MED-4901 } \\
\text { - } & \text { 3DM-Castable } \\
& \text { resin } \\
\end{array}$ & $\begin{array}{ll}\text { - } & \text { Lidocaine } \\
\text { - } & \text { Ibuprofen sodium } \\
\text { - } & \text { Diclofenac sodium } \\
\text { - Ketoprofen }\end{array}$ & Mixing & (Sun et al., 2016) \\
\hline \multicolumn{6}{|c|}{ Transdermal Patches } \\
\hline SLA & \multirow{3}{*}{$\begin{array}{l}\text { Microneedle drug } \\
\text { delivery }\end{array}$} & - PEG-PVA & - Cisplatin & N/A & (Uddin et al., 2020) \\
\hline DLP & & - 3DM & - N/A & N/A & (Lim et al., 2017) \\
\hline CLIP & & - PCL-tMa & $\begin{array}{ll}\text { - } & \text { Rhodamine } \\
\text { - } & \text { Fluorescein } \\
\end{array}$ & N/A & (Johnson et al., 2016) \\
\hline \multicolumn{6}{|c|}{ Scaffolds, Implants and Devices drug delivery } \\
\hline \multirow[t]{2}{*}{ SLA } & $\begin{array}{l}\text { Scaffold coated } \\
\text { with } \\
\text { pharmaceutical } \\
\text { layer }\end{array}$ & - PTMC & - Hydroxyapatite & Mixing & (Guillaume et al., 2017) \\
\hline & $\begin{array}{l}\text { Rapid } \\
\text { reconstitution } \\
\text { packages }\end{array}$ & - Acrylic polymer & - glucagon & None & (D'hers et al., 2019) \\
\hline CLIP & $\begin{array}{l}\text { Coated vascular } \\
\text { stents }\end{array}$ & $\begin{array}{ll}\text { - } & \text { mPDC } \\
\text { - } & \text { Irgacure } 819\end{array}$ & $\begin{array}{ll}\text { - } & \text { Intrinsic } \\
\text { - } & \text { Antioxidant }\end{array}$ & Coating & (van Lith et al., 2016) \\
\hline
\end{tabular}




\subsection{Binder Jetting (BJ)}

Binder jetting is one approach in which material powder are glued together according to a CAD design by using a jet of binder droplets deposited from a head on top of a layer of powder. The powder platform is then lowered to apply another powder layer onto the first one. The same procedure repeated until the part is fully completed. After the build is completed, a curing process takes place to strengthen the printed parts and help in separating them from the unbound powder. The benefits of this approach are that the parts can be created without the need for support structures. This is because of the lightweight materials used in this technique (powder, binder), which can be self-supported. A schematic diagram of the process is illustrated in Figure 18. In addition, the available BJ systems are characterised with their low cost, relatively large build volume, and high print speed (Ferrari et al., 2018). A variety of materials (polymers, ceramics, metals) has been used in BJ systems. This includes stainless steel, Inconel, tungsten, glass, alumina, zirconia, nylon, and many others. The resolution range of this technique is around $200 \mu \mathrm{m}$ (Ferrari et al., 2018). The drawback of this technique includes the poor resolution, poor layer adhesion, and poor surface finish.

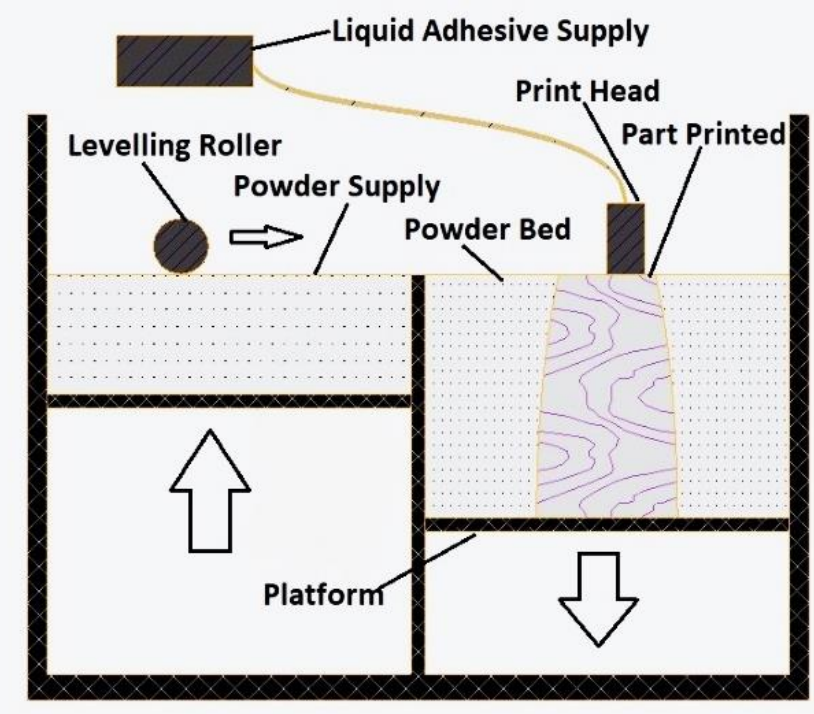

Figure 18: Schematic diagram of Binder Jetting (BJ)

Binder jetting process has been successfully implemented in the manufacturing of both oral solid tablets and drug-loaded biomedical implants, see Table 7. (Li et al., 2015) designed and printed complex and shaped geometries with controlled drug loading and releasing. They used solvent-free inkjet 3D printing to manufacture fenofibrate loaded tablets using beeswax, an FDA approved material, as a carrier of the medication. Figure 18 shows the manufacturing process to produce tablets with honeycomb structure. The process includes CAD design, printing, and drug releasing characterisation of the printed samples. Tablets with honeycomb geometries were designed with different cell size allowing the control over the surface area and hence the drug release profile. Similarly, other researchers studied the development of novel tablets with controlled $\mathrm{pH}$ formulation, gradient drug material, and complex geometries aiming to achieve fast disintegration and more control of drug release (Vorndran et al., 2010; Wu et al., 2016; Wu et al., 2009a; Wu et al., 2009b). 
(a)

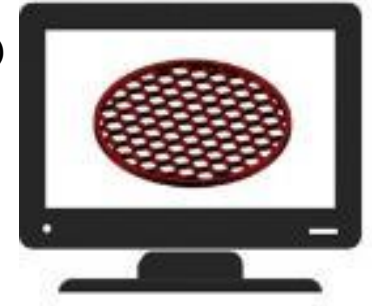

(c)

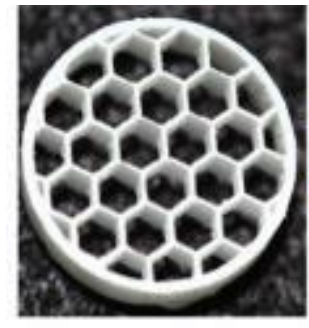

(b)

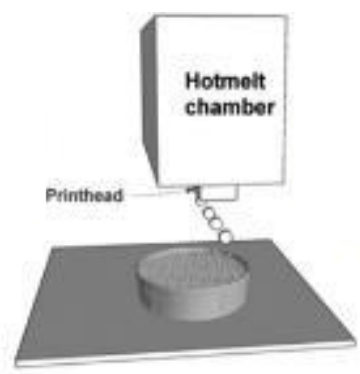

(d)

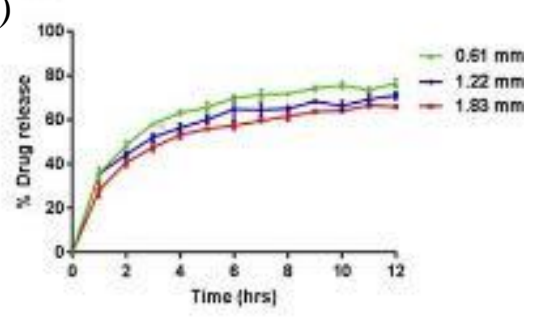

Figure 19: Inkjet 3D printing of oral solid tablets.

Drug loaded biomedical implants were also developed using inkjet printing. Most of the reported studies investigated the printing of PLA based implants. Huang et al. studied the utilisation of inkjet printing to develop levofloxacin, antibiotic, implants with complex drug release profiles. The antibiotic was loaded using powder mixing and milling of Polylactic acid (PLA) and the antibiotic. The authors found that PLA implants fabricated by inkjet printing exhibited a complex drug release profile when compared to implants fabricated using conventional techniques (Huang et al., 2007). Similar research works were also reported to develop PLA-based implants loaded with different drugs such as Isoniazid and Tobramycin (Vorndran et al., 2010; Wu et al., 2016; Wu et al., 2009a; Wu et al., 2009b). 
Table 7: Binder Jet technology applications for drug delivery

\begin{tabular}{|c|c|c|c|c|c|}
\hline $\begin{array}{l}\text { AM } \\
\text { Tech }\end{array}$ & Purpose of Use & Materials & Drug & Drug Loading & References \\
\hline \multicolumn{6}{|c|}{ Oral Solid Dosage } \\
\hline \multirow{4}{*}{ IJP } & $\begin{array}{ll}\text { Tablets } & \text { with } \\
\text { complex } & \\
\text { geometries } & \\
\end{array}$ & $\begin{array}{l}\text { - Beeswax } \\
\text { - HPMC } \\
\text { - Ethylcellulose }\end{array}$ & $\begin{array}{l}\text { - Fenofibrate } \\
\text { - APAP }\end{array}$ & $\begin{array}{l}\text { Mixed with powder } \\
\text { polymer }\end{array}$ & (Kyobula et al., 2017; Li et al., 2015) \\
\hline & $\begin{array}{l}\text { Tablets with multi } \\
\text { and different pH } \\
\text { based release } \\
\text { profiles }\end{array}$ & $\begin{array}{l}\text { - Avicel PH301 } \\
\text { - Eudragit RLPO } \\
\text { - Avicel PH301 } \\
\text { - Eudragit E-100 } \\
\text { - Pharmatose } \\
\text { DCL11 } \\
\end{array}$ & $\begin{array}{l}\text { - Chlorphenir } \\
\text { amine } \\
\text { maleate } \\
\text { - Diclofenac }\end{array}$ & $\begin{array}{l}\text { Mixed with powder } \\
\text { polymer }\end{array}$ & (Rowe et al., 2000) \\
\hline & $\begin{array}{l}\text { Tablet with } \\
\text { material gradient }\end{array}$ & $\begin{array}{l}\text { - Sodium lauryl } \\
\text { sulfate } \\
\text { - Ethylcellulose } \\
\text { - Eudragit RS- } \\
100 \\
\text { - Stearic acid } \\
\end{array}$ & - $\mathrm{APAP}$ & $\begin{array}{l}\text { Mixed with powder } \\
\text { polymer }\end{array}$ & (Yu et al., 2007) \\
\hline & $\begin{array}{l}\text { Fast disintegrating } \\
\text { tablets }\end{array}$ & $\begin{array}{l}\text { - PVP } \\
\text { - Colloidal } \\
\text { silicon dioxide } \\
\text { - Lactose } \\
\text { - K30 } \\
\text { - Mannitol } \\
\end{array}$ & - Paracetamol & $\begin{array}{l}\text { Mixed with powder } \\
\text { polymer }\end{array}$ & (Yu et al., 2009b) \\
\hline \multicolumn{6}{|c|}{ Implants Drug Delivery } \\
\hline \multirow{5}{*}{ IJP } & $\begin{array}{l}\text { Drug mixed } \\
\text { implant with a } \\
\text { slow-release } \\
\text { profile }\end{array}$ & - $\quad$ PLA & - $\quad$ INH & $\begin{array}{l}\text { Mixed with a binding } \\
\text { solution }\end{array}$ & (Wu et al., 2014) \\
\hline & $\begin{array}{lr}\text { Drug } & \text { mixed } \\
\text { implant } & \text { (Tablet } \\
\text { form) with a bi- } \\
\text { modal release } \\
\text { profile } \\
\begin{array}{lr}\text { orthopaedic } \\
\text { purpose }\end{array} \\
\end{array}$ & - $\quad$ PLA & - $\quad$ LVFX & $\begin{array}{l}\text { Mixed with a binding } \\
\text { solution }\end{array}$ & (Huang et al., 2007) \\
\hline & $\begin{array}{lr}\text { Multi-drug } & \text { loaded } \\
\text { implant } & \text { (Tablet } \\
\text { form) } & \text { with } \\
\text { sustained } & \& \\
\text { programmed } & \\
\text { release profile } & \\
\end{array}$ & - $\quad$ PDLLA & $\begin{array}{ll}- & \text { LVFX } \\
- & \text { TOB }\end{array}$ & $\begin{array}{l}\text { Mixed with a binding } \\
\text { solution }\end{array}$ & (Wu et al., 2016) \\
\hline & $\begin{array}{lr}\text { Multi-drug } & \text { loaded } \\
\text { implant } & \text { (Tablet } \\
\text { form) } & \text { with } \\
\text { sustained } & \& \\
\text { programmed } & \\
\text { release profile } & \\
\end{array}$ & - $\quad$ PDLLA & $\begin{array}{ll}- & \mathrm{INH} \\
- & \mathrm{RFP}\end{array}$ & $\begin{array}{l}\text { Mixed with binding } \\
\text { solution }\end{array}$ & (Wu et al., 2009b) \\
\hline & $\begin{array}{lr}\begin{array}{l}\text { Multi-drug } \\
\text { implant }\end{array} & \text { (Tablet } \\
\text { form) } & \text { with } \\
\text { controlled } & \text { release } \\
\text { profile } & \\
\end{array}$ & - $\quad$ PLA & $\begin{array}{ll}\text { - } & \text { LVFX } \\
- & \text { RFP }\end{array}$ & $\begin{array}{l}\text { Mixed with binding } \\
\text { solution }\end{array}$ & (Wu et al., 2009a) \\
\hline
\end{tabular}

\subsection{Powder Bed Fusion (PBF)}

Powder bed fusion uses a heat energy source such as a laser or an electron beam to selectively melt or fuse materials particles according to digital design and create 3D objects layer by layer. The heat energy source is applied to a layer of powder, which incrementally drops down upon the completion of each layer. Next, another layer is spread onto the build platform. The group of techniques is widely used for advanced applications such as aerospace, automotive healthcare and defence. Laser or beam energy can be utilised for metal powders with relatively low melting points. Selective laser sintering (SLS), Selective Heat Sintering (SHS), electron 
beam melting (EBM), Selective laser melting (SLM). SLM can be used to fully melt metal and alloy powders which results in nearly full dense parts with high mechanical strength while SLS and SHS can only elevate metal, polymer or ceramic powders surface temperature to be sufficiently fused without being melted, see Figure 20a (Ngo et al., 2018). On the other hand, EBM uses an electron beam gun to melt metal or alloy powders into the desired shape incrementally, see Figure 20b.
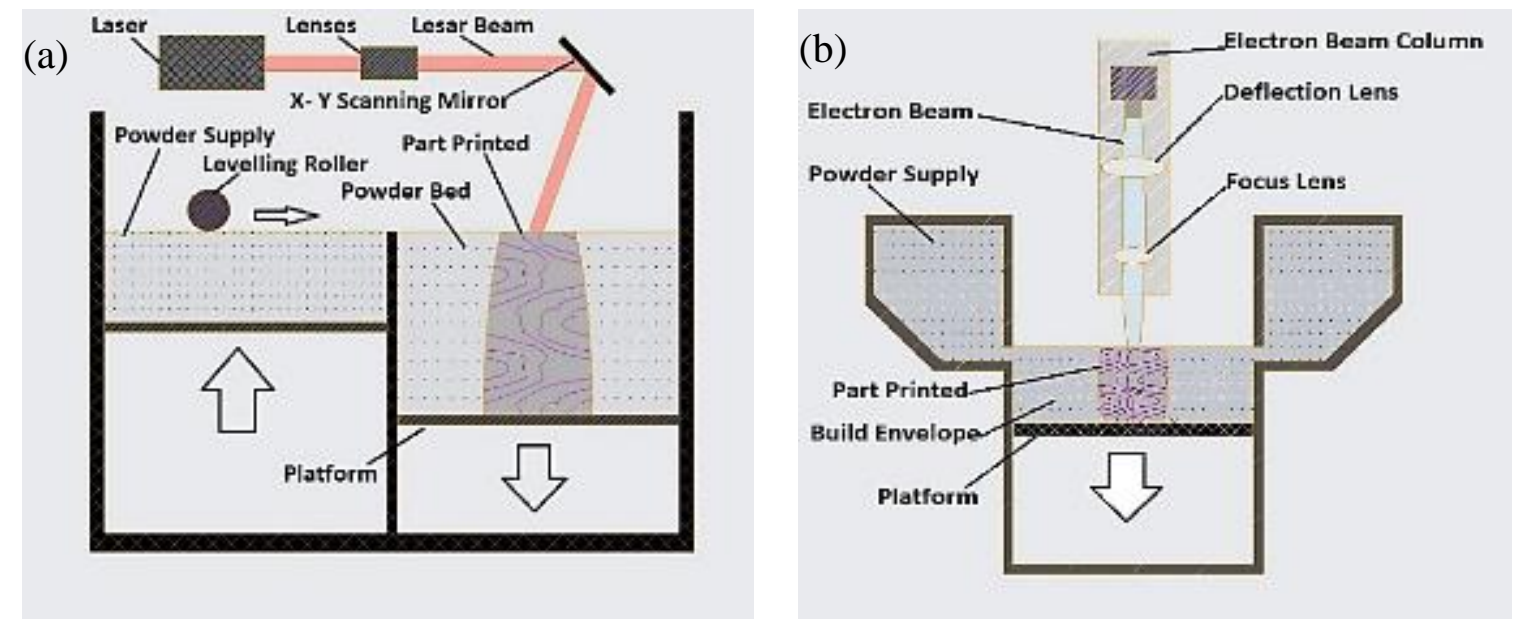

Figure 20: A schematic diagram of (a) SLM system, (b) EBM system.

Generally, powder bed fusion techniques are the least suitable methods for oral drug delivery. This is because the techniques are based on the use of a heat source to consolidate material powder, which may decompose the Active Pharmaceutical Ingredient (API). However, few studies were reported to use powder bed fusion (Table 8). Selective laser sintering was utilised to consolidate a mixture of drug and biopolymeric powder into personalised tablets. The tablets are typically with a porous structure to enable fast disintegration of the tablets. (Fina et al., 2017) used SLS to consolidate thermoplastic biopolymers, namely, polyvinyl alcohol (PVA), polyethylene glycol copolymer (PGC), methacrylic acid (MA), and ethyl acrylate copolymer (EAC). The polymeric matrix was mixed with different drug loading of paracetamol. The results revealed that it is viable to produce oral dosage with both immediate and controlled release profiles as shown in Figure 21 (a,b). In another study by the authors, SLS 3D printed medication-loaded tablets were produced with cylindrical bi-layer and gyroid lattice structures having customisable drug release characteristics, see Figure $21(\mathrm{c}, \mathrm{d})$. The figure shows a reduction in the time of the dissolution for the developed gyroid lattice structures which was attributed to the higher porosity and the increased surface area. As a result, additional water was able to penetrate through the formulation, resulting in a rapid drug release (Fina et al., 2018a). Tailoring the internal structures according to the required drug release profile is another advantage of using AM in preparation of oral dosage. On the other hand, EBM and SLM have been used to develop drug-loaded implants and devices made from biocompatible metals and alloys. The capability of the two techniques to manufacture complex shaped objects enabled the development of personalised implants, scaffolds and devices with interact details. Ti6Al7Nb Implants was fabricated using SLM and surface coated with antibiotic. The surface coated biomedical implants exhibited a considerably lower cytotoxicity to osteoblast and fibroblast cells when compared to uncoated samples. Gentamicin, the antibiotic used, discharged from the coated implants hindered Staphylococcus Aureus growth. The results showed that antibiotic- 
saturated SLM orthopaedic implants have the ability to accelerate the recovery process and to decrease the infections risk significantly (Dydak et al., 2018). (Cox et al., 2016) investigated the development of Ti64 implants incorporating a reservoir filled with gentamicin loaded brushite cement using SLM process. They explored the influence of the reservoir microchannels orientation on the drug discharge. Figure 22 shows CT scan of the SLM implants loaded with antibiotic and different releasing channels. The results showed that the technique has the potential to manage release profile by changing the orientation of the implant releasing channels. Furthermore, electron beam melting was implemented to develop biomedical scaffolds loaded with drugs. Figure 23 shows the EBM scaffold before and after adding chitosan. The results showed that the biological growth of osteoblasts on developed scaffolds was greater than those without chitosan. This suggests that the Ti64/chitosan composite scaffold holds a great potential for orthopedic surgeries (Guo and Li, 2016).
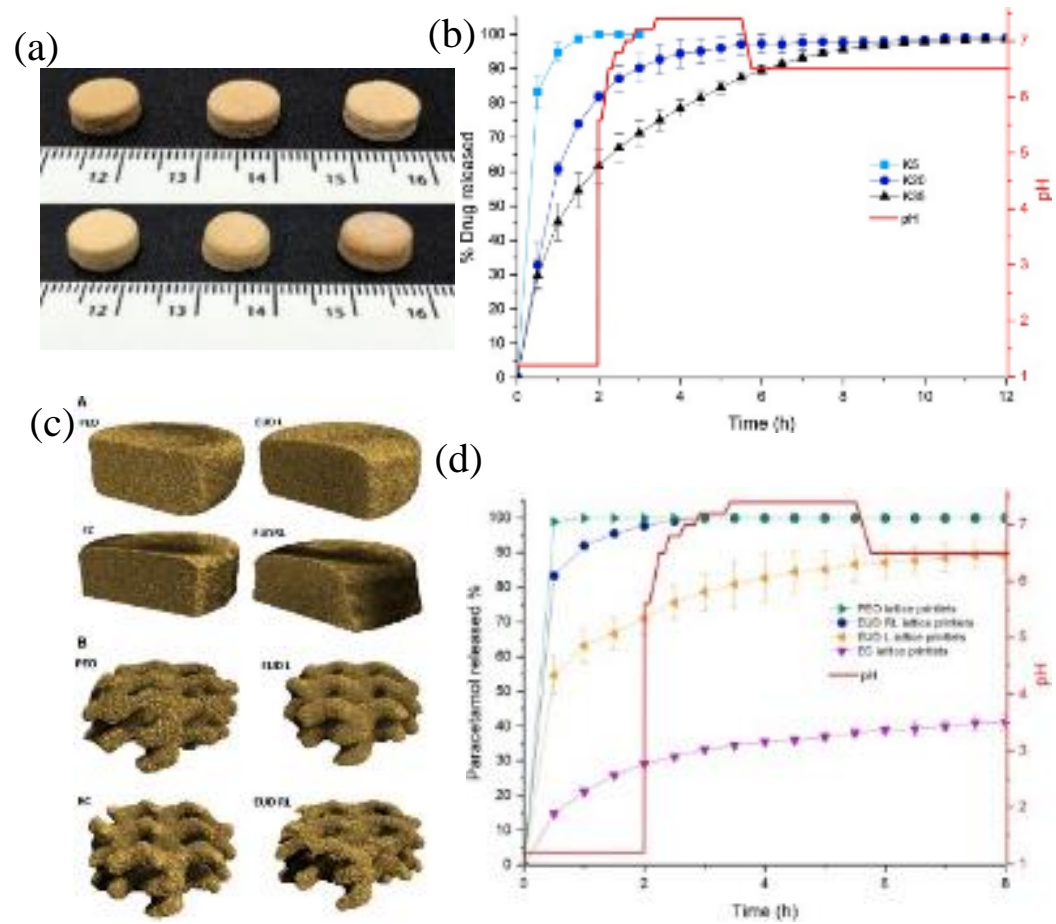

Figure 21: (a) SLS solid tablets with different drug loadings and polymer matrix, (b) drug release profiles for the printed samples, (c) CT images of drug-loaded tablets (d) drug release profiles (Fina et al., 2017; Fina et al., 2018a). 


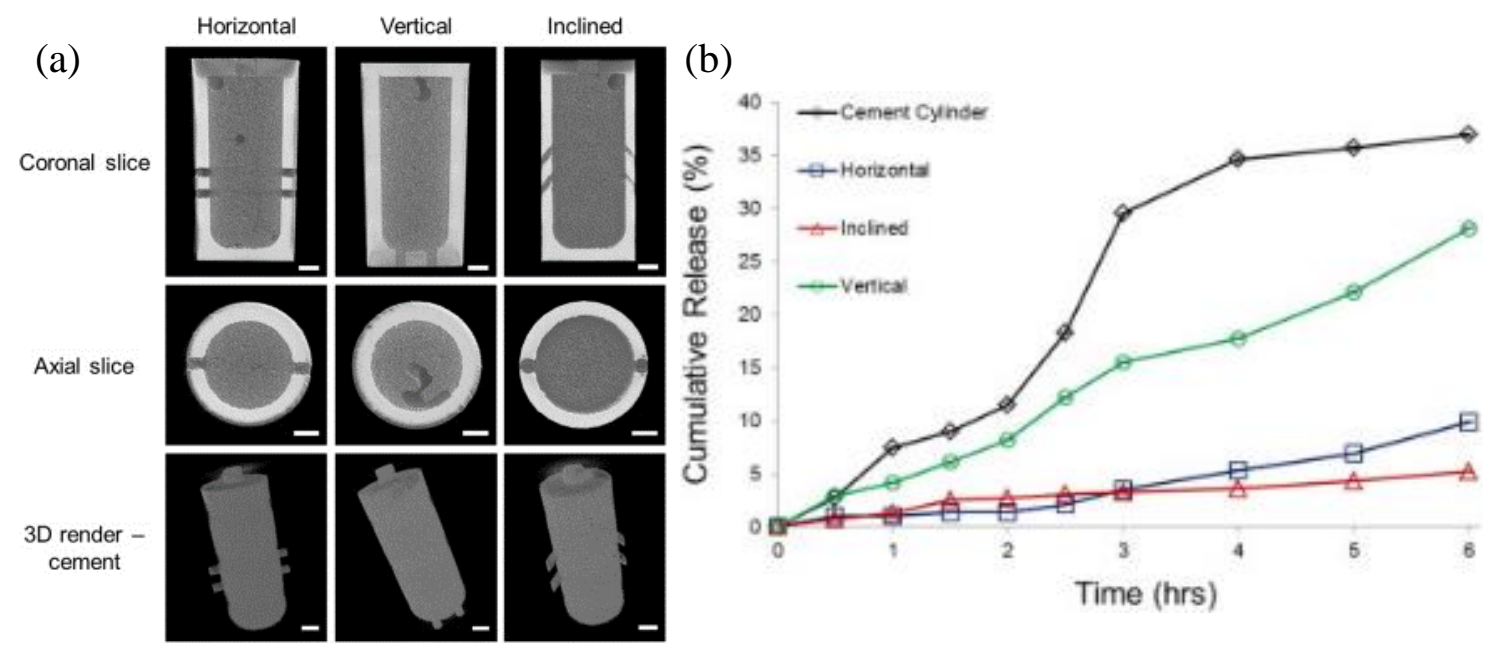

Figure 22: (a) CT scans of the drug-loaded reservoirs with different releasing channels orientation, (b) drug release profile with the corresponding channels (Cox et al., 2016).

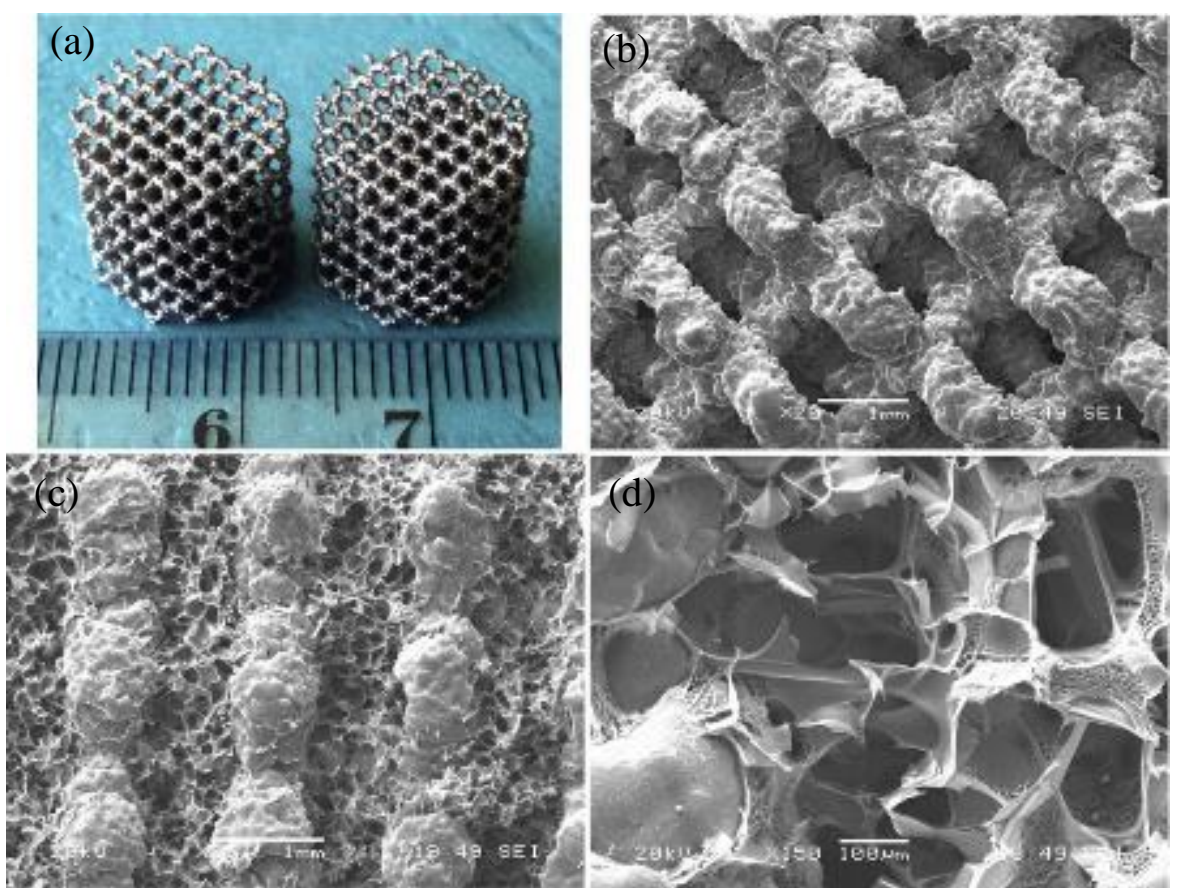

Figure 23: (a) EBM porous Ti64 parts, (b,c,d) chitosan loaded scaffold (Guo and Li, 2016). 
Table 8: Powder bed fusion for drug delivery systems

\begin{tabular}{|c|c|c|c|c|c|}
\hline $\begin{array}{l}\text { AM } \\
\text { Tech }\end{array}$ & Purpose of Use & Materials & Drug & Drug Loading & References \\
\hline \multicolumn{6}{|c|}{ Oral drug delivery } \\
\hline \multirow[t]{2}{*}{ SLS } & $\begin{array}{l}\text { Personalised drug- } \\
\text { loaded tablets }\end{array}$ & $\begin{array}{ll}- & \text { PVA-PEG } \\
- & \text { MAA-EEA } \\
- & \text { PCL } \\
- & \text { HPMC- PVP/VA } \\
- & \text { PE }\end{array}$ & $\begin{array}{l}\text { - Paracetamol } \\
\text { - Progesterone } \\
\text { - Ibuprofen } \\
\text { - }\end{array}$ & Mixing & $\begin{array}{l}\text { (Fina et al., 2017; Fina et al., 2018a; } \\
\text { Fina et al., 2018b; Salmoria et al., } \\
2017 \text { ) }\end{array}$ \\
\hline & $\begin{array}{ll}\text { Drug } & \text { loaded } \\
\text { pellets } & \end{array}$ & - Ethyl cellulose & - Paracetamol & Mixing & (Awad et al., 2019) \\
\hline \multicolumn{6}{|c|}{ Scaffolds, Implants and Devices drug delivery } \\
\hline \multirow{4}{*}{ SLM } & $\begin{array}{l}\text { Implants coated } \\
\text { with a } \\
\text { pharmaceutical } \\
\text { layer }\end{array}$ & $\begin{array}{ll}- & \text { Ti64 } \\
- & \text { Ti6Al7Nb }\end{array}$ & $\begin{array}{l}\text { - } \text { Silver } \\
\text { - } \text { Gentamyci } \\
\text { - PMPC } \\
\text { - Paracetamol }\end{array}$ & Coating & $\begin{array}{l}\text { (Dydak et al., 2018; Vaithilingam et } \\
\text { al., 2015; van Hengel et al., 2017) }\end{array}$ \\
\hline & $\begin{array}{ll}\begin{array}{l}\text { Drug } \\
\text { implants }\end{array} & \text { eluting } \\
\end{array}$ & - Ti64 & $\begin{array}{l}\text { - Gentamicin } \\
\text { - Vancomycin }\end{array}$ & Reservoir & $\begin{array}{l}\text { (Bezuidenhout et al., 2018; Cox et al., } \\
\text { 2016; Hassanin et al., 2018) }\end{array}$ \\
\hline & $\begin{array}{l}\text { Scaffold coated } \\
\text { with a a } \\
\text { pharmaceutical } \\
\text { layer }\end{array}$ & $\begin{array}{l}\text { - } \mathrm{CaSiO} 3 \\
\text { - } \mathrm{Ti} 64\end{array}$ & $\begin{array}{ll}\text { - } & \text { Vancomycin } \\
\text { - } & \text { hydroxyapatit } \\
\text { e }\end{array}$ & Coating & (Ilea et al., 2019; Lin et al., 2019) \\
\hline & $\begin{array}{ll}\begin{array}{l}\text { Drug } \\
\text { distributer }\end{array} & \text { flow } \\
\end{array}$ & - Ti64 & - None & None & (Mazur et al., 2019) \\
\hline EBM & $\begin{array}{l}\text { Scaffold roated } \\
\text { with } \quad \text { a } \\
\text { pharmaceutical } \\
\text { layer }\end{array}$ & - Ti64 & $\begin{array}{ll}\text { - } & \text { Calcium } \\
& \text { phosphate } \\
\text { - } & \text { Simvastatin/p } \\
\text { oloxamer } \\
\text { hydrogel } \\
\text { - } & \text { Chitosan } \\
\end{array}$ & Impregnation & $\begin{array}{l}\text { (Guo and Li, 2016; Liu et al., 2016; Lv } \\
\text { et al., 2015) }\end{array}$ \\
\hline
\end{tabular}

\subsection{Material Jetting (MJ)}

In material Jetting (MJ), material droplets are being deposited through a print head building and dried by solvent evaporation or by solidification under ultraviolet (UV) light and the object is built layer by layer, see Figure 24. The technique was patented by Objet Ltd. in 1999 and merged with Stratasys in 2012 combining both photopolymers and Inkjet technology. The technology offers multiple colours, high-resolution builds, and high-quality surface finish objects. Materials used in this technique are limited to polymers and waxes because of their ability to form droplets and deposited through nozzles. Using wax as support material is beneficial as it can be melted and reused. Examples of polymer materials used in MJ include Polypropylene (PP), Polymethyl methacrylate (PMMA), polycarbonate (PC), Acrylonitrile Butadiene Styrene (ABS), high-density polyethene (HDPE), Polystyrene (PS), and High Impact Polystyrene (HIPS). The technology was evolved to include the deposition of droplets loaded with metal or ceramic particles. MJ has two commonly known processes; continuous inkjet (CIJ) printer and a drop on demand (DOD). They are different in the way the droplets are deposited and controlled (Shama, 2017). On continuous inkjet the material is deposited through the nozzles with the aid of continues pressure. The material drops are then positioned and cured using UV light (Derby, 2015; Goole and Amighi, 2016). Drop on demand (DOD) on the other hand deposits material only when required through a discrete pressure. Poly-Jet printing (PJP) and multi-Jet printing (MJP) are two different types of MJ (Derby, 2010). 
(a)

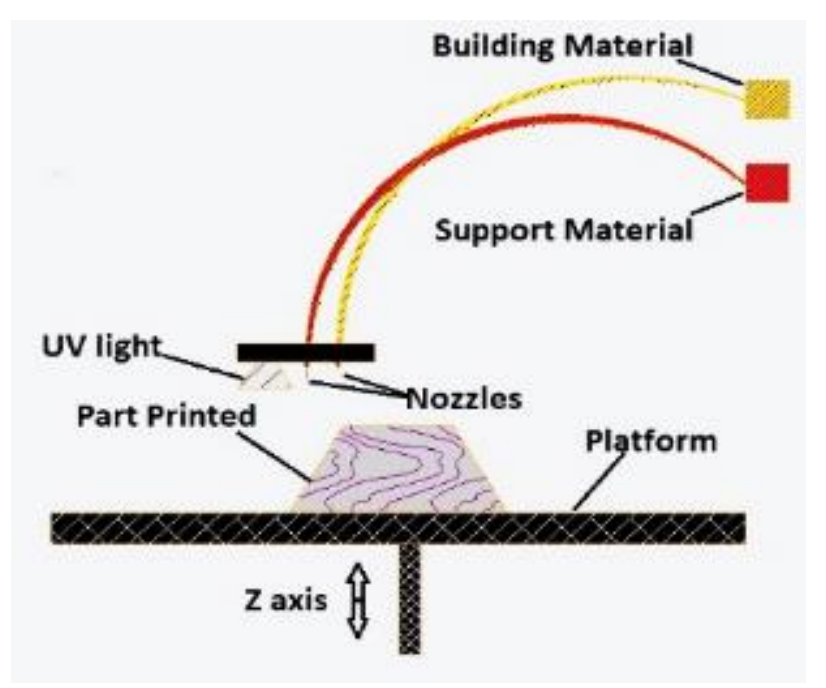

(b)

(c)

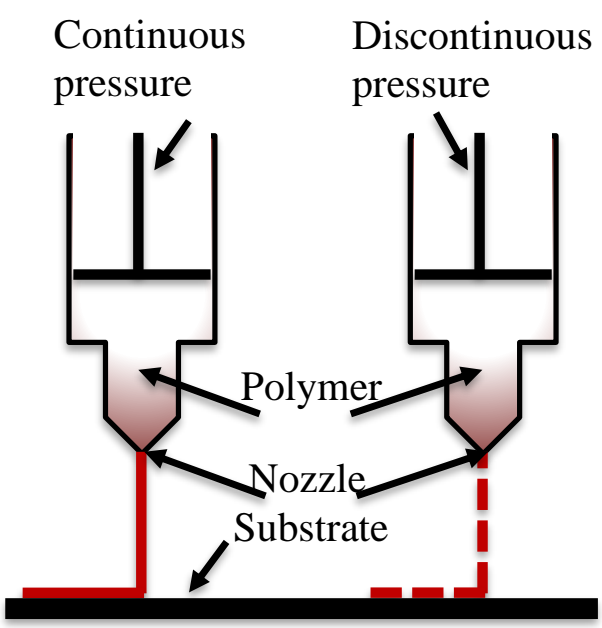

Figure 24: (a) A diagram of Material Jetting, (b) continuous inkjet, (c) drop on demand.

Several studies were found to investigate the use of material jetting to manufacture oral solid tablets, see Table 9. (Clark et al., 2017) developed a solvent-based ink formulation for the fabrication of oral medications that satisfy the standards needed for oral tablets, whereas allowing a flexible and personalized fabrication platform. The inkjet 3D printed tablets consist of both ropinirole and PEGDA. The drug release kinetics was shown to follow law type release profile with. Images of the additively manufactured tablets can be found in Figure 25. The tablets were translucent light yellow when compared to the clear ink solution (drug-free). The figure also shows small "banding" defects along the printing direction and small patches on the print surface. These defects can be minimised by optimisation of material and printing parameters. Although polyjet and multijet printing have been widely used to manufacture biomedical devices and prototypes, the two techniques have not well explored for drug delivery applications. (Xi et al., 2016) developed nasal spray pumps and nebulizers using PJP and tested with different protocols aiming to enhance aerosol deposition in the olfactory area.

(a)
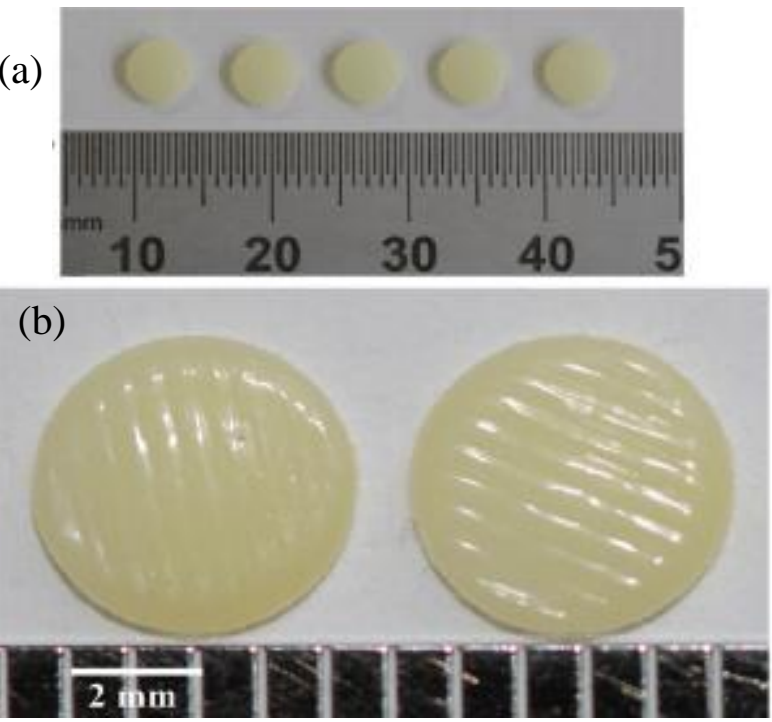

Figure 25: (a) Images of ropinirole 3D printed tablets, (a) 5X magnification of the top surfaces of the printed tablets. (Clark et al., 2017) 
Table 9: Material jetting for drug delivery systems.

\begin{tabular}{|c|c|c|c|c|c|}
\hline $\begin{array}{l}\text { AM } \\
\text { Tech }\end{array}$ & $\begin{array}{l}\text { Purpose of } \\
\text { Use }\end{array}$ & Materials & Drug & Drug Loading & References \\
\hline \multicolumn{6}{|c|}{ Oral drug delivery } \\
\hline \multirow[t]{2}{*}{ IJP } & $\begin{array}{l}\text { Personalised } \\
\text { tablets }\end{array}$ & $\begin{array}{l}\text { - } \text { PEGDA } \\
\text { - } \text { PEG } \\
\text { - } \text { HPC } \\
\text { - } \text { HPMC }\end{array}$ & $\begin{array}{ll}\text { - } & \text { Ropinirole } \\
& \text { HCl } \\
\text { - } & \text { Ibuprofen } \\
\text { - } & \text { Paracetamol } \\
\text { - } & \text { Indomethacin } \\
\end{array}$ & Mixing & $\begin{array}{l}\text { (Acosta-Vélez et al., 2018b; Clark et al., 2017; } \\
\text { Kollamaram et al., 2018) }\end{array}$ \\
\hline & $\begin{array}{l}\text { Combination } \\
\text { therapy } \\
\text { (Polypill) }\end{array}$ & $\begin{array}{l}\text { - Calcium } \\
\text { sulfate } \\
\text { hemihydrate }\end{array}$ & $\begin{array}{ll}\text { - } & \text { Lisinopril } \\
\text { - Spironolacto } & \text { ne }\end{array}$ & Mixing & (Acosta-Vélez et al., 2018a) \\
\hline \multicolumn{6}{|c|}{ Scaffolds, Implants and Devices drug delivery } \\
\hline IJP & $\begin{array}{l}\text { Hydrogel } \\
\text { structures }\end{array}$ & - Alginate & None & None & (Yoon et al., 2018) \\
\hline PJP & $\begin{array}{l}\text { Personalised } \\
\text { Nasal Airway }\end{array}$ & $\begin{array}{l}\text { - Polypropylen } \\
\mathrm{e}\end{array}$ & $\begin{array}{ll}\text { - } & \text { Apotex } \\
\text { - } & \text { Astelin } \\
\text { - } & \text { Miaoling } \\
\text { - } & \text { Nasonex } \\
\end{array}$ & None & (Xi et al., 2016) \\
\hline
\end{tabular}

\subsection{Direct Energy Deposition and Sheet Lamination}

In direct energy deposition (DED), energy is directed in a form of laser or electron beam into a focal region to melt material and deposit it through a nozzle on a heated substrate. A laser beam is used to meet with the feedstock in a powder or wire form at a focal point creating droplets of molten materials on a substrate layer by layer according to a predefined path, see Figure 26. The molten material is then fused and solidified on top of the substrate. Laser Deposition Welding (LDW), Laser Energy Net Shaping (LENS), and wire and Arc AM (WAAM) are different techniques of DED approach. Metals, alloys and their composites are mainly used in this approach such as stainless steel, titanium, aluminium, and nickel alloys. The approach is characterised by its high volumetric deposition rate, which can go ups to $10 \mathrm{Kg} / \mathrm{h}$ for WAAM technique. It is also characterised by its large build volume, which can go up to $6 \mathrm{~m}$ in length. However, the main drawbacks of this approach are its poor surface finish, poor accuracy, and the need for support structures for overhanging parts. As a result, the technique has been implemented in aerospace applications and has been used for cladding gas turbine engines, yet has not explored for drug delivery systems. Nevertheless, the technique was implemented to develop biomedical implants with improved surface modification (Balla et al., 2013; Bose et al., 2018; Shivaram et al., 2017). Sheet lamination (SL) on the other hand glue materials layers together and cut using either a laser beam or a knife. Localised ultrasonic energy can be also used to bond a stacked metal of accurately cut. Further machining and finishing can also be used after printing. The bonded sheets are stacked layer-by-layer to build a 3D object without using any heat source according to digital design, see Figure 27. Materials used in this technique include paper, plastic, or metal laminates are used in manufacturing. SL can be considered also as a partly subtracted method because it follows the contours of the part and removes the rest of the sheet laminate. On the other hand, it is one of the fastest AM techniques for building complex parts. However, it is hard to avoid creation of defects in the interfaces of bonded layers. This tool is very beneficial when producing functionally graded materials multi-layers as different materials sheets can be included in the supplied rolls. Similar to DED, SL technique has not yet investigated for drug delivery applications. The process complexity, material limitation and the poorness of this technique could be the main reasons behind lack of its applications in drug delivery. 


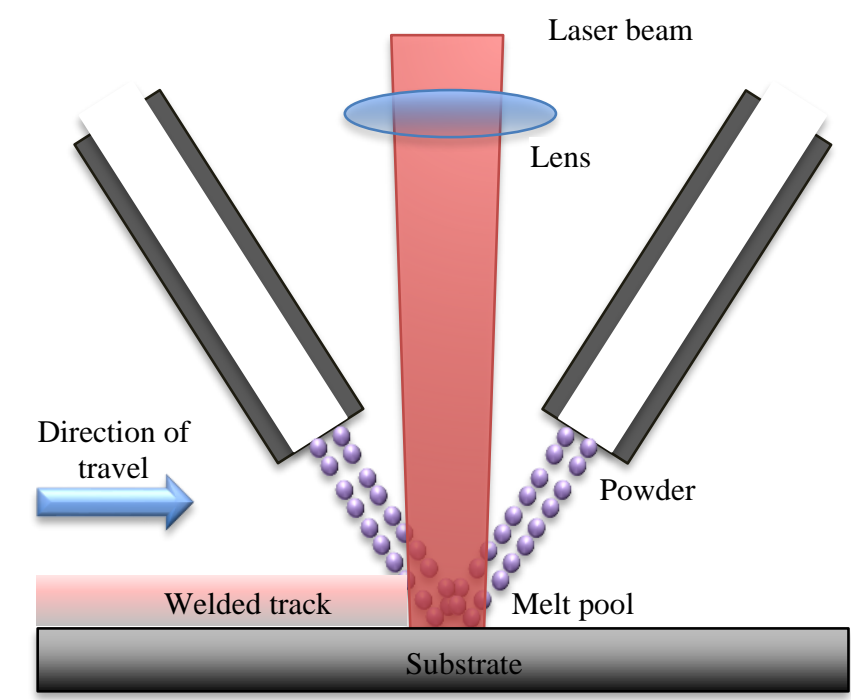

Figure 26: Schematic diagram of direct energy deposition (DED) process.

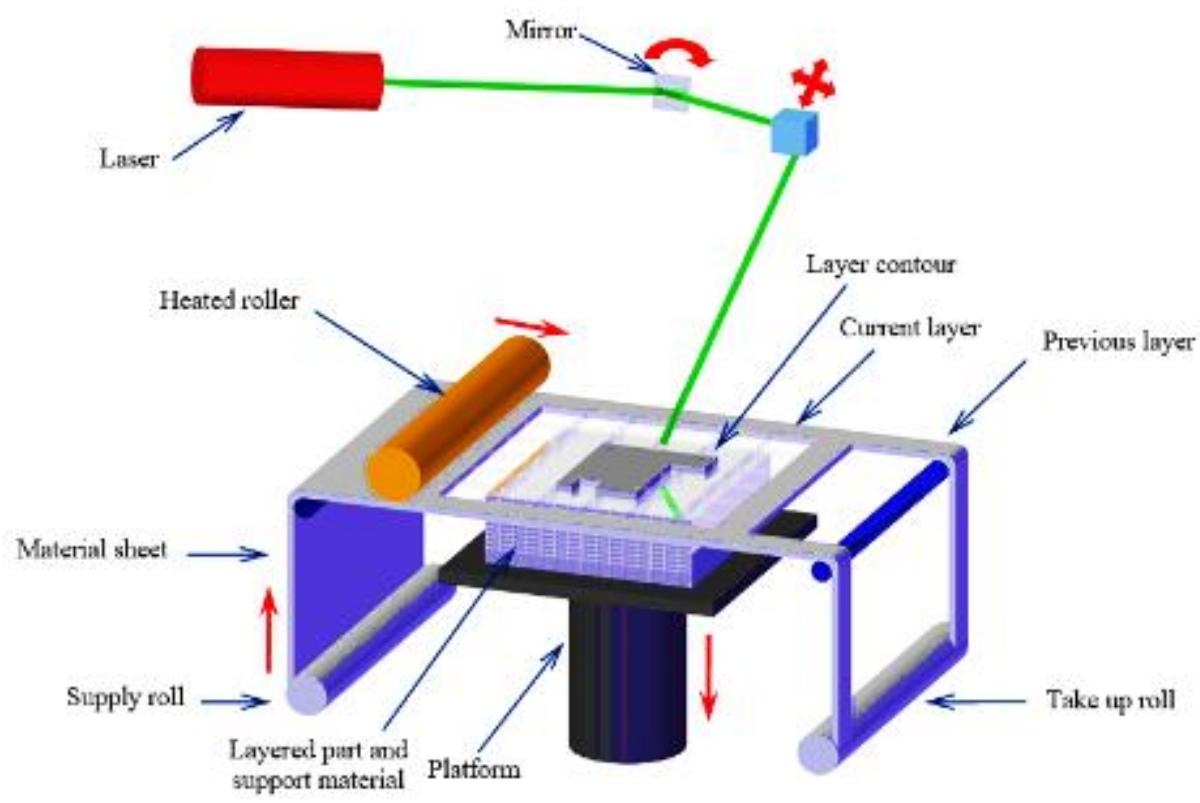

Figure 27: Schematic diagram of Sheet Lamination

\section{Industrial Scale, Current Progress, and Challenges}

The growing demand of AM technologies and the significant cost decrease of commercial 3D printers, their accessories and materials, particularly within the healthcare sector, have resulted in the expansion of these technologies in many applications. AM global market size was $\$ 1.4$ billion in 2010, compared to about $\$ 0.4$ billion in 1996. The market value jumped to $\$ 9$ billion in 2019 and is expected to surge to about $\$ 35$ billion in 2024 as shown in Figure 28. The growth in the AM sales has also a similar trend, rising from only $\$ 71$ million in 2001 to about $\$ 266$ million in 2010 and are predicted to increase to $\$ 8$ billion by 2025 (Caffrey, 2015; Wohlers et al., 2018). Apart from the prospective economic, technical, and environmental 
advantages of AM over other conventional manufacturing, there are also other interrelated factors, which can be identified to explain the rapid increase in the development of AM since 2010. The first is the introduction of relatively affordable and accessible AM, which has facilitated the widespread applications of AM technologies across considerably wider communities of learners, researchers, and practitioners. Another factor was the introduction of efficient and user-friendly software and mobile applications for the modelling and implementation of complex designs which has allowed the public to create virtual 3D parts and accordingly build the aspiration to manufacture physical objects (Bourell, 2016). Many countries have introduced additive manufacturing as parts of educational programs in schools and universities (Wohlers et al., 2018).

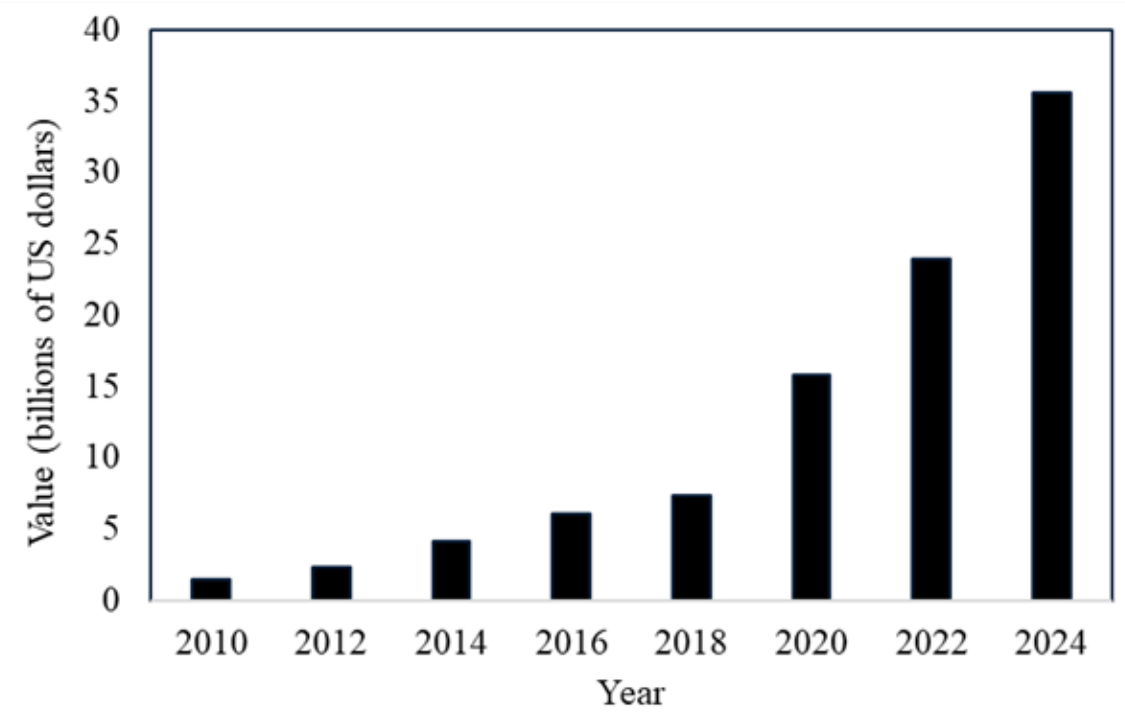

Figure 28: Revenue growth of AM worldwide (in billions of US dollars) from 2010 to 2024 (predicted values for 2020-2024).

The pharmaceutical industry undergoes a substantial shift from mass manufacture towards personalised medication and additive manufacturing has shown a great potential within drug delivery systems. In recent studies, GSK (GlaxoSmithKline) has successfully investigated the manufacturing of paracetamol tablets with rapid release profile. Typically, tablets comprises an active pharmaceutical ingredient (API) and a biocompatible binder substance. The tablets were loaded with paracetamol of up to $(81 \% \mathrm{w} / \mathrm{w})$, using PE 3D printer (Khaled et al., 2018b). The fabricated tablets released over $90 \%$ of the active phase just within $10 \mathrm{~min}$. The developed paracetamol tablets did not show any degradation during printing and no interaction with the binding material (PVP K25 and NaCCS). The tablets was assessed and showed a controlled release and dosage by controlling the microstructure, composition and geometry of the printed tablets (Khaled et al., 2018a). Aprecia Pharmaceuticals was the first company that developed 3D printed oral tablets (Spritam) in the market. The tablets is for treating epileptic seizures, and it is designed to disintegrate in the mouth in few seconds, which makes it suitable for patients who struggle to swallow solid tablets, pills, or capsules (spritam, 2019). The printed tablets were made with a design that allows them to be easily swallowed and disintegrates very quickly once the pill is taken. The tablet was approved by the U.S. Food and Drug Administration (FDA) in the year 2015 (Pharmaceuticals, 2019). Johnson \& Johnson's 3-D Printing Centre of Excellence has also introduced a significant advancement of adopting AM technologies for drug delivery systems. Solutions to improve medications adherence for older patients have been investigated such as polymer and metal implants, bioprinting, personalised medicines, and AM sensor tablets that could send text messages to smart phones. In addition, personalised 
facemask made of cellulose, locust beans and red seaweed that uses patient information from a mobile or a digital camera to construct the mask (Griffiths, 2019). Furthermore, 3D musculoskeletal tendon-like tissues were also developed using 3D bio printing by a research team from Novartis. Cell-tissue suspension mixed with photo-polymerised gelatinmethacryloyl was printed in a dumbbell shape onto novel potholder. The cells also exhibited a high viability in good tissue differentiation (Laternser et al., 2018). Moreover, researchers from Roche and Organovo have printed human liver composed of hepatocyte (patient-derived parenchymal) and non-parenchymal cell populations to simulate drug-induced liver damage and differentiate between compounds with different toxicity levels (Nguyen et al., 2016). The trend towards digitalisation in pharmaceutical industry was triggered by the great potential of AM, personalisation, and control over drug release and sustainability within the body and how the pharmacodynamics of the medication can be improved by altering its structure, shape, and composition. Personalized drug delivery systems have shown to be a reliable approach in treating patients considering their personal conditions. Although additive manufacturing enabled the potential for new possibilities in drug delivery, the concept behind it and how it works is remarkably very simple.

The case studies discussed in this review revealed many potentials that AM holds for future drug delivery systems. However, there are still challenges that need to be addressed in order to penetrate AM technology widely within industry and community. Five of seven of AM standard technologies have been implemented to develop pharmaceuticals medications, see Figure 29a. These techniques are vat polymerization, material extrusion, powder bed Fusion, materials jetting, and binder jetting, Figure 29a. The figures show that vat polymerization, material extrusion, and powder bed fusion shares similar research amount while direct energy deposition and sheet lamination found no applications in drug delivery. In particular, FDM and Inkjet printing technologies was found to be interesting to pharmaceutical industry because of its ability to print multiple materials with high precision and low cost. In addition, the technologies have many similarities with the current production technologies. However, the low productivity of $3 \mathrm{D}$ printing is one of the barriers that needs to be addressed. Conventional technologies can manufacture over than 1.5 million tablets, which cannot be achieved using the current 3D printing technologies. In addition, 3D printing offers tablets with rapid drug release and a high drug loading, which is difficult using conventional technology. Furthermore, oral, implants and scaffolds drug delivery fabricated using AM were the most researched applications while rectal, vaginal and transdermal patches show the least interest by researchers as shown in Figure 29 and Figure 30. However, this does not mean they were less important, but this was mainly because they are often used by specific patients in terms of gender, age, and type of disease. The increased amount of research on using AM technologies in areas such as oral, scaffolds and implants drug delivery is triggered by the many factors such as the ability of AM to control the drug release. AM to realise flexibility in tablets formulation with multi-objective release profiles. It helps improvements in innovative drugs such as poly therapy and fixed-dose combination (FDC) with various medication release. In addition, the AM has ability to produce complex designs of oral tablets with tailored density loaded with the prescribed drug. Furthermore, complex geometries scaffolds and implants allow body tissue and fluid to flow freely, hence, improve osseointegration of the devices. The discussed studies showed that addition of the medication to scaffold and implants by either coating, mixing, or as a reservoir helped to overcome inherent problems such as infection, stress shielding, and enabled a faster healing process of patience. Additional advantages of AM in drug delivery are cost efficiency, high yield, design, and manufacturing freedom. 
(a)

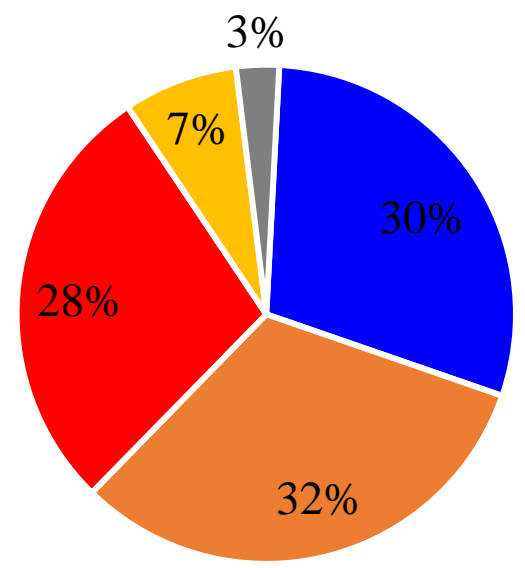

- Material Extrusion $\quad$ Vat Polymerization

- Powder Bed Fusion " Materials Jetting

- Binder Jetting (b)

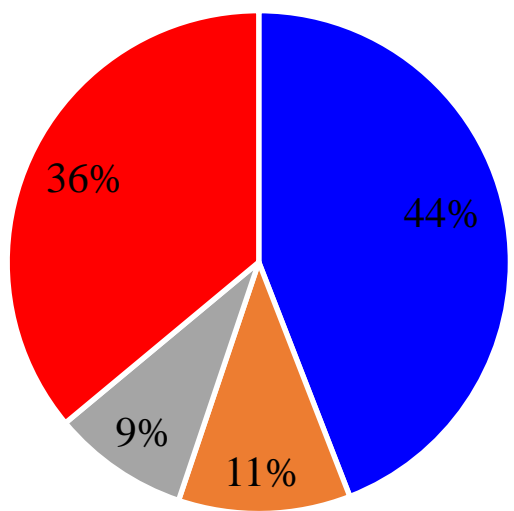

- Oral drug delivery

- Rectal \& Vaginal drug Delivery

- Transdermal drug delivery

- Implants \& Scaffolds Drug Delivery

Figure 29: Research amount of (a) AM Techniques used in Drug Delivery Systems, (b) drug delivery systems developed using AM (Source: Scopus.com).

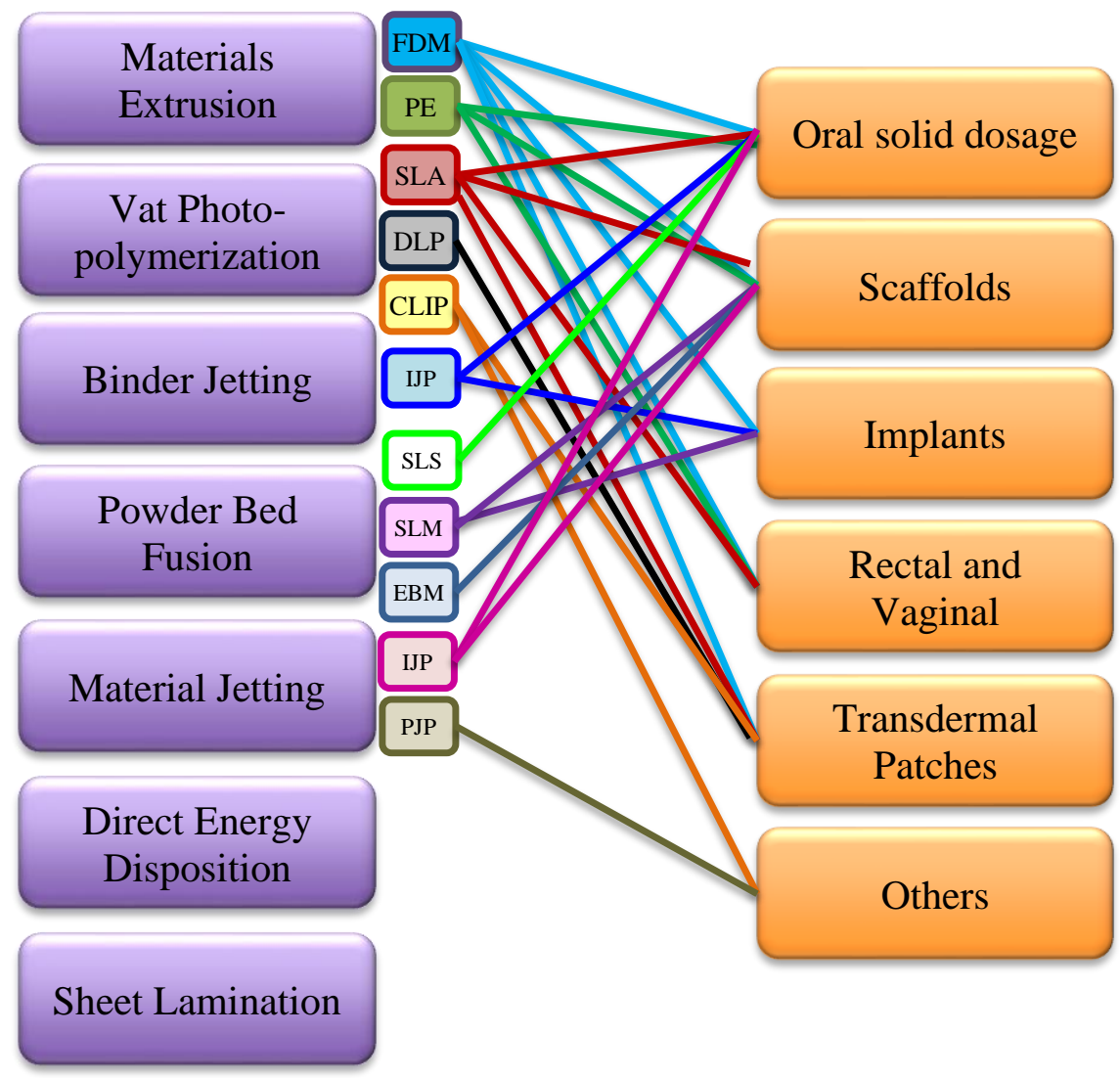

Figure 30: Current research trend between AM technologies and drug delivery systems.

Although the current research work seems to be bringing us closer to understand the potential and limitations of AM technologies for drug delivery applications, there is still a lot of work needed to enable the technology widely into the pharmaceutical market. AM can fabricate a wide range of materials using commercial printers. Therefore, the materials and equipment used must be biocompatible. In addition, most of sterilisation techniques such as autoclave involve 
the use of high-temperature steam, which may only a limited number of materials, particularly metals, and ceramics while the use of polymers may require other less aggressive sterilisation methods. The limited number of in vivo studies and the difficulties to scale up these technologies are other challenges that restrict the penetration of this technology further. Pharmaceutical companies are required to spend much efforts and money to modify their production line with biocompatible grade printers that can fulfil the mass/patch production nature of this sector. Environmental impact and sustainability of AM are limitations that require a great depth of understanding. Although material saving of AM is great, there is still a gap in recycling of AM materials. For example, recycling plastic waste into filaments is a reliable way to solve this problem using commercially available extruders. However, issues such as mixing of drugs, carrier polymers, colours, and material degradation can lead to a significant issue to the properties of filaments.

\section{Conclusions}

The review showed that AM technologies allow customization of drug delivery systems to fit patients' needs and health conditions. The progress in this area is supported by the progress in computer-aided design (CAD) and computer-aided manufacturing (CAM) that enable rapid and accurate scanning and designing of patient organs. Over the past few years, implementing additive manufacturing for drug delivery systems has remarkably helped to discover new routes to develop novel medications. The unique characteristics of developed AM drug delivery systems including controlled release profile tablets and suppositories, personalised microneedle detrimental patch, drug-coated scaffold, and drug-eluting implants are now achievable with the use of AM. In orthopaedics, for example, AM technology has managed to change the perspective of bone fracture treatments. With the unique capabilities of AM, drug-loaded implants and/or scaffolds with complex geometries and high resolution can be used to speed up the healing process and restore bone shapes and strengths. In addition, the effectiveness of oral drug delivery dosage can be significantly improved by controlling the drug release process and the interior structure of the tablets. Such control would allow the drug to provide the body with the exactly needed amount of the medication at the time it is needed, minimizing any overdose side effects. Technologies such as FDM, SLA, SLS, and SLM have been extensively used to fabricate drug delivery systems. FDM has been proven to process wide range of oral dosage tablets with complex formulations and geometries. SLA techniques showed high-resolution drug devices and microneedles transdermal patches. On the other hand, technologies such as direct laser deposition and sheet lamination have not been investigated in this field because of their either processing nature or the quality of their products. Clinical evaluations of the developed systems by either academia or industry showed a great potential. Pharmaceutical companies have started to revolutionize the research and production line aiming to provide effective dose to patients. Although AM has successfully developed functional products in other industries such as automobile and aerospace, AM of drug delivery is still faces several technical and regulatory challenges before a wide adoption in the pharmaceutical industry. In particular, research on pharmaceutical materials recycling, quality control, and the effect of inherited issues of AM such as surface roughness, internal defects post processing, and resolution are still lacking. 


\section{References}

2003. Adherence to longterm therapies. Evidence for action. World Health Organization, Geneva.

Acosta-Vélez, G.F., Linsley, C.S., Zhu, T.Z., Wu, W., Wu, B.M., 2018a. Photocurable Bioinks for the 3D Pharming of Combination Therapies. Polymers (Basel) 10, 1372.

Acosta-Vélez, G.F., Zhu, T.Z., Linsley, C.S., Wu, B.M., 2018b. Photocurable poly(ethylene glycol) as a bioink for the inkjet 3D pharming of hydrophobic drugs. International Journal of Pharmaceutics 546, 145-153.

Ahlfeld, T., Akkineni, A.R., Förster, Y., Köhler, T., Knaack, S., Gelinsky, M., Lode, A., 2017. Design and Fabrication of Complex Scaffolds for Bone Defect Healing: Combined 3D Plotting of a Calcium Phosphate Cement and a Growth Factor-Loaded Hydrogel. Annals of Biomedical Engineering 45, 224-236.

Al-Hashimi, N., Begg, N., Alany, R.G., Hassanin, H., Elshaer, A., 2018. Oral Modified Release Multiple-Unit Particulate Systems: Compressed Pellets, Microparticles and Nanoparticles. Pharmaceutics 10, 176.

Alonso-Morán, E., Orueta, J.F., Esteban, J.I.F., Axpe, J.M.A., González, M.L.M., Polanco, N.T., Loiola, P.E., Gaztambide, S., Nuño-Solinís, R., 2015. Multimorbidity in people with type 2 diabetes in the Basque Country (Spain): Prevalence, comorbidity clusters and comparison with other chronic patients. European Journal of Internal Medicine 26, 197-202.

Awad, A., Fina, F., Trenfield, S.J., Patel, P., Goyanes, A., Gaisford, S., Basit, A.W., 2019. 3D Printed Pellets (Miniprintlets): A Novel, Multi-Drug, Controlled Release Platform Technology. Pharmaceutics 11, 148.

Balla, V.K., Das, M., Bose, S., Janaki Ram, G.D., Manna, I., 2013. Laser surface modification of $316 \mathrm{~L}$ stainless steel with bioactive hydroxyapatite. Materials Science and Engineering C 33, 4594-4598.

Ballard, D.H., Weisman, J.A., Jammalamadaka, U., Tappa, K., Alexander, J.S., Griffen, F.D., 2017. Three-dimensional printing of bioactive hernia meshes: In\&\#xa0;vitro proof of principle. Surgery 161, 1479-1481.

Baylón, K., Rodríguez-Camarillo, P., Elías-Zúñiga, A., Díaz-Elizondo, J.A., Gilkerson, R., Lozano, K., 2017. Past, present and future of surgical meshes: A review. Membranes 7. Beck, R.C.R., Chaves, P.S., Goyanes, A., Vukosavljevic, B., Buanz, A., Windbergs, M., Basit, A.W., Gaisford, S., 2017. 3D printed tablets loaded with polymeric nanocapsules: An innovative approach to produce customized drug delivery systems. International Journal of Pharmaceutics 528, 268-279.

Bezuidenhout, M.B., Booysen, E., van Staden, A.D., Uheida, E.H., Hugo, P.A., Oosthuizen, G.A., Dimitrov, D.M., Dicks, L.M.T., 2018. Selective Laser Melting of Integrated Ti6A14V ELI Permeable Walls for Controlled Drug Delivery of Vancomycin. ACS Biomaterials Science \& Engineering 4, 4412-4424.

Blonde, L., Wogen, J., Kreilick, C., Seymour, A.A., 2003. Greater reductions in A1C in type 2 diabetic patients new to therapy with glyburide/metformin tablets as compared to glyburide co-administered with metformin. Diabetes, Obesity and Metabolism 5, 424-431.

Boetker, J., Water, J.J., Aho, J., Arnfast, L., Bohr, A., Rantanen, J., 2016. Modifying release characteristics from 3D printed drug-eluting products. European Journal of Pharmaceutical Sciences 90, 47-52.

Bose, S., Banerjee, D., Shivaram, A., Tarafder, S., Bandyopadhyay, A., 2018. Calcium phosphate coated 3D printed porous titanium with nanoscale surface modification for orthopedic and dental applications. Materials and Design 151, 102-112.

Bourell, D.L., 2016. Perspectives on additive manufacturing. Annual Review of Materials Research 46, 1-18. 
Caffrey, T., 2015. Wohlers Report 2015: Additive Manufacturing and 3D Printing, State of the Industry. Ft. Collins, CO: Wohlers Associates.

Caudill, C.L., Perry, J.L., Tian, S., Luft, J.C., DeSimone, J.M., 2018. Spatially controlled coating of continuous liquid interface production microneedles for transdermal protein delivery. Journal of Controlled Release 284, 122-132.

Chai, X., Chai, H., Wang, X., Yang, J., Li, J., Zhao, Y., Cai, W., Tao, T., Xiang, X., 2017. Fused Deposition Modeling (FDM) 3D Printed Tablets for Intragastric Floating Delivery of Domperidone. Scientific Reports 7, 2829.

Chou, Y.-C., Lee, D., Chang, T.-M., Hsu, Y.-H., Yu, Y.-H., Chan, E.-C., Liu, S.-J., 2017. Combination of a biodegradable three-dimensional (3D) - printed cage for mechanical support and nanofibrous membranes for sustainable release of antimicrobial agents for treating the femoral metaphyseal comminuted fracture. Journal of the Mechanical Behavior of Biomedical Materials 72, 209-218.

Clark, E.A., Alexander, M.R., Irvine, D.J., Roberts, C.J., Wallace, M.J., Sharpe, S., Yoo, J., Hague, R.J.M., Tuck, C.J., Wildman, R.D., 2017. 3D printing of tablets using inkjet with UV photoinitiation. International Journal of Pharmaceutics 529, 523-530.

Cox, S.C., Jamshidi, P., Eisenstein, N.M., Webber, M.A., Hassanin, H., Attallah, M.M., Shepherd, D.E.T., Addison, O., Grover, L.M., 2016. Adding functionality with additive manufacturing: Fabrication of titanium-based antibiotic eluting implants. Materials Science and Engineering: C 64, 407-415.

D’hers, S., Abad Vazquez, A.N., Gurman, P., Elman, N.M., 2019. Rapid reconstitution packages (RRPs) for stable storage and delivery of glucagon. Drug Delivery and Translational Research 9, 631-640.

Derby, B., 2010. Inkjet Printing of Functional and Structural Materials: Fluid Property Requirements, Feature Stability, and Resolution, pp. 395-414.

Derby, B., 2015. Additive Manufacture of Ceramics Components by Inkjet Printing.

Engineering 1, 113-123.

Domínguez-Robles, J., Mancinelli, C., Mancuso, E., García-Romero, I., Gilmore, B.F., Casettari, L., Larrañeta, E., Lamprou, D.A., 2020. 3D Printing of Drug-Loaded Thermoplastic Polyurethane Meshes: A Potential Material for Soft Tissue Reinforcement in Vaginal Surgery. Pharmaceutics 12, 63.

Dydak, K., Junka, A., Szymczyk, P., Chodaczek, G., Toporkiewicz, M., Fijałkowski, K., Dudek, B., Bartoszewicz, M., 2018. Development and biological evaluation of Ti6Al7Nb scaffold implants coated with gentamycin-saturated bacterial cellulose biomaterial. PloS one 13, e0205205-e0205205.

Economidou, S.N., Pere, C.P.P., Reid, A., Uddin, M.J., Windmill, J.F.C., Lamprou, D.A., Douroumis, D., 2019. 3D printed microneedle patches using stereolithography (SLA) for intradermal insulin delivery. Materials Science and Engineering: C 102, 743-755. Elsayed, M., Ghazy, M., Youssef, Y., Essa, K., 2019. Optimization of SLM process parameters for Ti6A14V medical implants. Rapid Prototyping Journal 25, 433-447.

Essa, K., Hassanin, H., Attallah, M.M., Adkins, N.J., Musker, A.J., Roberts, G.T., Tenev, N., Smith, M., 2017. Development and testing of an additively manufactured monolithic catalyst bed for HTP thruster applications. Applied Catalysis A: General 542, 125-135.

Farias, C., Lyman, R., Hemingway, C., Chau, H., Mahacek, A., Bouzos, E., MobedMiremadi, M., 2018. Three-Dimensional (3D) Printed Microneedles for Microencapsulated Cell Extrusion. Bioengineering 5, 59.

Ferrari, A., Frank, D., Hennen, L., Moniz, A., Torgersen, H., Torgersen, J., Van Bodegom, L., Duijne, F., Geesink, I., Boucher, P., Van der Meulen, B., Mordini, E., Riisgaard, K., Nielsen, R.Ø., Baumann, M., Coenen, C., 2018. Additive bio-manufacturing: 3D printing for medical recovery and human enhancement. 
Fina, F., Goyanes, A., Gaisford, S., Basit, A.W., 2017. Selective laser sintering (SLS) 3D printing of medicines. International Journal of Pharmaceutics 529, 285-293.

Fina, F., Goyanes, A., Madla, C.M., Awad, A., Trenfield, S.J., Kuek, J.M., Patel, P., Gaisford, S., Basit, A.W., 2018a. 3D printing of drug-loaded gyroid lattices using selective laser sintering. International Journal of Pharmaceutics 547, 44-52.

Fina, F., Madla, C.M., Goyanes, A., Zhang, J., Gaisford, S., Basit, A.W., 2018b. Fabricating 3D printed orally disintegrating printlets using selective laser sintering. International Journal of Pharmaceutics 541, 101-107.

Fu, J., Yu, X., Jin, Y., 2018. 3D printing of vaginal rings with personalized shapes for controlled release of progesterone. International Journal of Pharmaceutics 539, 75-82.

Galatas, A., Hassanin, H., Zweiri, Y., Seneviratne, L., 2018. Additive Manufactured Sandwich Composite/ABS Parts for Unmanned Aerial Vehicle Applications. Polymers (Basel) 10, 1262.

Genina, N., Holländer, J., Jukarainen, H., Mäkilä, E., Salonen, J., Sandler, N., 2016. Ethylene vinyl acetate (EVA) as a new drug carrier for 3D printed medical drug delivery devices. European Journal of Pharmaceutical Sciences 90, 53-63.

Goole, J., Amighi, K., 2016. 3D printing in pharmaceutics: A new tool for designing customized drug delivery systems. International Journal of Pharmaceutics 499, 376-394. Goyanes, A., Buanz, A.B.M., Basit, A.W., Gaisford, S., 2014. Fused-filament 3D printing (3DP) for fabrication of tablets. International Journal of Pharmaceutics 476, 88-92.

Goyanes, A., Buanz, A.B.M., Hatton, G.B., Gaisford, S., Basit, A.W., 2015a. 3D printing of modified-release aminosalicylate (4-ASA and 5-ASA) tablets. European Journal of Pharmaceutics and Biopharmaceutics 89, 157-162.

Goyanes, A., Chang, H., Sedough, D., Hatton, G.B., Wang, J., Buanz, A., Gaisford, S., Basit, A.W., 2015b. Fabrication of controlled-release budesonide tablets via desktop (FDM) 3D printing. International Journal of Pharmaceutics 496, 414-420.

Goyanes, A., Det-Amornrat, U., Wang, J., Basit, A.W., Gaisford, S., 2016a. 3D scanning and $3 \mathrm{D}$ printing as innovative technologies for fabricating personalized topical drug delivery systems. Journal of Controlled Release 234, 41-48.

Goyanes, A., Fina, F., Martorana, A., Sedough, D., Gaisford, S., Basit, A.W., 2017.

Development of modified release 3D printed tablets (printlets) with pharmaceutical excipients using additive manufacturing. International Journal of Pharmaceutics 527, 21-30.

Goyanes, A., Kobayashi, M., Martínez-Pacheco, R., Gaisford, S., Basit, A.W., 2016b. Fusedfilament 3D printing of drug products: Microstructure analysis and drug release characteristics of PVA-based caplets. International Journal of Pharmaceutics 514, 290-295.

Goyanes, A., Robles Martinez, P., Buanz, A., Basit, A.W., Gaisford, S., 2015c. Effect of geometry on drug release from 3D printed tablets. International Journal of Pharmaceutics 494, 657-663.

Goyanes, A., Wang, J., Buanz, A., Martínez-Pacheco, R., Telford, R., Gaisford, S., Basit, A.W., 2015d. 3D Printing of Medicines: Engineering Novel Oral Devices with Unique Design and Drug Release Characteristics. Molecular Pharmaceutics 12, 4077-4084.

Griffiths, L., 2019. Interview: J\&J's Center of Excellence head talks personalised healthcare and bioprinting. tctmagazine.

Guillaume, O., Geven, M.A., Sprecher, C.M., Stadelmann, V.A., Grijpma, D.W., Tang, T.T., Qin, L., Lai, Y., Alini, M., de Bruijn, J.D., Yuan, H., Richards, R.G., Eglin, D., 2017.

Surface-enrichment with hydroxyapatite nanoparticles in stereolithography-fabricated composite polymer scaffolds promotes bone repair. Acta Biomaterialia 54, 386-398.

Guo, M., Li, X., 2016. Development of porous Ti6A14V/chitosan sponge composite scaffold for orthopedic applications. Materials Science and Engineering: C 58, 1177-1181.

Hallaj-Nezhadi, S., Lotfipour, F., Dass, C.R., 2010. Delivery of nanoparticulate drug delivery systems via the intravenous route for cancer gene therapy. Pharmazie 65, 855-859. 
Hassanin, H., Al-Kinani, A.A., ElShaer, A., Polycarpou, E., El-Sayed, M.A., Essa, K., 2017. Stainless steel with tailored porosity using canister-free hot isostatic pressing for improved osseointegration implants. Journal of Materials Chemistry B 5, 9384-9394.

Hassanin, H., Finet, L., Cox, S.C., Jamshidi, P., Grover, L.M., Shepherd, D.E.T., Addison, O., Attallah, M.M., 2018. Tailoring selective laser melting process for titanium drug-delivering implants with releasing micro-channels. Additive Manufacturing 20, 144-155.

Hassanin, H., Jiang, K., 2009a. Alumina composite suspension preparation for softlithography microfabrication. Microelectronic Engineering 86, 929-932.

Hassanin, H., Jiang, K., 2009b. Fabrication of Al2O3/SiC Composite Microcomponents using Non-aqueous Suspension. Advanced Engineering Materials 11, 101-105.

Hassanin, H., Jiang, K., 2010a. Functionally graded microceramic components.

Microelectronic Engineering 87, 1610-1613.

Hassanin, H., Jiang, K., 2010b. Optimized process for the fabrication of zirconia micro parts. Microelectronic Engineering 87, 1617-1619.

Hassanin, H., Jiang, K., 2011. Multiple replication of thick PDMS micropatterns using surfactants as release agents. Microelectronic Engineering 88, 3275-3277.

Hassanin, H., Jiang, K., 2013a. Fabrication and characterization of stabilised zirconia micro parts via slip casting and soft moulding. Scripta Materialia 69, 433-436.

Hassanin, H., Jiang, K., 2013b. Net shape manufacturing of ceramic micro parts with tailored graded layers. Journal of Micromechanics and Microengineering 24, 015018.

Holländer, J., Genina, N., Jukarainen, H., Khajeheian, M., Rosling, A., Mäkilä, E., Sandler, N., 2016. Three-Dimensional Printed PCL-Based Implantable Prototypes of Medical Devices for Controlled Drug Delivery. Journal of Pharmaceutical Sciences 105, 2665-2676.

Hua, S., 2019. Physiological and Pharmaceutical Considerations for Rectal Drug Formulations. Frontiers in Pharmacology 10.

Huang, C.Y., 2018. Extrusion-based 3D Printing and Characterization of Edible Materials. UWSpace.

Huang, W., Zheng, Q., Sun, W., Xu, H., Yang, X., 2007. Levofloxacin implants with predefined microstructure fabricated by three-dimensional printing technique. International Journal of Pharmaceutics 339, 33-38.

Hung, K.-C., Tseng, C.-S., Dai, L.-G., Hsu, S.-h., 2016. Water-based polyurethane 3D printed scaffolds with controlled release function for customized cartilage tissue engineering. Biomaterials 83, 156-168.

Hussain, A., Ahsan, F., 2005. The vagina as a route for systemic drug delivery. Journal of controlled release 103, 301-313.

Ilea, A., Vrabie, O.-G., Băbțan, A.-M., Miclăuş, V., Ruxanda, F., Sárközi, M., BarbuTudoran, L., Mager, V., Berce, C., Boșca, B.A., Petrescu, N.B., Cadar, O., Câmpian, R.S., Barabás, R., 2019. Osseointegration of titanium scaffolds manufactured by selective laser melting in rabbit femur defect model. Journal of Materials Science: Materials in Medicine 30, 26.

Iliescu, F.S., Paunica, S., Vrtacnik, D., Bobei, A.R., 2017. A double softlithography method for processing of noa63 microneedles arrays. UPB Scientific Bulletin, Series B: Chemistry and Materials Science 79, 121-132.

Jain, K.K., 2008. Drug delivery systems. Springer.

Jain, K.K., 2014. Current Status and Future Prospects of Drug Delivery Systems, in: Jain, K.K. (Ed.), Drug Delivery System. Springer New York, New York, NY, pp. 1-56. Jamróz, W., Kurek, M., Łyszczarz, E., Szafraniec, J., Knapik-Kowalczuk, J., Syrek, K., Paluch, M., Jachowicz, R., 2017. 3D printed orodispersible films with Aripiprazole. International Journal of Pharmaceutics 533, 413-420.

Johnson, A.R., Caudill, C.L., Tumbleston, J.R., Bloomquist, C.J., Moga, K.A., Ermoshkin, A., Shirvanyants, D., Mecham, S.J., Luft, J.C., DeSimone, J.M., 2016. Single-Step 
Fabrication of Computationally Designed Microneedles by Continuous Liquid Interface Production. PLOS ONE 11, e0162518.

Kavaldzhiev, M., Perez, J.E., Ivanov, Y., Bertoncini, A., Liberale, C., Kosel, J., 2017. Biocompatible 3D printed magnetic micro needles. Biomedical Physics \& Engineering Express 3, 025005.

Khaled, S.A., Alexander, M.R., Irvine, D.J., Wildman, R.D., Wallace, M.J., Sharpe, S., Yoo, J., Roberts, C.J., 2018a. Extrusion 3D Printing of Paracetamol Tablets from a Single Formulation with Tunable Release Profiles Through Control of Tablet Geometry. AAPS PharmSciTech 19, 3403-3413.

Khaled, S.A., Alexander, M.R., Wildman, R.D., Wallace, M.J., Sharpe, S., Yoo, J., Roberts, C.J., 2018b. 3D extrusion printing of high drug loading immediate release paracetamol tablets. International Journal of Pharmaceutics 538, 223-230.

Khaled, S.A., Burley, J.C., Alexander, M.R., Roberts, C.J., 2014. Desktop 3D printing of controlled release pharmaceutical bilayer tablets. International Journal of Pharmaceutics 461, 105-111.

Khaled, S.A., Burley, J.C., Alexander, M.R., Yang, J., Roberts, C.J., 2015a. 3D printing of five-in-one dose combination polypill with defined immediate and sustained release profiles. Journal of Controlled Release 217, 308-314.

Khaled, S.A., Burley, J.C., Alexander, M.R., Yang, J., Roberts, C.J., 2015b. 3D printing of tablets containing multiple drugs with defined release profiles. International Journal of Pharmaceutics 494, 643-650.

Klippstein, H., Diaz De Cerio Sanchez, A., Hassanin, H., Zweiri, Y., Seneviratne, L., 2018a. Fused Deposition Modeling for Unmanned Aerial Vehicles (UAVs): A Review. Advanced Engineering Materials 20, 1700552.

Klippstein, H., Hassanin, H., Diaz De Cerio Sanchez, A., Zweiri, Y., Seneviratne, L., $2018 b$. Additive Manufacturing of Porous Structures for Unmanned Aerial Vehicles Applications. Advanced Engineering Materials 20, 1800290.

Kollamaram, G., Hopkins, S.C., Glowacki, B.A., Croker, D.M., Walker, G.M., 2018. Inkjet printing of paracetamol and indomethacin using electromagnetic technology: Rheological compatibility and polymorphic selectivity. European Journal of Pharmaceutical Sciences 115, 248-257.

Krezić, S., Krhan, E., Mandžuka, E., Kovaĉ, N., Krajina, D., Marić, A., Komić, S., Nikšić, A., Tucak, A., Sirbubalo, M., Vranić, E., 2020. Fabrication of rectal and vaginal suppositories using $3 \mathrm{~d}$ printed moulds: the challenge of personalized therapy, IFMBE Proceedings, pp. 729734.

Kyobula, M., Adedeji, A., Alexander, M.R., Saleh, E., Wildman, R., Ashcroft, I., Gellert, P.R., Roberts, C.J., 2017. 3D inkjet printing of tablets exploiting bespoke complex geometries for controlled and tuneable drug release. Journal of Controlled Release 261, 207-215.

Laternser, S., Keller, H., Leupin, O., Rausch, M., Graf-Hausner, U., Rimann, M., 2018. A Novel Microplate 3D Bioprinting Platform for the Engineering of Muscle and Tendon Tissues. SLAS Technol 23, 599-613.

Lee, J.H., Kim, H.N., Lim, H.S., Cho, S.O., 2019. Three-dimensional-printed vaginal applicators for electronic brachytherapy of endometrial cancers. Medical Physics 46, 448-455. Li, K., Zhu, M., Xu, P., Xi, Y., Cheng, Z., Zhu, Y., Ye, X., 2015. Three-dimensionally plotted MBG/PHBHHx composite scaffold for antitubercular drug delivery and tissue regeneration. Journal of Materials Science: Materials in Medicine 26, 102.

Li, Q., Wen, H., Jia, D., Guan, X., Pan, H., Yang, Y., Yu, S., Zhu, Z., Xiang, R., Pan, W., 2017. Preparation and investigation of controlled-release glipizide novel oral device with three-dimensional printing. International Journal of Pharmaceutics 525, 5-11. 
Li, S., Hassanin, H., Attallah, M.M., Adkins, N.J.E., Essa, K., 2016. The development of TiNi-based negative Poisson's ratio structure using selective laser melting. Acta Materialia $105,75-83$.

Lim, S.H., Kathuria, H., Tan, J.J.Y., Kang, L., 2018. 3D printed drug delivery and testing systems - a passing fad or the future? Advanced Drug Delivery Reviews 132, 139-168. Lim, S.H., Ng, J.Y., Kang, L., 2017. Three-dimensional printing of a microneedle array on personalized curved surfaces for dual-pronged treatment of trigger finger. Biofabrication 9, 015010.

Lin, K., Sheikh, R., Romanazzo, S., Roohani, I., 2019. 3D Printing of Bioceramic ScaffoldsBarriers to the Clinical Translation: From Promise to Reality, and Future Perspectives. Materials 12, 2660.

Liu, H., Li, W., Liu, C., Tan, J., Wang, H., Hai, B., Cai, H., Leng, H.-J., Liu, Z.-J., Song, C.L., 2016. Incorporating simvastatin/poloxamer 407 hydrogel into 3D-printed porous Ti6Al4V scaffolds for the promotion of angiogenesis, osseointegration and bone ingrowth.

Biofabrication 8, 045012.

Long, J., Etxeberria, A.E., Nand, A.V., Bunt, C.R., Ray, S., Seyfoddin, A., 2019. A 3D printed chitosan-pectin hydrogel wound dressing for lidocaine hydrochloride delivery. Materials Science and Engineering: C 104, 109873.

Luzuriaga, M.A., Berry, D.R., Reagan, J.C., Smaldone, R.A., Gassensmith, J.J., 2018. Biodegradable 3D printed polymer microneedles for transdermal drug delivery. Lab on a Chip $18,1223-1230$.

Lv, J., Xiu, P., Tan, J., Jia, Z., Cai, H., Liu, Z., 2015. Enhanced angiogenesis and osteogenesis in critical bone defects by the controlled release of BMP-2 and VEGF: implantation of electron beam melting-fabricated porous Ti6Al4V scaffolds incorporating growth factordoped fibrin glue. Biomedical Materials 10, 035013.

Martinez, P.R., Goyanes, A., Basit, A.W., Gaisford, S., 2018. Influence of Geometry on the Drug Release Profiles of Stereolithographic (SLA) 3D-Printed Tablets. AAPS PharmSciTech 19, 3355-3361.

Mathew, E., Domínguez-Robles, J., Stewart, S.A., Mancuso, E., O’Donnell, K., Larrañeta, E., Lamprou, D.A., 2019. Fused Deposition Modeling as an Effective Tool for Anti-Infective Dialysis Catheter Fabrication. ACS Biomaterials Science \& Engineering 5, 6300-6310. Mazur, M., Bhatelia, T., Kuan, B., Patel, J., Webley, P.A., Brandt, M., Pareek, V., Utikar, R., 2019. Additively manufactured, highly-uniform flow distributor for process intensification. Chemical Engineering and Processing - Process Intensification 143, 107595.

Min, Z., Shichang, Z., Chen, X., Yufang, Z., Changqing, Z., 2015. 3D-printed dimethyloxallyl glycine delivery scaffolds to improve angiogenesis and osteogenesis. Biomaterials Science 3, 1236-1244.

Misra, S.K., Ostadhossein, F., Babu, R., Kus, J., Tankasala, D., Sutrisno, A., Walsh, K.A., Bromfield, C.R., Pan, D., 2017. 3D-Printed Multidrug-Eluting Stent from Graphene-

Nanoplatelet-Doped Biodegradable Polymer Composite. Advanced Healthcare Materials 6, 1700008.

Mohanty, S., Larsen, L.B., Trifol, J., Szabo, P., Burri, H.V.R., Canali, C., Dufva, M., Emnéus, J., Wolff, A., 2015. Fabrication of scalable and structured tissue engineering scaffolds using water dissolvable sacrificial 3D printed moulds. Materials Science and Engineering: C 55, 569-578.

Muwaffak, Z., Goyanes, A., Clark, V., Basit, A.W., Hilton, S.T., Gaisford, S., 2017. Patientspecific 3D scanned and 3D printed antimicrobial polycaprolactone wound dressings.

International Journal of Pharmaceutics 527, 161-170.

Ngo, T.D., Kashani, A., Imbalzano, G., Nguyen, K.T.Q., Hui, D., 2018. Additive

manufacturing (3D printing): A review of materials, methods, applications and challenges.

Composites Part B: Engineering 143, 172-196. 
Nguyen, D.G., Funk, J., Robbins, J.B., Crogan-Grundy, C., Presnell, S.C., Singer, T., Roth, A.B., 2016. Bioprinted 3D Primary Liver Tissues Allow Assessment of Organ-Level Response to Clinical Drug Induced Toxicity In Vitro. PloS one 11, e0158674-e0158674. Okwuosa, T.C., Pereira, B.C., Arafat, B., Cieszynska, M., Isreb, A., Alhnan, M.A., 2017. Fabricating a Shell-Core Delayed Release Tablet Using Dual FDM 3D Printing for PatientCentred Therapy. Pharmaceutical Research 34, 427-437.

Okwuosa, T.C., Stefaniak, D., Arafat, B., Isreb, A., Wan, K.-W., Alhnan, M.A., 2016. A Lower Temperature FDM 3D Printing for the Manufacture of Patient-Specific Immediate Release Tablets. Pharmaceutical Research 33, 2704-2712.

Paul, K., Darzi, S., McPhee, G., Del Borgo, M.P., Werkmeister, J.A., Gargett, C.E., Mukherjee, S., 2019. 3D bioprinted endometrial stem cells on melt electrospun poly $\varepsilon$ caprolactone mesh for pelvic floor application promote anti-inflammatory responses in mice. Acta Biomaterialia 97, 162-176.

Peterfreund, R.A., Philip, J.H., 2013. Critical parameters in drug delivery by intravenous infusion. Expert Opinion on Drug Delivery 10, 1095-1108.

Pharmaceuticals, A., 2019. THE FIRST AND ONLY PROVEN 3DP PLATFORM

COMMERCIALLY AVAILABLE TODAY. www.aprecia.com.

Pietrzak, K., Isreb, A., Alhnan, M.A., 2015. A flexible-dose dispenser for immediate and extended release 3D printed tablets. European Journal of Pharmaceutics and

Biopharmaceutics 96, 380-387.

Prasad, L.K., Smyth, H., 2016. 3D Printing technologies for drug delivery: a review. Drug Development and Industrial Pharmacy 42, 1019-1031.

Prausnitz, M.R., Langer, R., 2008. Transdermal drug delivery. Nature biotechnology 26, 1261.

Qamar, N., Abbas, N., Irfan, M., Hussain, A., Arshad, M.S., Latif, S., Mehmood, F., Ghori, M.U., 2019. Personalized 3D printed ciprofloxacin impregnated meshes for the management of hernia. Journal of Drug Delivery Science and Technology 53, 101164.

Qiu, C., Adkins, N.J.E., Hassanin, H., Attallah, M.M., Essa, K., 2015. In-situ shelling via selective laser melting: Modelling and microstructural characterisation. Materials \& Design 87, 845-853.

Robles-Martinez, P., Xu, X., Trenfield, S.J., Awad, A., Goyanes, A., Telford, R., Basit, A.W., Gaisford, S., 2019. 3D Printing of a Multi-Layered Polypill Containing Six Drugs Using a Novel Stereolithographic Method. Pharmaceutics 11, 274.

Rowe, C.W., Katstra, W.E., Palazzolo, R.D., Giritlioglu, B., Teung, P., Cima, M.J., 2000. Multimechanism oral dosage forms fabricated by three dimensional printing ${ }^{\text {TM }}$. Journal of Controlled Release 66, 11-17.

Sabouri, A., Yetisen, A.K., Sadigzade, R., Hassanin, H., Essa, K., Butt, H., 2017. ThreeDimensional Microstructured Lattices for Oil Sensing. Energy \& Fuels 31, 2524-2529.

Sadia, M., Sośnicka, A., Arafat, B., Isreb, A., Ahmed, W., Kelarakis, A., Alhnan, M.A., 2016. Adaptation of pharmaceutical excipients to FDM 3D printing for the fabrication of patienttailored immediate release tablets. International Journal of Pharmaceutics 513, 659-668.

Salmoria, G.V., Klauss, P., Kanis, L.A., 2017. Laser Printing of PCL/Progesterone Tablets for Drug Delivery Applications in Hormone Cancer Therapy. Lasers in Manufacturing and Materials Processing 4, 108-120.

Sandler, N., Salmela, I., Fallarero, A., Rosling, A., Khajeheian, M., Kolakovic, R., Genina, N., Nyman, J., Vuorela, P., 2014. Towards fabrication of 3D printed medical devices to prevent biofilm formation. International Journal of Pharmaceutics 459, 62-64.

Schwab, K., 2017. The Fourth Industrial Revolution: what it means, how to respond (2016), World Economic Forum.

Shama, A., 2017. title. 
Shim, J.-H., Kim, M.-J., Park, J.Y., Pati, R.G., Yun, Y.-P., Kim, S.E., Song, H.-R., Cho, D.W., 2015. Three-dimensional printing of antibiotics-loaded poly- $\varepsilon$-caprolactone/poly(lacticco-glycolic acid) scaffolds for treatment of chronic osteomyelitis. Tissue Engineering and Regenerative Medicine 12, 283-293.

Shivaram, A., Bose, S., Bandyopadhyay, A., 2017. Understanding long-term silver release from surface modified porous titanium implants. Acta Biomaterialia 58, 550-560.

Skowyra, J., Pietrzak, K., Alhnan, M.A., 2015. Fabrication of extended-release patienttailored prednisolone tablets via fused deposition modelling (FDM) 3D printing. European Journal of Pharmaceutical Sciences 68, 11-17.

Smith, J.M., Rastogi, R., Teller, R.S., Srinivasan, P., Mesquita, P.M.M., Nagaraja, U., McNicholl, J.M., Hendry, R.M., Dinh, C.T., Martin, A., Herold, B.C., Kiser, P.F., 2013. Intravaginal ring eluting tenofovir disoproxil fumarate completely protects macaques from multiple vaginal simian-HIV challenges. Proceedings of the National Academy of Sciences $110,16145-16150$.

spritam, 2019. What is SPRITAM? www.spritam.com.

Sun, Y., Ruan, X., Li, H., Kathuria, H., Du, G., Kang, L., 2016. Fabrication of non-dissolving analgesic suppositories using 3D printed moulds. International Journal of Pharmaceutics 513, 717-724.

Sun, Y., Soh, S., 2015. Printing Tablets with Fully Customizable Release Profiles for Personalized Medicine. Advanced Materials 27, 7847-7853.

Tagami, T., Fukushige, K., Ogawa, E., Hayashi, N., Ozeki, T., 2017. 3D Printing Factors Important for the Fabrication of Polyvinylalcohol Filament-Based Tablets. Biological and Pharmaceutical Bulletin 40, 357-364.

Tagami, T., Hayashi, N., Sakai, N., Ozeki, T., 2019. 3D printing of unique water-soluble polymer-based suppository shell for controlled drug release. International Journal of Pharmaceutics 568, 118494.

Tiwari, G., Tiwari, R., Sriwastawa, B., Bhati, L., Pandey, S., Pandey, P., Bannerjee, S.K., 2012. Drug delivery systems: An updated review. Int J Pharm Investig 2, 2-11.

Uddin, M.J., Scoutaris, N., Economidou, S.N., Giraud, C., Chowdhry, B.Z., Donnelly, R.F., Douroumis, D., 2020. 3D printed microneedles for anticancer therapy of skin tumours.

Materials Science and Engineering: C 107, 110248.

Vaithilingam, J., Kilsby, S., Goodridge, R.D., Christie, S.D.R., Edmondson, S., Hague, R.J.M., 2015. Functionalisation of Ti6Al4V components fabricated using selective laser melting with a bioactive compound. Materials Science and Engineering: C 46, 52-61. van Hengel, I.A.J., Riool, M., Fratila-Apachitei, L.E., Witte-Bouma, J., Farrell, E., Zadpoor, A.A., Zaat, S.A.J., Apachitei, I., 2017. Selective laser melting porous metallic implants with immobilized silver nanoparticles kill and prevent biofilm formation by methicillin-resistant Staphylococcus aureus. Biomaterials 140, 1-15.

van Lith, R., Baker, E., Ware, H., Yang, J., Farsheed, A.C., Sun, C., Ameer, G., 2016. 3DPrinting Strong High-Resolution Antioxidant Bioresorbable Vascular Stents. Advanced Materials Technologies 1, 1600138.

Vorndran, E., Klammert, U., Ewald, A., Barralet, J.E., Gbureck, U., 2010. Simultaneous Immobilization of Bioactives During 3D Powder Printing of Bioceramic Drug-Release Matrices. Advanced Functional Materials 20, 1585-1591.

Wang, J., Goyanes, A., Gaisford, S., Basit, A.W., 2016. Stereolithographic (SLA) 3D printing of oral modified-release dosage forms. International Journal of Pharmaceutics 503, 207-212.

Water, J.J., Bohr, A., Boetker, J., Aho, J., Sandler, N., Nielsen, H.M., Rantanen, J., 2015. Three-Dimensional Printing of Drug-Eluting Implants: Preparation of an Antimicrobial Polylactide Feedstock Material. Journal of Pharmaceutical Sciences 104, 1099-1107. Weisman, J.A., Ballard, D.H., Jammalamadaka, U., Tappa, K., Sumerel, J., D'Agostino, H.B., Mills, D.K., Woodard, P.K., 2019. 3D Printed Antibiotic and Chemotherapeutic Eluting 
Catheters for Potential Use in Interventional Radiology: In Vitro Proof of Concept Study. Academic Radiology 26, 270-274.

Welsh, N.R., Malcolm, R.K., Devlin, B., Boyd, P., 2019. Dapivirine-releasing vaginal rings produced by plastic freeforming additive manufacturing. International Journal of

Pharmaceutics 572.

Wohlers, T., Caffrey, T., Campbell, R.I., Diegel, O., Kowen, J., 2018. Wohlers Report 2018: 3D Printing and Additive Manufacturing State of the Industry; Annual Worldwide Progress Report. Wohlers Associates.

Wu, G., Wu, W., Zheng, Q., Li, J., Zhou, J., Hu, Z., 2014. Experimental study of PLLA/INH slow release implant fabricated by three dimensional printing technique and drug release characteristics in vitro. BioMedical Engineering OnLine 13, 97.

Wu, W., Ye, C., Zheng, Q., Wu, G., Cheng, Z., 2016. A therapeutic delivery system for chronic osteomyelitis via a multi-drug implant based on three-dimensional printing technology. Journal of Biomaterials Applications 31, 250-260.

Wu, W., Zheng, Q., Guo, X., Huang, W., 2009a. The controlled-releasing drug implant based on the three dimensional printing technology: Fabrication and properties of drug releasing in vivo. Journal of Wuhan University of Technology-Mater. Sci. Ed. 24, 977.

Wu, W., Zheng, Q., Guo, X., Sun, J., Liu, Y., 2009b. A programmed release multi-drug implant fabricated by three-dimensional printing technology for bone tuberculosis therapy. Biomedical Materials 4, 065005.

Xi, J., Yuan, J.E., Zhang, Y., Nevorski, D., Wang, Z., Zhou, Y., 2016. Visualization and Quantification of Nasal and Olfactory Deposition in a Sectional Adult Nasal Airway Cast. Pharmaceutical Research 33, 1527-1541.

Yeung, C., Chen, S., King, B., Lin, H., King, K., Akhtar, F., Diaz, G., Wang, B., Zhu, J., Sun, W., Khademhosseini, A., Emaminejad, S., 2019. A 3D-printed microfluidic-enabled hollow microneedle architecture for transdermal drug delivery. Biomicrofluidics 13, 064125.

Yi, H.-G., Choi, Y.-J., Kang, K.S., Hong, J.M., Pati, R.G., Park, M.N., Shim, I.K., Lee, C.M., Kim, S.C., Cho, D.-W., 2016. A 3D-printed local drug delivery patch for pancreatic cancer growth suppression. Journal of Controlled Release 238, 231-241.

Yoon, S., Park, J.A., Lee, H.-R., Yoon, W.H., Hwang, D.S., Jung, S., 2018. Inkjet-Spray Hybrid Printing for 3D Freeform Fabrication of Multilayered Hydrogel Structures. Advanced Healthcare Materials 7, 1800050.

Yu, D.-G., Branford-White, C., Ma, Z.-H., Zhu, L.-M., Li, X.-Y., Yang, X.-L., 2009a. Novel drug delivery devices for providing linear release profiles fabricated by 3DP. International Journal of Pharmaceutics 370, 160-166.

Yu, D.-G., Shen, X.-X., Branford-White, C., Zhu, L.-M., White, K., Yang, X.L., 2009b. Novel oral fast-disintegrating drug delivery devices with predefined inner structure fabricated by Three-Dimensional Printing. Journal of Pharmacy and Pharmacology 61, 323-329. Yu, D.G., Yang, X.L., Huang, W.D., Liu, J., Wang, Y.G., Xu, H., 2007. Tablets With Material Gradients Fabricated by Three-Dimensional Printing. Journal of Pharmaceutical Sciences 96, 2446-2456.

Zhang, J., Feng, X., Patil, H., Tiwari, R.V., Repka, M.A., 2017a. Coupling 3D printing with hot-melt extrusion to produce controlled-release tablets. International Journal of Pharmaceutics 519, 186-197.

Zhang, J., Zhao, S., Zhu, Y., Huang, Y., Zhu, M., Tao, C., Zhang, C., 2014. Threedimensional printing of strontium-containing mesoporous bioactive glass scaffolds for bone regeneration. Acta Biomaterialia 10, 2269-2281.

Zhang, Y., Zhai, D., Xu, M., Yao, Q., Zhu, H., Chang, J., Wu, C., 2017b. 3D-printed bioceramic scaffolds with antibacterial and osteogenic activity. Biofabrication 9, 025037. 
Zhu, Z., Hassanin, H., Jiang, K., 2010. A soft moulding process for manufacture of net-shape ceramic microcomponents. The International Journal of Advanced Manufacturing Technology 47, 147-152. 